STEAM SYSTEM NETWORK SYNTHESIS USING PROCESS INTEGRATION

\author{
W.A.S. Coetzee
}




\title{
Steam system network synthesis using process integration
}

\author{
by \\ W.A.S. Coetzee \\ A dissertation submitted in partial fulfillment \\ of the requirements for the degree
}

\section{MEng: Chemical Engineering}

in the

Faculty of Engineering, the Built Environment and Information Technology

Supervisor: Prof T. Majozi

University of Pretoria

Pretoria 


\section{Synopsis}

Steam boilers are used to generate steam in order to meet cold process heat requirements. The most common heat exchanger network layout associated with the boiler is a completely parallel design. This observation suggests that the flowrate of steam needed for the system can be reduced, while maintaining the required duty, simply by changing the layout of the network. Phase change of saturated steam to saturated liquid plays a vital role in the targeting method as well as the design of the network layout. A hybrid graphical and mathematical technique for targeting and network synthesis is presented. The main objective of the technique is to reduce steam flowrate without compromising duty requirements of the process heat exchangers. In order to assess the advantage of a hybrid technique, a case study is used where steam savings of $29.6 \%$ is obtained. A complete mathematical technique to demonstrate the advantage of the graphical targeting concept in solution time improvement is further presented.

KEYWORDS: process integration, synthesis, optimization, utility, MILP 


\section{Acknowledgments}

I would like to acknowledge the following people for the support and contribution during the writing of this dissertation.

Professor Thokozani Majozi for his insightfully tuition, constructive criticism and academic support for the project.

SASOL Ltd. for financial assistance.

My two colleagues, Thomas Pattinson and Jacques Gouws, for their input and constructive criticism of this project.

My parents for believing in me and their support.

Blizzard Entertainment, for making World of Warcraft to keep me sane. 


\section{CONTENTS}

1 Introduction 1

1.1 Background ........................... 1

1.2 Problem Statement . . . . . . . . . . . . . . . . . . . 2

1.3 Motivation . . . . . . . . . . . . . . . . . . . 3

1.4 Aims . . . . . . . . . . . . . . . . . . . 4

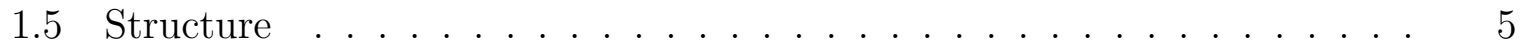

2 Literature Survey $\quad 6$

2.1 Process Integration $\ldots \ldots \ldots \ldots$

2.2 Pinch Technology . . . . . . . . . . . . . . . . . . . 8

2.2 .1 Heat Integration . . . . . . . . . . . . . . . . . 10

2.2 .2 Mass integration . . . . . . . . . . . . . . . 16

2.2.3 Simultaneous heat and mass integration . . . . . . . . . . . 20

2.2.4 Mathematical models for pinch technology . . . . . . . . . . . 21

2.3 Utilities . . . . . . . . . . . . . . . . . . . . . . 23

2.3.1 External cold utilities . . . . . . . . . . . . . . . . 23 
2.3.2 External hot utilities . . . . . . . . . . . . . . 26

3 Methodology $\quad 30$

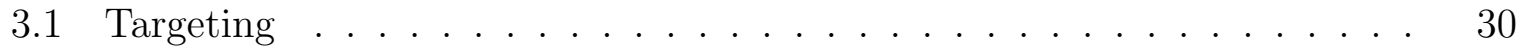

3.1.1 Graphical targeting method . . . . . . . . . . . . . . . 35

3.1 .2 Stream splitting . . . . . . . . . . . . . . . . . 37

3.2 Network synthesis . . . . . . . . . . . . . . . . . . . . . . . 38

4 Simultaneous targeting and synthesis 42

$\begin{array}{lll}5 & \text { Case study } & 47\end{array}$

6 Conclusions and recommendations $\quad 58$

6.1 Conclusions . . . . . . . . . . . . . . . . . . . . 58

6.2 Recommendations . . . . . . . . . . . . . . . . . . . . 59

$\begin{array}{ll}\text { A GAMS mathematical models } & 60\end{array}$

A.1 LP model . . . . . . . . . . . . . . . . . . . . . . . . . . . 60

A.2 MILP model . . . . . . . . . . . . . . . . . . . . . . 62 


\section{LIST OF FIGURES}

1.1 The hot and cold process composite curves. . . . . . . . . . . . . . . 2

1.2 Steam boiler cost as a function of steam flowrate (Peters \& Timmerhaus

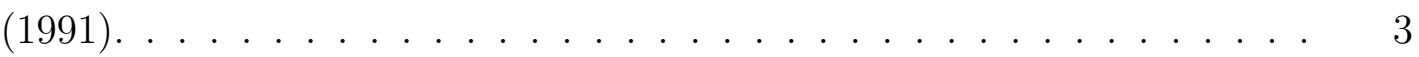

1.3 Steam network including turbines. . . . . . . . . . . . . . 4

2.1 Process design hierarchy. . . . . . . . . . . . . . . 7

2.2 The pinch philosophy. . . . . . . . . . . . . . . . . . 10

2.3 Targeting for the maximising process-process heat integration via graphical pinch analysis. . . . . . . . . . . . . . . . . . . . . . 11

2.4 Combined cost curve to determine the range of $\Delta T_{\min }$ values that will give the minimum combined cost. . . . . . . . . . . . . . . . . . 12

2.5 An example of a positive heat flow cascade diagram. . . . . . . . . . . . 12

2.6 The grand composite curve. . . . . . . . . . . . . . . . . . . . . . 13

2.7 A typical grid diagram. . . . . . . . . . . . . . . . . . . 14

2.8 Temperature as a constraint for heat integration for continuous processes. $\quad 15$

2.9 Time as a constraint for heat integration for batch processes. . . . . . . . 15

2.10 Targeting for the maximum process-process heat integration for batch processes. . . . . . . . . . . . . . . . . . . . 16 
2.11 Mass integration using pinch analysis. . . . . . . . . . . . . . . .

2.12 Three options to reduce wastewater (a) re-use, (b) regeneration re-use and (c) regeneration recycling. . . . . . . . . . . . . . . . . . 18

2.13 Concentration as a constraint for continuous processes. . . . . . . . . 19

2.14 Concentration and time as constraints for batch processes. . . . . . . . 19

2.15 A superstructure model for wastewater minimization. . . . . . . . . 23

2.16 Schematic of a counter current cooling tower. . . . . . . . . . . . . 24

2.17 The COP of a cooling tower influenced by the mass flowrate and return temperature of the cooling water. . . . . . . . . . . . 25

2.18 (a) Standard cooling tower and HEN layout, (b) optimization of the cooling tower and HEN as one unit. . . . . . . . . . . . . . . . . 26

2.19 Parallel network layout of steam as a utility. . . . . . . . . . . . . 28

2.20 Steam levels on a GCC. . . . . . . . . . . . . . . . . . . . . . 29

3.1 Heat exchanger with a hot utility and cold process stream. . . . . . . . . 31

3.2 The hot utility composite curve. . . . . . . . . . . . . . . . . 32

3.3 The hot utility composite curve divides the graph into two regions. . . . 32

3.4 Saturated steam represented as a straight horizontal line. . . . . . . . . . 33

3.5 (a) Saturated liquid and reuse liquid represented as a straight line, (b) changing the flowrate of one line influences the other line. . . . . . . . . . 34

3.6 Saturated steam and hot liquid are used to target for the minimum flowrate. 35

3.7 The hot utility composite curve determines where the pinch point will

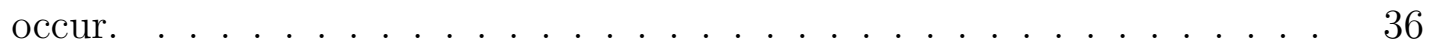

3.8 The algorithm to use when targetting for the minimum flowrate. . . . . 36

3.9 Splitting of cold process stream. . . . . . . . . . . . . . . 37

3.10 The latent heat and sensible heat region. . . . . . . . . . . . . . . . 39

3.11 The superstructure for the sensible heat region. . . . . . . . . . . . . . 39 
4.1 The superstructure for the latent and sensible heat region. . . . . . . . . 43

5.1 The hot utility composite curve. . . . . . . . . . . . . . . . . . . 48

5.2 The potential pinch points on the hot composite curve. . . . . . . . . 49

5.3 Targeting result for the first pinch point. . . . . . . . . . . . 50

5.4 Targeting result for the second pinch point. . . . . . . . . . . . . . . 52

5.5 Graphical targeting for the minimum water flowrate. . . . . . . . . . 53

5.6 Heat exchanger network layout using the graphical method and LP model. 56

5.7 Heat exchanger network layout using the MILP model. . . . . . . . . . 56 


\section{LIST OF TABLES}

5.1 Cold process stream data for the example. . . . . . . . . . . . . . . 48

5.2 Hot utility data for the example. . . . . . . . . . . . . . . . 48 


\section{NOMENCLATURE}

$\dot{m} \quad$ Water/steam flowrate in $\mathrm{kg} / \mathrm{s}$

$\lambda \quad$ Latent heat of vaporization of the saturated steam in $\mathrm{kJ} / \mathrm{kg}$

$c_{p} \quad$ Specific heat capacity of the water in $\mathrm{kJ} / \mathrm{kg}^{\circ} \mathrm{C}$

$C P \quad$ Heat capacity flowrate in $\mathrm{kJ} / \mathrm{s}^{\circ} \mathrm{C}$

$Q \quad$ Energy supplied by the saturated steam and hot liquid in $\mathrm{kW}$

$Q_{L} \quad$ Energy supplied by the saturated liquid and reuse liquid in $\mathrm{kW}$

$Q_{S S} \quad$ Energy supplied by the saturated steam in $\mathrm{kW}$

$T_{i} \quad$ Target temperature in ${ }^{\circ} \mathrm{C}$

$T_{o} \quad$ Supply temperature in ${ }^{\circ} \mathrm{C}$

\section{Binary variables}

$x_{i} \begin{cases}1 & \text { if heat exchanger } i \text { is supplied by hot liquid } \\ 0 & \text { otherwise }\end{cases}$

$y_{i} \begin{cases}1 & \text { if heat exchanger } i \text { is supplied by saturated steam } \\ 0 & \text { otherwise }\end{cases}$

\section{Sets}

I Heat exchangers 


\section{Parameters}

$F R R_{i}^{U}$ Maximum flowrate of hot liquid to heat exchanger $i,(\mathrm{~kg} / \mathrm{s})$

$Q_{i} \quad$ Duty of the heat exchanger $i,(\mathrm{~kW})$

$S S_{i}^{U} \quad$ Maximum flowrate of saturated steam to heat exchanger $i,(\mathrm{~kg} / \mathrm{s})$

$\operatorname{Tin}_{i}^{L} \quad$ Minimum inlet temperature to heat exchanger $i,\left({ }^{\circ} \mathrm{C}\right)$

Tout $_{i}^{L}$ Minimum outlet temperature out of heat exchanger $i,\left({ }^{\circ} \mathrm{C}\right)$

Scalars

$T \quad$ Temperature of the saturated liquid, $\left({ }^{\circ} \mathrm{C}\right)$

TL Total saturated liquid supplied to the heat exchangers, $(\mathrm{kg} / \mathrm{s})$

$T R_{1} \quad$ Total flowrate of hot liquid returning to the steam boiler, $(\mathrm{kg} / \mathrm{s})$

\section{Continuous variables}

$F_{i n} \quad$ Total flowrate entering heat exchanger $i,(\mathrm{~kg} / \mathrm{s})$

Fout $_{i}$ Total flowrate leaving heat exchanger $i,(\mathrm{~kg} / \mathrm{s})$

$F R_{i} \quad$ Flowrate of hot liquid returning to the steam boiler from heat exchanger $i,(\mathrm{~kg} / \mathrm{s})$

$F R R_{i, i^{\prime}}$ Liquid reused from heat exchanger $i$ to heat exchanger $i^{\prime},(\mathrm{kg} / \mathrm{s})$

$L_{i, i^{\prime}} \quad$ Hot liquid reused from heat exchanger $i$ to heat exchanger $i^{\prime},(\mathrm{kg} / \mathrm{s})$

$O B J$ Total error allowance, $(\mathrm{kg} / \mathrm{s})$

$Q_{i}^{H L} \quad$ Duty of heat exchanger $i$ supplied by hot liquid, (kW)

$Q_{i}^{S S} \quad$ Duty of heat exchanger $i$ supplied by saturated steam, $(\mathrm{kW})$

$S_{1}^{+} \quad$ Slack variable for undershooting $T L,(\mathrm{~kg} / \mathrm{s})$

$S_{2}^{+} \quad$ Slack variable for undershooting $T R_{1},(\mathrm{~kg} / \mathrm{s})$

$S_{1}^{-} \quad$ Slack variable for overshooting $T L,(\mathrm{~kg} / \mathrm{s})$

$S_{2}^{-} \quad$ Slack variable for overshooting $T R_{1},(\mathrm{~kg} / \mathrm{s})$

$S L_{i, i^{\prime}}$ Saturated liquid reused from heat exchanger $i$ to heat exchanger $i^{\prime},(\mathrm{kg} / \mathrm{s})$

$S L_{i} \quad$ Flowrate of saturated liquid entering heat exchanger $i,(\mathrm{~kg} / \mathrm{s})$ 
$S S_{i} \quad$ Flowrate of saturated steam entering heat exchanger $i,(\mathrm{~kg} / \mathrm{s})$

$\operatorname{Tin}_{i}$ Temperature of the hot liquid entering heat exchanger $i,\left({ }^{\circ} \mathrm{C}\right)$

Tout $_{i}$ Temperature of the hot liquid leaving heat exchanger $i,\left({ }^{\circ} \mathrm{C}\right)$

$T R_{2}$ Total flowrate of hot liquid returning to the steam boiler, $(\mathrm{kg} / \mathrm{s})$

TS Total flowrate of saturated steam supplied to the heat exchangers, $(\mathrm{kg} / \mathrm{s})$ 


\section{CHAPTER 1}

\section{Introduction}

\subsection{Background}

As part of process design, it has become a necessity to apply process integration on all the existing and future operations on a chemical plant. The main reason for process integration is the optimization of processes, which has an economical and ecological impact for a chemical plant. The main advantage of process integration is its holistic, rather than discrete approach to process design, with an emphasis on the unity of a process. Therefore, process integration can be seen as a holistic approach to process design, retrofitting and operation which emphasises the unity of a process (El-Halwagi (1997)).

As stated before, by implementing process integration on either a grassroot or retrofit design, economical advantages can be achieved. Reduction in capital costs, utility costs, fuel usage etc. can increase the profit of a chemical plant. Kaggerud et al. (2006) reported that by using process integration, better raw material utilization, higher overall energy efficiencies, reduction in investment costs and less costly solutions for $\mathrm{CO}_{2}$ capturing were obtained, therefore, gaining economical advantages in profit earnings. Process integration is usually applied in mass and heat integration, mostly in a dichotomous manner. However, recent advances have shown that it has equal capabilities in systems characterised by simultaneous heat and mass transfer, i.e., a cooling tower.

Looking at Figure 1.1 which is used for heat integration, one can see that for hot and 
cold composite curves, the duties of the external hot and cold utilities are minimised by increasing process-process heat integration (Linnhoff \& Hindmarsh (1983)). Furthermore, the external cold utilities section, can readily be optimised using the cooling water system design method of (Kim \& Smith (2001)). However, there exists no equal method for the hot utility section in Figure 1.1.

The network layout of steam that is used as an external hot utility is generally of a parallel design, even for systems that have been designed following a pinch analysis study. The main reason for this is that when steam levels and their duties are determined with the Grand Composite Curve, only the latent heat of steam is used to transfer heat to cold process streams. This concept results in energy losses since some of the condensate still has sufficient energy to supply some of the processes in most instances. Therefore, by allowing condensate reuse at sufficiently high energy levels, one can reduce the overall steam demand. This study presents a systematic approach to this effect.

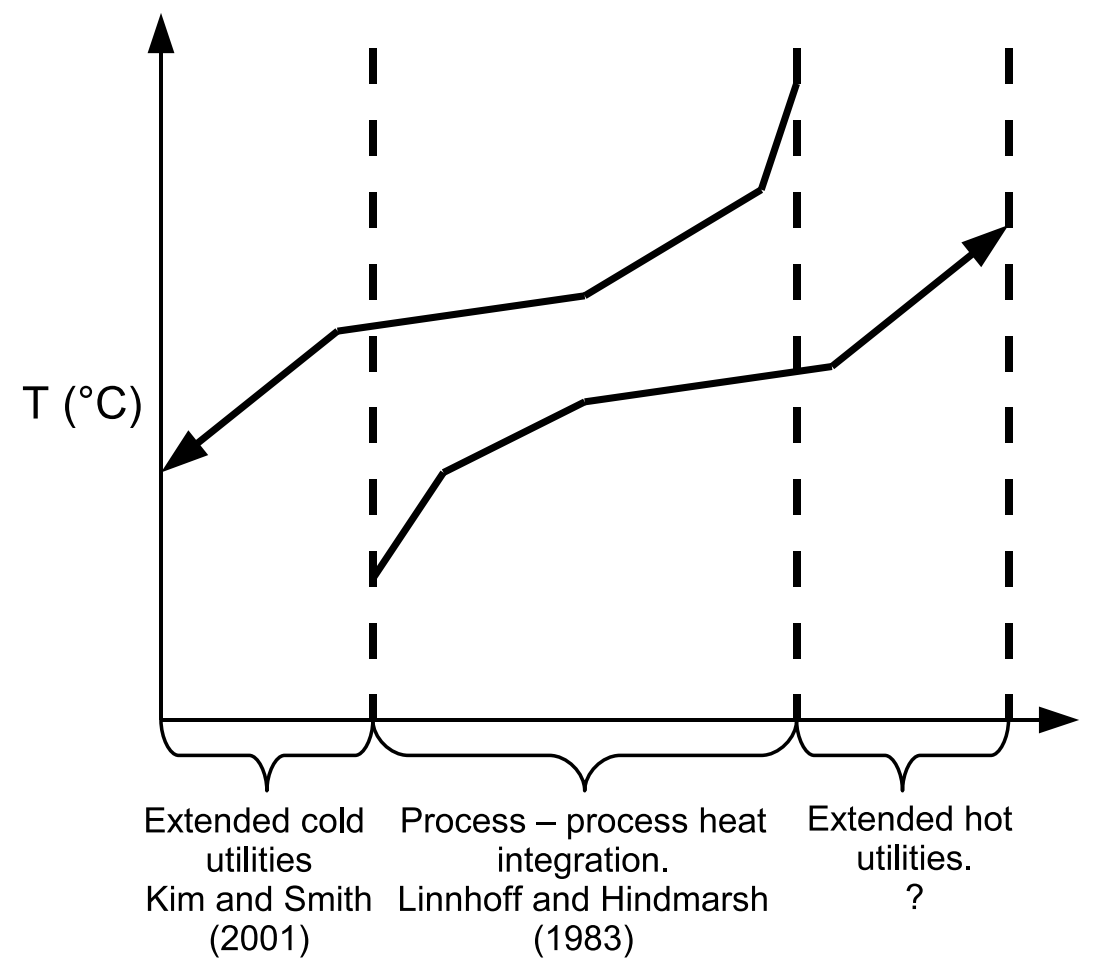

Figure 1.1: The hot and cold process composite curves.

\subsection{Problem Statement}

The problem addressed in this dissertation can be stated as follows. Given:

i) a set of heat exchangers, 
ii) the fixed duties of each heat exchanger,

iii) the limiting data for each heat exchanger, and

iv) the minimum driving force $\Delta T_{\min }$ for the overall network,

determine the minimum amount of steam required to satisfy the heat exchanger network, as well as the steam utility network layout without compromising the heat duty requirement.

\subsection{Motivation}

Reducing the steam flowrate results in savings in the capital cost for grassroot design, and debottlenecks the boiler for retrofit designs. From Figure 1.2, it is evident that if the steam flowrate is reduced, the cost of the steam boiler is also reduced significantly. Therefore, in grassroot design, capital costs can be reduced directly when designing for the steam network layout. In retrofit design the existing steam boiler is debottlenecked, which implies that steam will be available from the existing steam boiler for new heat exchangers which require steam as a hot utility, thereby reducing capital costs.

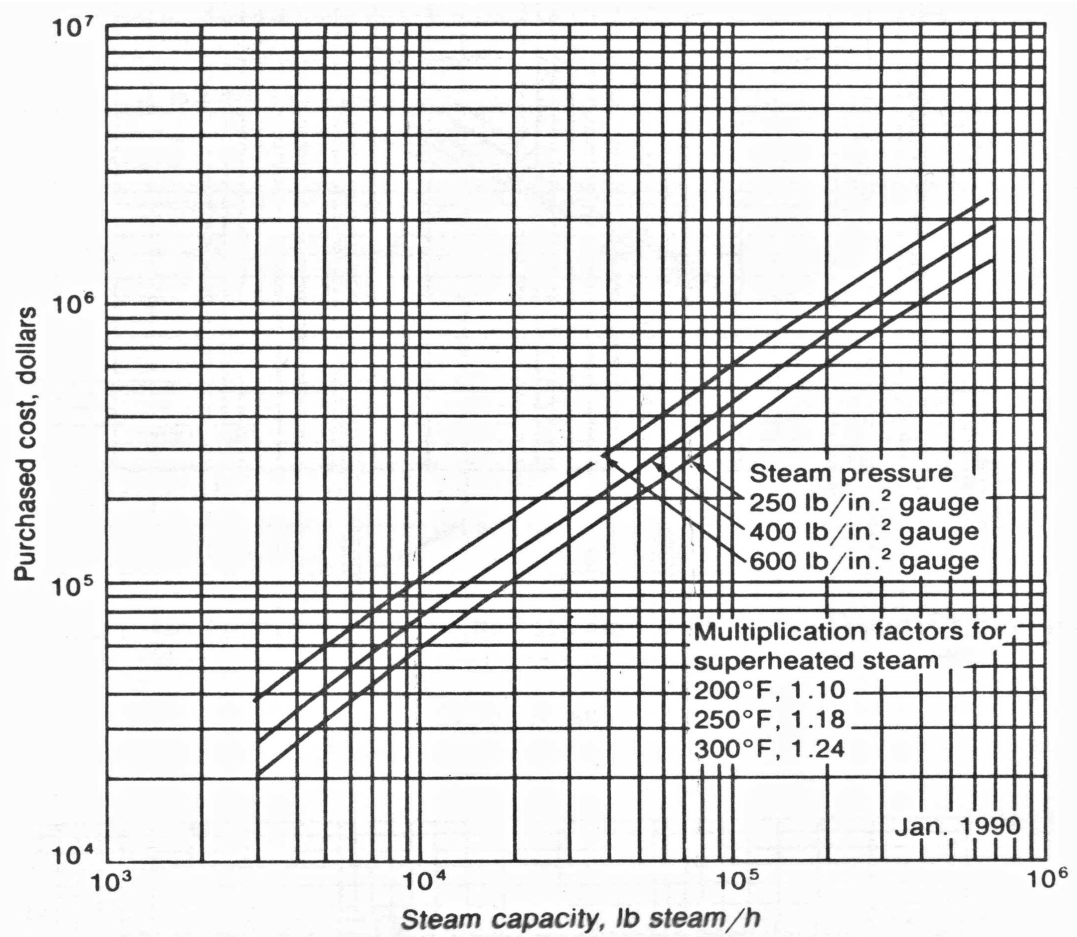

Figure 1.2: Steam boiler cost as a function of steam flowrate (Peters \& Timmerhaus (1991). 
Traditionally, minimization of the amount of external steam needed in the system has been accomplished by optimising the steam boiler, or optimising each heat exchanger individually. However, in this work it is demonstrated that by optimising the steam system as one entity instead of individual components, better results are obtained. Furthermore, the optimization technique for the overall steam system is presented. In the context of this research, the steam system refers to the combination of a steam boiler and heat exchangers that require heating by steam. The aim is to show that the steam flowrate can be significantly reduced by consideration of an integrated system.

It must be noted, however, that the steam flowrate that is supplied to the cold processes can only be reduced when a turbine is not present, as seen in Figure 1.3. The reason for this is that the steam flowrate supplied to a turbine, has to be a certain fixed amount to generate the desired quantity of electricity. Therefore, by reducing the steam flowrate, the quantity of electricity generated will also reduce in order to still satisfy the duty demand of the cold processes.

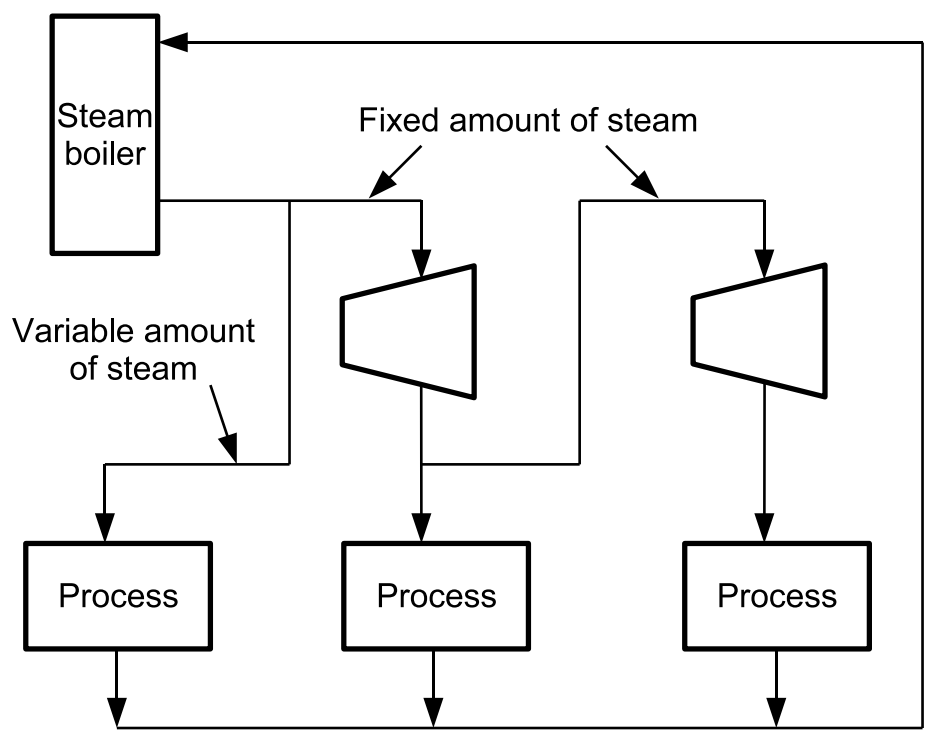

Figure 1.3: Steam network including turbines.

\subsection{Aims}

The aims of this study were:

i) development of a graphical targeting method for the minimum steam flowrate,

ii) a method to obtain a valid network layout after targeting, and 
iii) development of a mathematical model to simultaneously target and design for the minimum flowrate.

\subsection{Structure}

In Chapter 2, an overview of the literature of process integration and pinch technology is given. The methodology developed for the graphical targeting, as well as the mathematical modeling for obtaining the network layout in the sensible heat region, is given in Chapter 3. The mathematical model to obtain the target and network layout simultaneously is developed in Chapter 4. To demonstrate the applicability of the methods developed in Chapters 3 and 4, a case study together with the results is presented in Chapter 5. Chapter 6 contains the conclusions and recommendations for further action. 


\section{CHAPTER 2}

\section{Literature Survey}

This chapter explores the origins of pinch technology, which stems from process integration, and the different fields that use pinch technology. The chapter covers literature dealing in the following subjects:

- The principles of heat integration including the use in batch operations

- Mass integration and the application in batch environments

- The use of simultaneous heat and mass integration

- Mathematical models that can be applied to solve process integration problems

- The discussion and the reduction of external cold utilities

- The discussion of external hot utilities

The chapter is structured to present the path of how pinch technology has evolved with applications in different fields in the chemical industry. The path leads to showing how the flowrate of cooling water as an external cold utility can be further reduced, after heat integration has taken place, by means of pinch technology. The question then arises, when viewing the external hot utilities, if the flowrate of steam cannot be reduced by means of pinch technology. 


\subsection{Process Integration}

On any chemical plant one will find processes that are there to produce products - either being directly involved in the production of products or indirectly involved. A reactor, for instance, is a process that is directly involved in the production of products, while a steam boiler that supplies external hot utilities is indirectly involved. All processes are designed to meet certain specifications to help produce certain products. Process design follows a certain hierarchy, starting with the reactor.

A reactor is first designed to produce certain products. The second step is to design a separation system in order to separate the products of the reactor from the by-products and remaining feed. Of course, if there is more than one reactor required to produce the desired products, the first and second step will have to be repeated until the final design is obtained. After step one and two are completed, the material and energy balances are known for the next step, which is the design of the Heat Exchanger Network (HEN). When this step is complete, the last step can be executed, i.e., the specification of the utilities. Figure 2.1 shows a schematic representation of the above hierarchy.

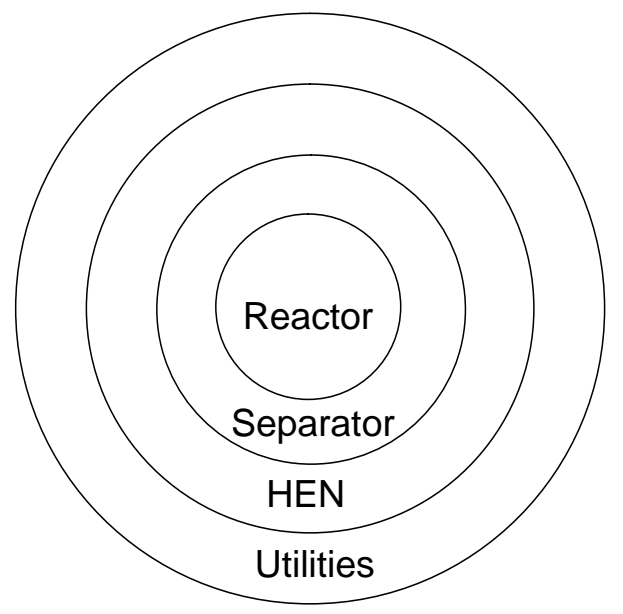

Figure 2.1: Process design hierarchy.

After process design, it has become a necessity to apply process integration on all the existing and future processes on a chemical plant. The objective of process integration is the optimization of processes, which have an economical and ecological impact on a chemical plant.

As stated before, by implementing process integration on either a grassroot level or retrofit design, economical advantages can be achieved. Reduction in capital costs, utility costs, fuel usage etc. can increase the profitability of a chemical plant. Kaggerud et al. (2006) reported that by using process integration, better raw material utilization, higher overall 
energy efficiencies, reduction in investment costs and less costly solutions for capturing of $\mathrm{CO}_{2}$ were obtained, therefore, gaining economical advantages in profit earnings.

However, these days, the ecological impact is the prime focus of process integration. Emissions, containing mainly $\mathrm{CO}_{2}$, from chemical plants have over the decades contributed significantly to the so called "greenhouse gases". These greenhouse gases contribute to global warming (Kaggerud et al. (2006)), and the effect of global warming is becoming more evident. Climate changes are viewed as a direct result of global warming (Lund (2006)), which also leads to the increased frequency of natural disasters. Therefore, environmental policies have been created and implemented to try and reduce the emissions of especially $\mathrm{CO}_{2}$ to the atmosphere, one of these policies being the Kyoto protocol. Countries who have agreed to implement the protocol have to try and reduce their $\mathrm{CO}_{2}$ emissions (Soytas \& Sari (2006)) in order to reduce the effect of global warming. Process integration is therefore a means to reduce not only $\mathrm{CO}_{2}$ emissions, but other pollutant emissions as well.

Recently, however, process integration technologies have been applied to other developments. Some of these new areas of development are in the financial, multiple resource management and integration of small and medium enterprises (SMEs) fields (Zhelev (2007)). In the financial field the evaluation of financial risks of projects are studied by means of process integration. With multiple resource management, every factor is taken into account to produce a product, where solar energy is used as the common unit. Integration of SMEs that are located in close proximity to each other consists of integration of energy, water and wastes between these enterprises.

\subsection{Pinch Technology}

In the late seventies and early eighties, pinch technology was introduced to the chemical engineering society as a highly powerful design tool. Pinch technology has been widely adopted and used in two areas, namely heat integration and mass integration. However, pinch technology was originally developed with heat integration in mind, since at that time no readily available method for optimum heat integration with regards to heat exchanger networks existed.

From 1973 to 1979 the western world was facing an energy crisis. The Organization of Arab Petroleum Exporting Countries (OAPEC), consisting of the Arab members of OPEC plus Egypt and Syria, announced that they would be exporting their crude oil at 
higher prices, and would also restrict the quantity of oil barrels it would sell to the western nations, such as the USA and the Netherlands. The reason for OAPEC's decision was as a result of the ongoing Yom Kippur War between Israel and Syria, where the USA and its allies in Europe supported Israel in the conflict. Because of OAPEC's new policies, the USA and parts of Europe where experiencing an oil crisis, which in turn lead to an energy crisis. During this crisis alternative fuel sources were being considered and means to reduce the amount of energy used, particularly in industry, were sought.

Before the energy crisis, the chemical industry saw little use of heat integration to reduce energy usage, since energy in the form of oil was relatively inexpensive and abundant. Cold process streams that needed to be heated, could be individually supplied by external hot utilities, with only a little consideration given to process-process heat integration, where cold and hot process streams exchange heat with one another instead of using external utilities. However, with the energy crisis energy usage had to be reduced in order to reduce fuel consumption. Hence, process-process heat integration became an important feature to implement on chemical plants. The main problem that surfaced for process engineers was that one could obtain several different process-process heat integration designs, each one requiring its own amount of external utility usage. Furthermore, cost played an important role which further increased the number of design possibilities in order to reduce the heat load of the external utilities.

As a result, some process-process heat integration designs gave better results than others. Therefore, there was no specific method available to determine the global optimal processprocess heat integration design, which would reduce the external utility usage as well as be the most economical design. Pinch technology was the method developed in order to meet the above problem. Pinch technology for heat integration can therefore be defined as a systematic methodology for energy saving in processes and total sites which is based on thermodynamic principles.

Pinch analysis can be described by the following four steps in chronological order:

- data extraction,

- analysis,

- design, and

- selection of alternatives

The pinch design philosophy is illustrated in Figure 2.2. 


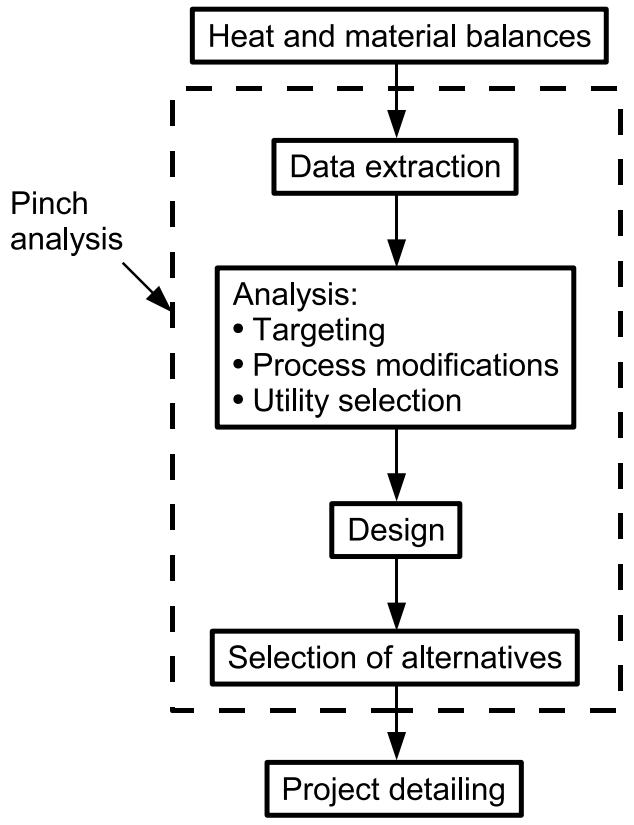

Figure 2.2: The pinch philosophy.

\subsubsection{Heat Integration}

Linnhoff \& Hindmarsh (1983) were some of the first pioneers of pinch technology development to target for the optimum process-process heat integration and design. Heat integration, using pinch technology, is based on the minimum temperature difference $\left(\Delta T_{\min }\right)$ between hot and cold streams. A pinch between a hot and cold stream is formed whenever there is a temperature difference between the two streams which is equal to the set $\Delta T_{\min }$. When several hot and cold streams are encountered the composite curves of each type of stream, namely the cold and hot composite curves, can be obtained. A composite curve is a graph representing the combined heat loads of several streams in each temperature interval. By using the hot and cold process composite curves, Linnhoff \& Hindmarsh (1983) could graphically target for the maximum process-process heat integration, and therefore obtain the minimum heat load of the external utilities for a given $\Delta T_{\min }$ as can be seen in Figure 2.3.

Another problem that came to light was that when one reduced the heat load of the external utilities, the investment cost increased (Umeda et al. (1979)). Therefore, by reducing $\Delta T_{\min }$ to save energy, the capital investment cost increased, which resulted in a trade-off between energy and capital cost. According to Linnhoff \& Ahmad (1990) early methods relied on choosing a $\Delta T_{\min }$ value which was based on the designer's experience in the trade-off between energy and capital cost. The minimum heat load for the external utilities would then be targeted using pinch analysis, and a corresponding network would be designed using the pinch design philosophy. After the design of the network, the 


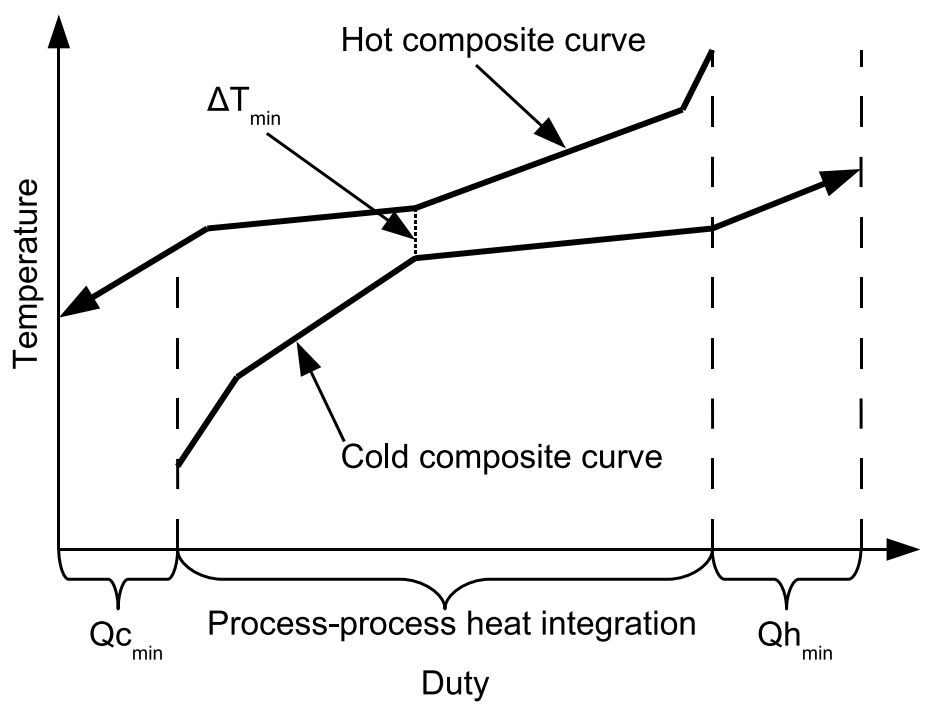

Figure 2.3: Targeting for the maximising process-process heat integration via graphical pinch analysis.

designer would then evolve the design to adjust the trade-off between energy and capital cost. This was generally done by varying the $\Delta T_{\min }$ values, adding or removing units to the design or even developing a completely new design. Linnhoff \& Ahmad (1990) proposed that the optimal $\Delta T_{\min }$ value, which gave the best cost saving on both energy and capital, be obtained before targeting and design.

To obtain the optimum $\Delta T_{\min }$ value with regards to cost savings, a cost analysis is performed. By combining the costs of utilities as well as the cost of the heat transfer area for different $\Delta T_{\min }$ values, a region is encountered were the $\Delta T_{\min }$ values gives the minimum combined costs of utilities and capital, as illustrated in Figure 2.4. By using a $\Delta T_{\min }$ value in this range, the designer is assured of a minimum combined utility and capital cost when targeting and designing for maximum process-process heat integration.

\section{The algebraic method}

There exists an algebraic method for targeting the maximum process-process heat integration using pinch analysis. The reason for using an algebraic method comes from the fact that hot and cold process composite curves can become complicated as the number of streams increases. The algebraic method, which uses a problem table algorithm to solve for the maximum process-process heat integration, is more simplistic to use to obtain energy targets. Linnhoff \& Hindmarsh (1983) introduced a problem table algorithm method to obtain the maximum process-process heat integration without using any graphs.

The basis for this method is to adjust all the process streams to their shifted temper- 


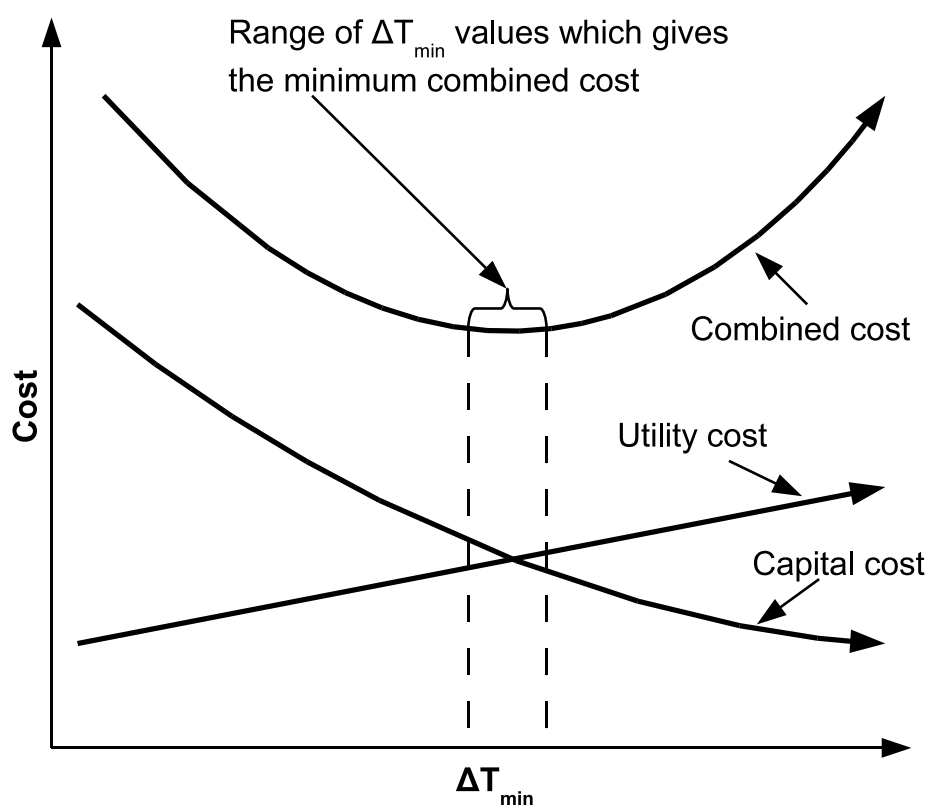

Figure 2.4: Combined cost curve to determine the range of $\Delta T_{\min }$ values that will give the minimum combined cost.

atures, in order to produce heat intervals, which include cold as well as hot streams. The temperatures of cold streams increase by $\Delta T_{\min } / 2$, while the temperature of hot streams decrease by $\Delta T_{\min } / 2$. After shifting the temperatures, the process streams are divided into temperature intervals. In each interval a heat balance is obtained, which is then cascaded. Since heat flows cannot be negative, the highest negative heat flow is reduced to zero by adding heat, therefore obtaining a positive heat flow cascade diagram as illustrated in Figure 2.5.

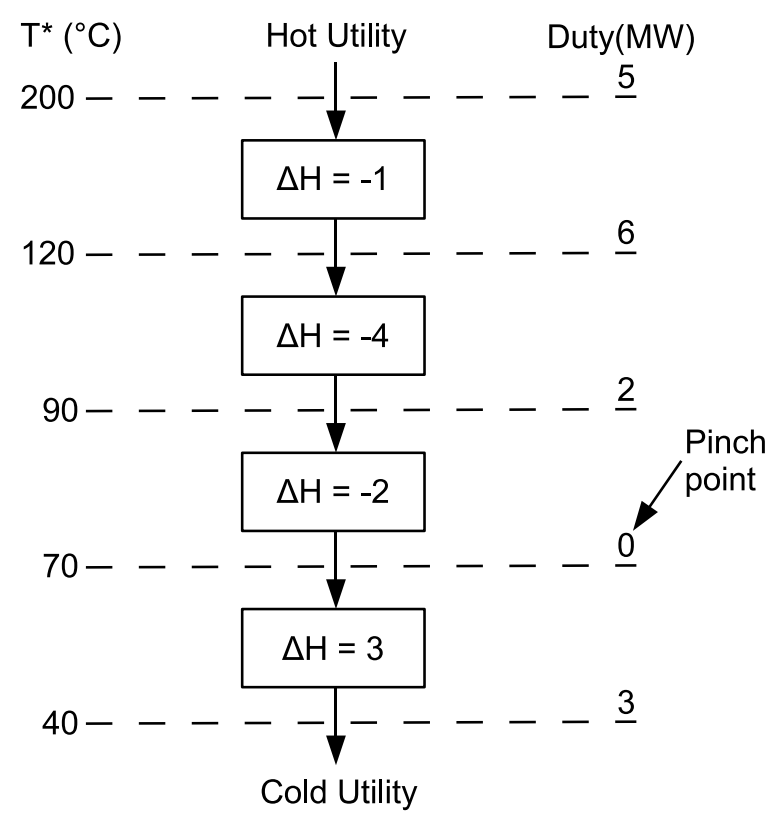

Figure 2.5: An example of a positive heat flow cascade diagram. 
From the problem cascade diagram, the Grand Composite Curve (GCC) can be constructed, as shown in Figure 2.6. The main use of the GCC is that it allows one to set up multiple utilities, e.g. steam, as well as being able to generate utilities. For instance, steam as a hot utility at different pressure levels (such as low pressure steam, medium pressure steam etc.) can be targeted through the GCC as the designer sees fit. The same can be done with cooling water at different supply temperatures. Also, utility generation can be done by using the GCC, i.e. low pressure steam can be generated.

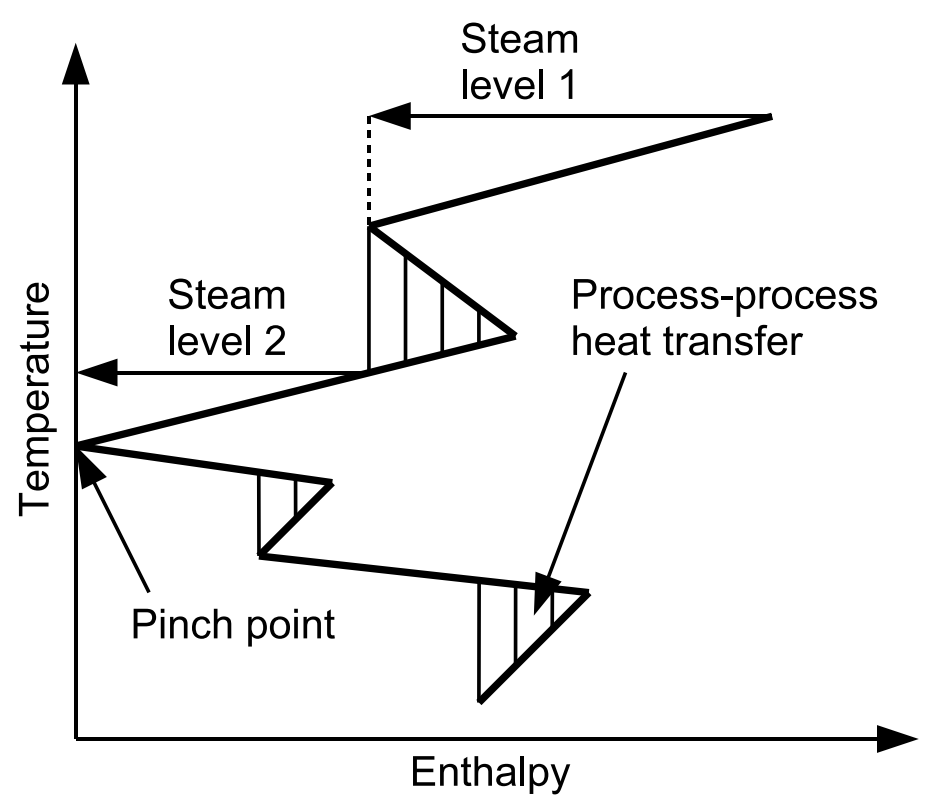

Figure 2.6: The grand composite curve.

\section{Heat exchanger network design}

Once targeting has been done using pinch analysis, a heat exchanger network layout has to be designed to meet the predetermined targets. However, using process diagrams is difficult and complex to obtain the new HEN layout. The grid diagram introduced by Linnhoff \& Flower (1978) has become the popular graphical tool to design the HEN layout, since the pinch is more clearly shown on it, as it only shows heat transfer units. Also, because of the layout of the grid diagram, it is easier to change connections between cold and hot streams without changing the layout of the streams themselves by much. Figure 2.7 shows the layout of a typical grid diagram.

Authors such as Linnhoff et al. (1979) addressed several key issues regarding the design of heat exchanger networks. The key issues that were discussed for network design were the following: the role of $\Delta T_{\min }$ in the network, the role of multiple matchings, the number of units, stream splitting, the role of constraints and lastly, the role of uncertain data. 
From these key issues, designing a HEN using the grid diagram became feasible. The grid diagram is split into sections for each pinch point. In each section the allocation of heat exchange units, either between cold and hot streams or individual streams, are done so that the duty of each process stream is met. The sections are then added together to form an overall design, where further reduction of units is then performed, if possible.

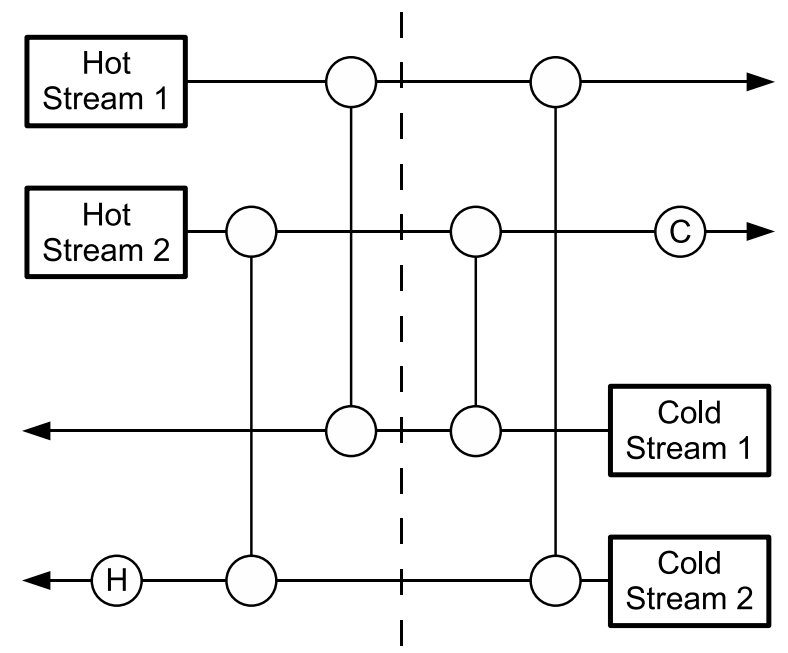

Figure 2.7: A typical grid diagram.

\section{Heat integration of batch processes}

Heat integration using pinch technology is not only limited to continuous processes, but can be applied to batch processes as well. The main difference between heat integration in batch processes, compared to that of continuous processes, is that time also plays a role. In continuous processes, temperature is used as the main constraint to determine which streams can transfer heat to one another, as illustrated in Figure 2.8. However, in batch processes not only is temperature a constraint, but time as well in determining the heat transfer between process streams. As can be seen from Figure 2.9, a source (hot stream) cannot exchange heat with a sink (cold stream) which begins before the source (Wang \& Smith (1995)).

Vaselenak et al. (1986) were the first to consider heat integration in batch processes. They determined the best pairing between hot and cold units using three different heat exchange methods. Firstly, where both hot and cold fluids return to their original vessels, secondly, where both hot and cold fluids move to new vessels and thirdly, where one stream (either hot or cold) moves through to another vessel and the other returns to its original vessel after heat exchange.

Since time plays a significant role in batch processes, the duty of each process and utility 


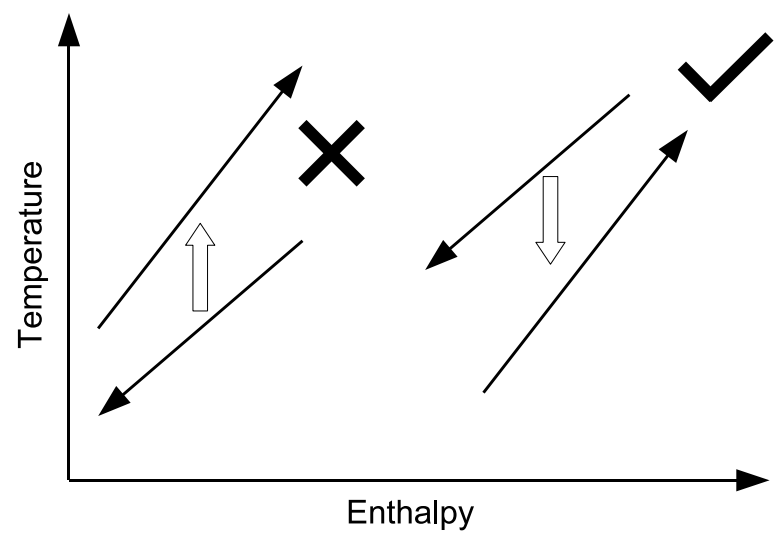

Figure 2.8: Temperature as a constraint for heat integration for continuous processes.

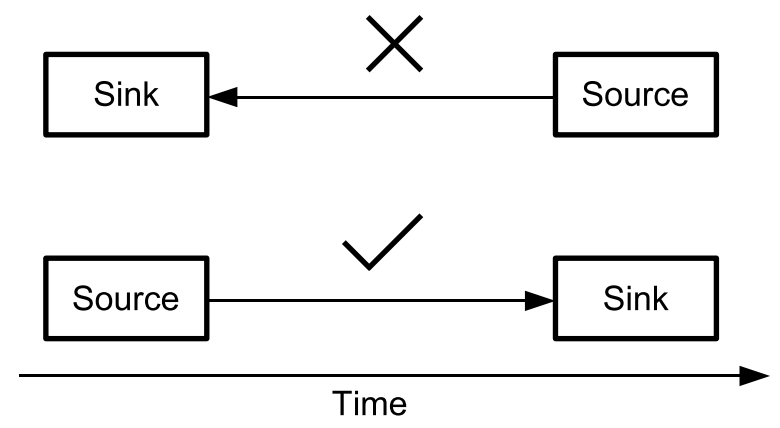

Figure 2.9: Time as a constraint for heat integration for batch processes.

stream is referred to as the amount of heat transfered in a given time, i.e. $k W h$ instead of $k W$. In continuous processes one would encounter hot and cold composite curves on a Temperature vs. Duty diagram, while in batch processes one would encounter hot and cold composite curves on a Heat transfered vs. Time diagram as seen in Figure 2.10 (Wang \& Smith (1995)). From the gradients of the aforementioned diagram, the heat flow or duty is obtained for each temperature interval. However, before heat integration can be applied to batch processes, the schedule of the batch processes has to be known.

According to Adonyi et al. (2003) scheduling and heat integration have in the past been done separately from each other. Either scheduling is optimised first and then from the results heat integration is applied (as in the case of Vaselenak et al. (1986)), or vice versa. Since the two models (scheduling and heat integration) influence each other, Adonyi et al. (2003) developed a mathematical model which incorporated heat integration and batch scheduling, solving the two models simultaneously instead of consecutively. Other authors such as Papageorgiou et al. (1994), Lee \& Reklaitis (1995) and Majozi (2006) have also developed mathematical models where batch scheduling and heat integration is done simultaneously instead of separately. Although these authors used the same core idea of solving the two models simultaneously, each one's mathematical model was designed to 


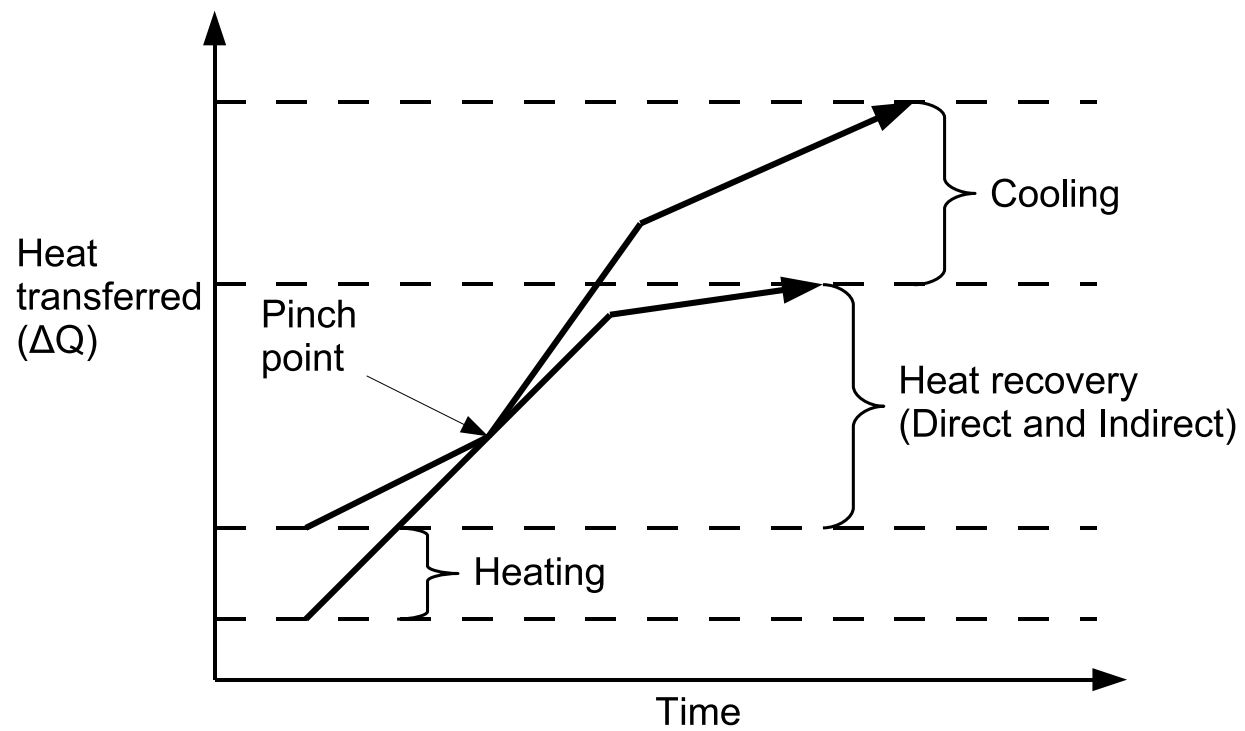

Figure 2.10: Targeting for the maximum process-process heat integration for batch processes.

take into account different scenarios, solving techniques and constraints.

\subsubsection{Mass integration}

Mass integration is broadly used to minimize water consumption in process industries. There are two main fields where mass integration is utilised to reduce water consumption, i.e. water pinch method (Wang \& Smith (1994)) and to reduce water as a mass separating agent (El-Halwagi \& Manousiouthakis (1990)).

Many process industries make intensive use of water in their processes, thereby generating wastewater streams. In the past these wastewater streams would be mixed and treated on site before they were discharged to the local municipality for further treatment. This method, which is called end-of-pipe treatment, has become economical and ecologically taxing on the industries which utilise it. Stricter environmental regulations, rising costs of treatment and the scarcity of water sources are the main factors contributing to expenses associated with the end-of-pipe treatment method.

Following the method developed by Linnhoff \& Hindmarsh (1983), El-Halwagi \& Manousiouthakis (1990) developed a method to reduce the contaminant load that needed to be removed by external mass separating agents (MSA), by maximising process-process mass integration, as seen in Figure 2.11. A minimum allowable composition difference value is used throughout between each lean and rich process stream. This is to ensure that the mass exchange driving force is sufficient as to ensure practical feasibility. However, for each lean process stream the corresponding equilibrium data is required, which 
is often difficult to obtain.

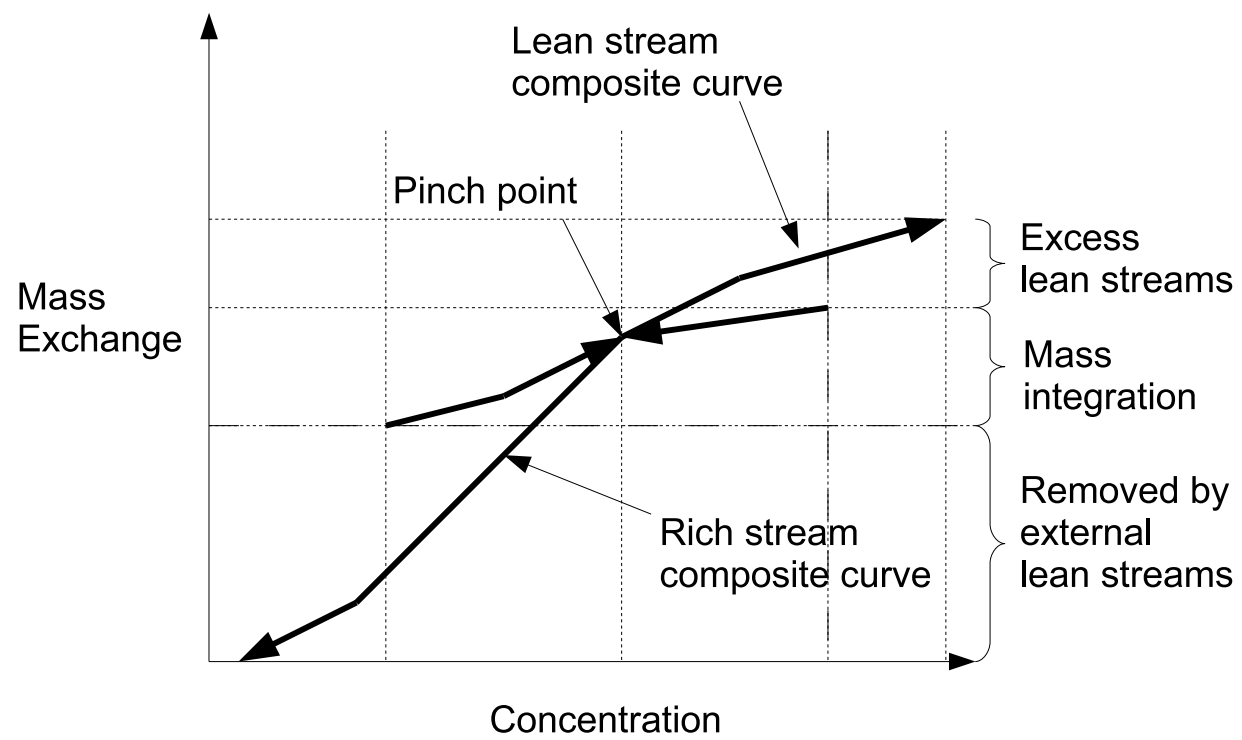

Figure 2.11: Mass integration using pinch analysis.

Wang \& Smith (1994) developed a method for wastewater minimization in water using operations, where only one lean stream is used, i.e. water. Since only one lean stream is used, there is no need for lean stream scales, as in the work done by El-Halwagi \& Manousiouthakis (1990). The limiting water profile curve was introduced by Wang \& Smith (1994), where the curve incorporates the process constraints directly, i.e. concentration driving forces as well as other constraints due to corrosion limitations etc. Therefore, several minimum allowable concentration differences are allowed throughout the network. With the method by Wang \& Smith (1994), water and wastewater is minimised whilst the process streams remain unchanged. Furthermore, Wang \& Smith (1994) showed how wastewater regeneration, regeneration re-use and regeneration recycle could be implemented with the graphical water pinch targeting method. These three options are illustrated in Figure 2.12.

Savelski \& Bagajewicz (2000b) proposed a set of necessary conditions for optimality when trying to minimise the wastewater flowrates for single contaminants. The authors argued that the existing design methods have limited design capabilities, since they focused only on certain aspects of the problem. Furthermore, superstructure models presented numerical difficulties and most solved as a non-linear programming (NLP) model, therefore not guaranteeing a global optimum. Savelski \& Bagajewicz (2000a) developed an algorithm design method, utilising the set of optimality conditions they derived, which can be solved by hand without the use of graphical targeting. Therefore, the design method can simultaneously find the target and network design. 


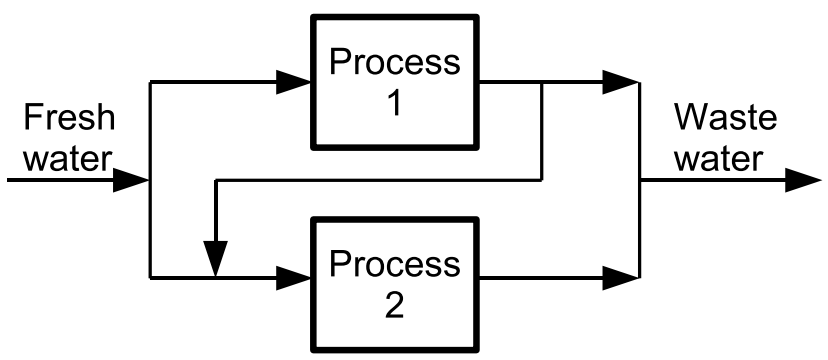

(a)

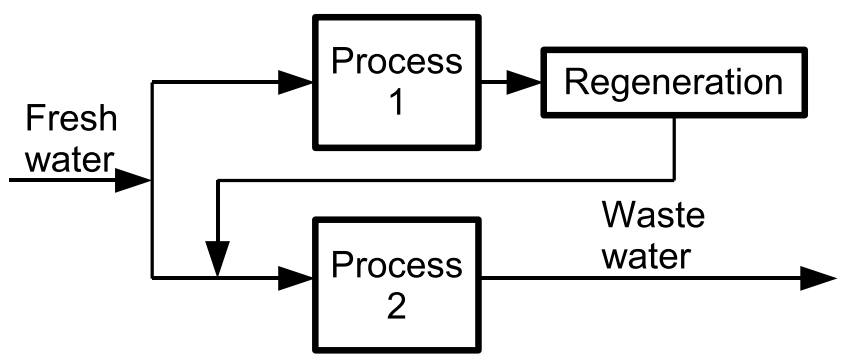

(b)

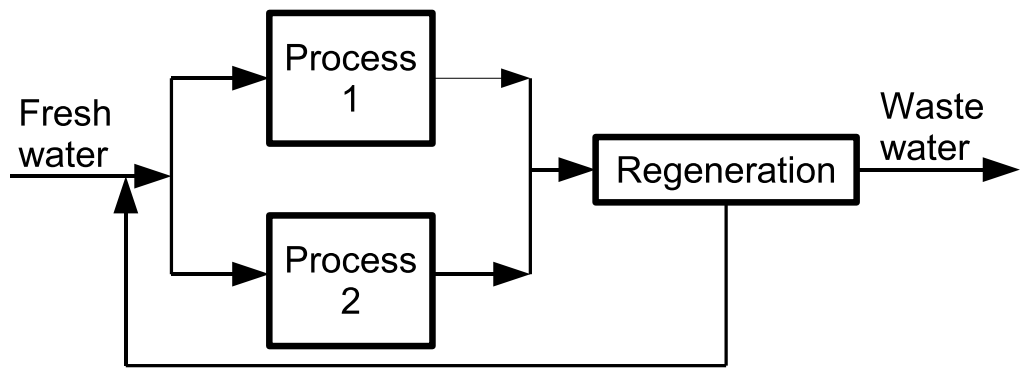

(c)

Figure 2.12: Three options to reduce wastewater (a) re-use, (b) regeneration re-use and (c) regeneration recycling.

However, since the set conditions for optimality only cater for single contaminants, Savelski \& Bagajewicz (2002) obtained a new set of necessary conditions for optimality in systems with multiple contaminants. To compensate for the multiple contaminants in the design problem, Savelski \& Bagajewicz (2002) introduced the 'key component'. The key component is defined as the contaminant which requires the largest quantity of freshwater in a unit, if the maximum outlet concentration of the unit is reached. Therefore, the new conditions derived by Savelski \& Bagajewicz (2002) utilise the key component, since each freshwater consuming unit will have a key component reaching its maximum concentration. 


\section{Mass integration of batch processes}

Mass integration using pinch technology is not only limited to continuous processes, but applies to batch processes as well. In continuous processes, concentration is used as the constraint to determine which streams can transfer mass to each other, as illustrated in Figure 2.13 (Majozi (2005)). However, in batch processes, not only is concentration a constraint, but time is as well in determining the mass transfer between process streams. As shown in Figure 2.14, stream A cannot exchange mass with stream B, which begins before stream A (Majozi (2005)).

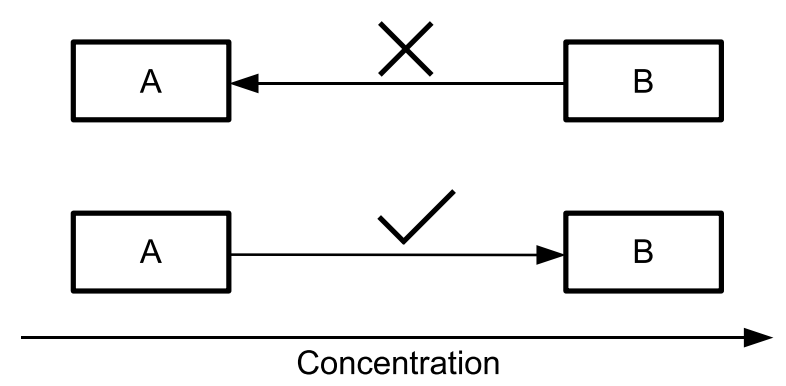

Figure 2.13: Concentration as a constraint for continuous processes.

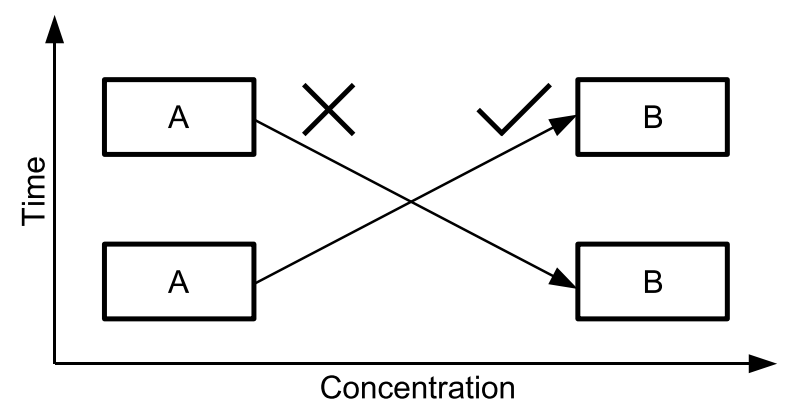

Figure 2.14: Concentration and time as constraints for batch processes.

Wastewater minimization depends on the schedule of the batch processes. As is the case with heat integration of batch plants, optimising the schedule as well as the mass integration simultaneously, instead of separately, yields the optimum solution. Solving for the minimum wastewater flow rate in batch plants can either be done graphically (Wang \& Smith (1995), Wang et al. (2005), Majozi et al. (2006)) or mathematically (Grau et al. (1996), Almató et al. (2004), Kim \& Smith (2004), Majozi (2005)). Most graphical models however, assume that the schedule has been obtained prior to wastewater minimization. 


\subsubsection{Simultaneous heat and mass integration}

Individual use of energy and water in process industries is crucial as mentioned above. However, in some processes both water and energy needs to be considered. For instance, the performance of separation agents used in mass exchange units can depend on temperature. Another example is water used for washing purposes; the quality and the temperature of the washing stream determines how adequate the process-washing will be. In the past minimization of water and energy have been done separately, even for processes that entail simultaneous heat and mass transfer.

According to Savulescu et al. (2005a) several conceptual and graphical techniques have been developed in the past for individual or combined analysis of water and energy systems. However, the authors stated that water and energy systems interact with each other, and therefore have to be addressed simultaneously. The main reason for this is that several network designs can be obtained when targeting for the minimization of water. Since streams can be mixed to facilitate heat transfer, different water connections between mass exchange units will result in different energy requirements.

In the first part of their work, Savulescu et al. (2005a) focused on obtaining a methodology for the network design concerning the heat exchange network. It must be noted that in the first part, the authors assumed no re-use of water streams in the water network, i.e. every mass exchange unit was supplied with fresh water. Therefore, the authors concentrated on developing a new graphical design procedure to yield fewer heat exchange units and to reduce the complexity of the network, while still meeting the energy targets of the mass exchange units. This was accomplished by obtaining separate systems and the use of isothermal mixing between the composite curves. The separate systems can be obtained by fixing either the hot or cold composite curve whilst shifting the other composite curve; the flowrates between the composite curves are changed through stream mixing of the fixed composite curve and stream splitting of the other composite curve.

In the second part of their work, Savulescu et al. (2005b) allowed for water streams to be re-used. Since different re-use connections can be obtained for the same water flowrate target and energy consumption is dependent on the water network, different energy networks can result. Another problem is the use of direct and indirect heat transfer options with regards to the re-use connections. Direct heat transfer requires fewer heat exchangers at the expense of energy consumption, whereas indirect heat transfer can be used to recover the maximum amount of heat but at the cost of more heat exchangers. The authors therefore developed the two-dimensional grid diagram to overcome these difficulties. 
The two-dimensional grid diagram is a graphical method where re-use options are determined with regards to water minimization as well as energy allocation. The diagram uses four design steps, where step four exploits the benefits of both direct and indirect heat transfer options. Once the water network layout has been obtained with the help of the two-dimensional grid diagram, stream data can be extracted for use in the final heat network layout. The separate systems approach is once again used as aforementioned. Furthermore, the authors successfully applied the two-dimensional grid diagram and separate systems procedure to processes with heat losses.

Even though in the first and second part (Savulescu et al. (2005a); Savulescu et al. $(2005 b))$ tools are designed in which water and energy consumption was minimized simultaneously using process-process integration, there is a potential for further minimization of the external utilities. As mentioned in Chapter 1, the flowrate of cooling water, as a cold utility, can be further minimised, however, the external hot utilities are not addressed.

Kim \& Smith (2001) developed a graphical technique based on the water pinch method to combine heat and mass integration for a cooling tower and the heat exchange network of the tower. What must be noted is that the cooling water flowrate supplied by the cooling tower is reduced whilst still meeting the duty required by the heat exchanger network. Therefore, the flowrate of the external cold utility (cooling water) is reduced after the duty of the external cold utility has been fixed using process-process integration.

\subsubsection{Mathematical models for pinch technology}

Pinch analysis does not have to be done graphically to obtain a solution. Mathematical models can incorporate pinch technology to solve for the optimal solution. Large problems - especially those that deal with total site integration - can be solved with reasonable computational effort. In the first part of their work, Papoulias \& Grossman (1983a) derived a MILP model for the utility section of a chemical plant. The utility section consisted of boilers, turbines, electric motors to name a few, where each of these components affects the configuration of the required utility demand. Therefore, by developing a MILP model, Papoulias \& Grossman (1983a) could find the optimum structure and operating conditions for the utility section with regards to costs.

In part two of their work, Papoulias \& Grossman (1983b) derived a MILP model to cater for the heat recovery network. The MILP model successfully maximises process-process integration, therefore minimising the external utility demands. Furthermore, the model 
yields the optimal network design (minimum number of units) for the given processprocess integration target obtained. The authors even included a weighing scheme where the designer can specify different levels of priority for stream matches.

Finally, in the third part of their work, Papoulias \& Grossman (1983c) derived a MILP model to obtain the layout for a chemical company. Furthermore, they combined the previous two MILP models (Papoulias \& Grossman (1983a) and Papoulias \& Grossman (1983b)) with the third MILP model. The final MILP model can therefore optimise the utility section, the heat recovery network and the chemical company simultaneously, whilst taking into account the interactions of the three systems with each other.

Marechal \& Kalitventzeff (1998) developed a three step mathematical procedure to satisfy the minimum energy requirement at the minimum cost when process integration is done on a site scale. The first step identifies the technologies that may be used and their sizes for the requirement of the Minimum Energy Requirement (MER). The second step identifies the technologies that are readily available on the market to satisfy the technology requirement. Step three entails the targeting for the optimal process configuration, or the best combination of the available technologies. In essence, mathematical models have been developed and applied to many different problems, i.e. obtaining the steam turbine network layout (Mavromatis \& Kokossis (1998)), energy management with uncertainty (Papalexandri et al. (1996)), designing of heat exchanger networks (De Oliveira Filho et al. (2007)), targeting and design for cooling water systems with more than one cooling water supplying unit (Majozi \& Moodley (2007)) to name but a few.

However, one has to be able to develop a mathematical model for a given scenario before design can take place. To obtain a mathematical model, a superstructure is developed which contains all the features that contribute to the best design. Figure 2.15 shows an example of a superstructure. Different configurations of a superstructure can result in faster solution times as well as a reduction in the complexity of the formulation. For instance, Bauer \& Stichlmair (1996) stated that previous superstructures for distillation separation sequences did not take into account direct column coupling, non ideal and azeotropic mixtures. Therefore, the authors developed a superstructure where coupled columns and complex separation schemes could be handled as well as handling zeotropic and homogeneous azeotropic mixtures.

One of the best features of mathematical models is the ease of incorporating constraints. In practice, certain constraints have to be taken into account, whether they be in the targeting or design phase. Examples of constraints could be flowrates, network topology, forbidden matches, quantity of streams mixing and splitting, pressure drops, etc. 


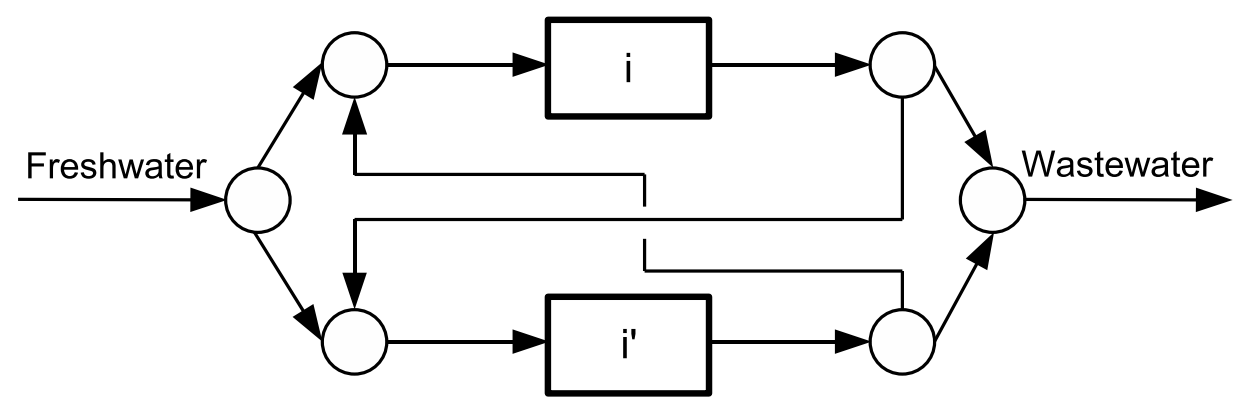

Figure 2.15: A superstructure model for wastewater minimization.

Incorporating these constraints in a graphical pinch analysis makes the targeting and design complex and near impossible. However, by using mathematical models, constraints are easily added and the resulting solution can be obtained without changing the model structure.

The main problem with mathematical models is that in many cases the model is nonlinear, therefore, global optimality cannot be guaranteed. The second problem is that mathematical models do not give the user an understanding of the method of finding the solution, i.e. they are a black box approach, where the data goes in at one end and the answers come out the other end.

\section{$2.3 \quad$ Utilities}

\subsubsection{External cold utilities}

External cold utilities are used to cool process streams which could not exchange their heat using process-process heat transfer. The type of external cold utility to be used for a given hot process stream can vary greatly, from steam generation, cooling water for cooling processes above ambient temperature to sub-zero refrigerants for cooling below ambient temperature. Cooling towers which supply cooling water, are viewed as one of the biggest mass and heat transfer devices that are in use today. Two types of cooling towers are encountered, i.e. the cross flow and counter flow cooling towers.

In counterflow cooling towers the hot returning water (liquid-phase) is distributed into sprays of water droplets, which enter at the top of the cooling tower. The hot spray flows downwards through the tower while relatively cold air is blown upwards through the column. The air flow can either be induced by fans blowing at the bottom or top of the tower, or through the natural chimney effect. The heat transfer between the hot 
spray and cool air primarily takes place on a large interface between the two phases. This large interface can either be provided by filled packaging made out of PVC or trays/decks of wooden boards as slats (Khan et al. (2003)). The cooled water droplets collect at the bottom of the cooling tower from where water can be reused as an external cold utility. Unfortunately, a fraction of the incoming water droplets will escape the cooling tower by means of the air flow. Figure 2.16 shows a schematic diagram of the aforementioned description.

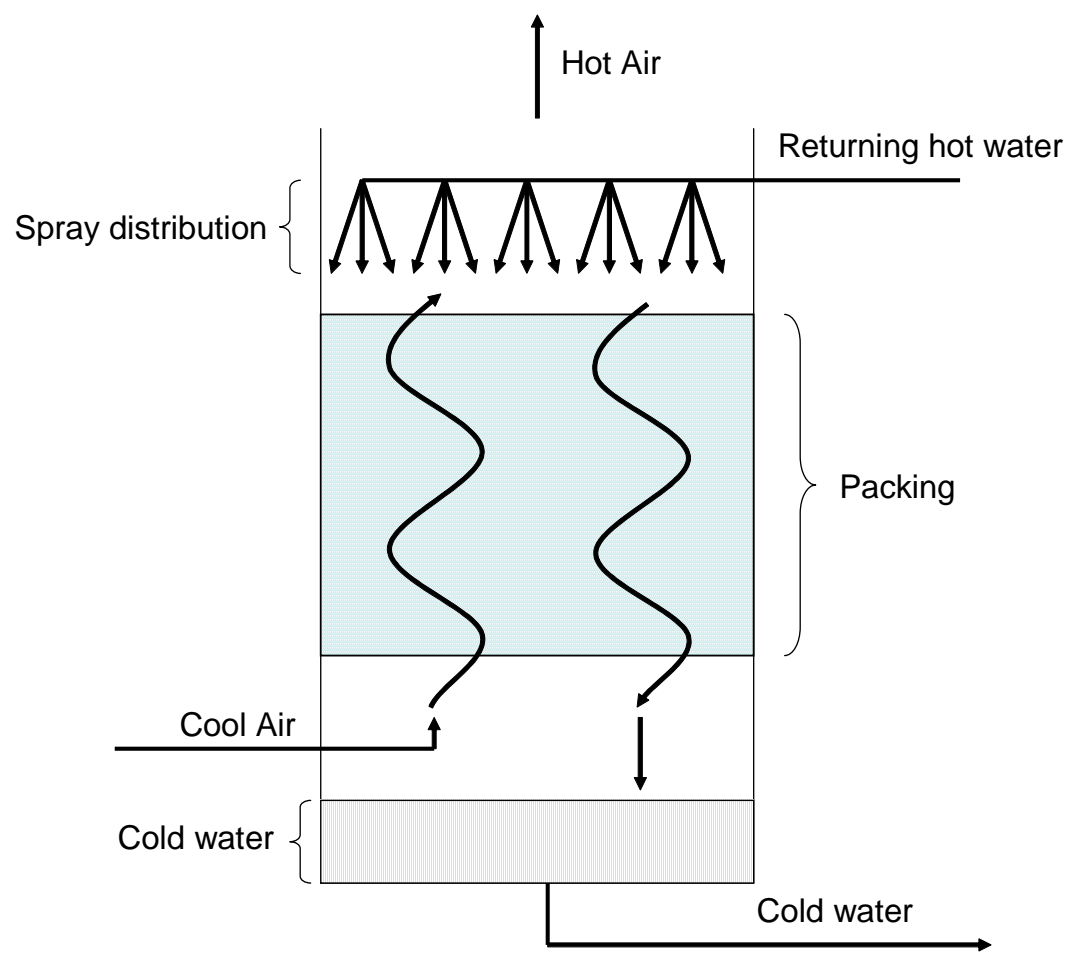

Figure 2.16: Schematic of a counter current cooling tower.

Optimization of cooling towers is primarily concerned with the optimization of the thermal efficiency of the cooling tower. In order to obtain the optimal thermal efficiency of the cooling tower, the optimal operating conditions of the tower must be obtained (Söylemz (2004)). To obtain the optimal operating conditions, mathematical models are used and the results are then verified by experiments (Milosavljevic \& Heikkillä (2003), Khan et al. (2003), Naphon (2005)).

In the experimental work done by Bernier (1994), it was shown that as the ratio of cooling water to air flowrate in a cooling tower decreased, the coefficient of performance (COP) of the tower increased. It must be noted that the duty that had to be met by the cooling water remained the same; therefore, the temperature of the returning cooling water to the tower increases as the flowrate decreased. Furthermore, in the experiment done by Bernier (1994), the flowrate of the air in the cooling tower was kept constant, 
therefore, only the cooling water flowrate was decreased. Figure 2.17 shows the data from the experimental work of Bernier (1994), where the COP increases when the flowrate of cooling water decreases. Furthermore, the corresponding return temperature of the cooling water is given in Figure 2.17, where it is evident that the COP increases as the return temperature increases.

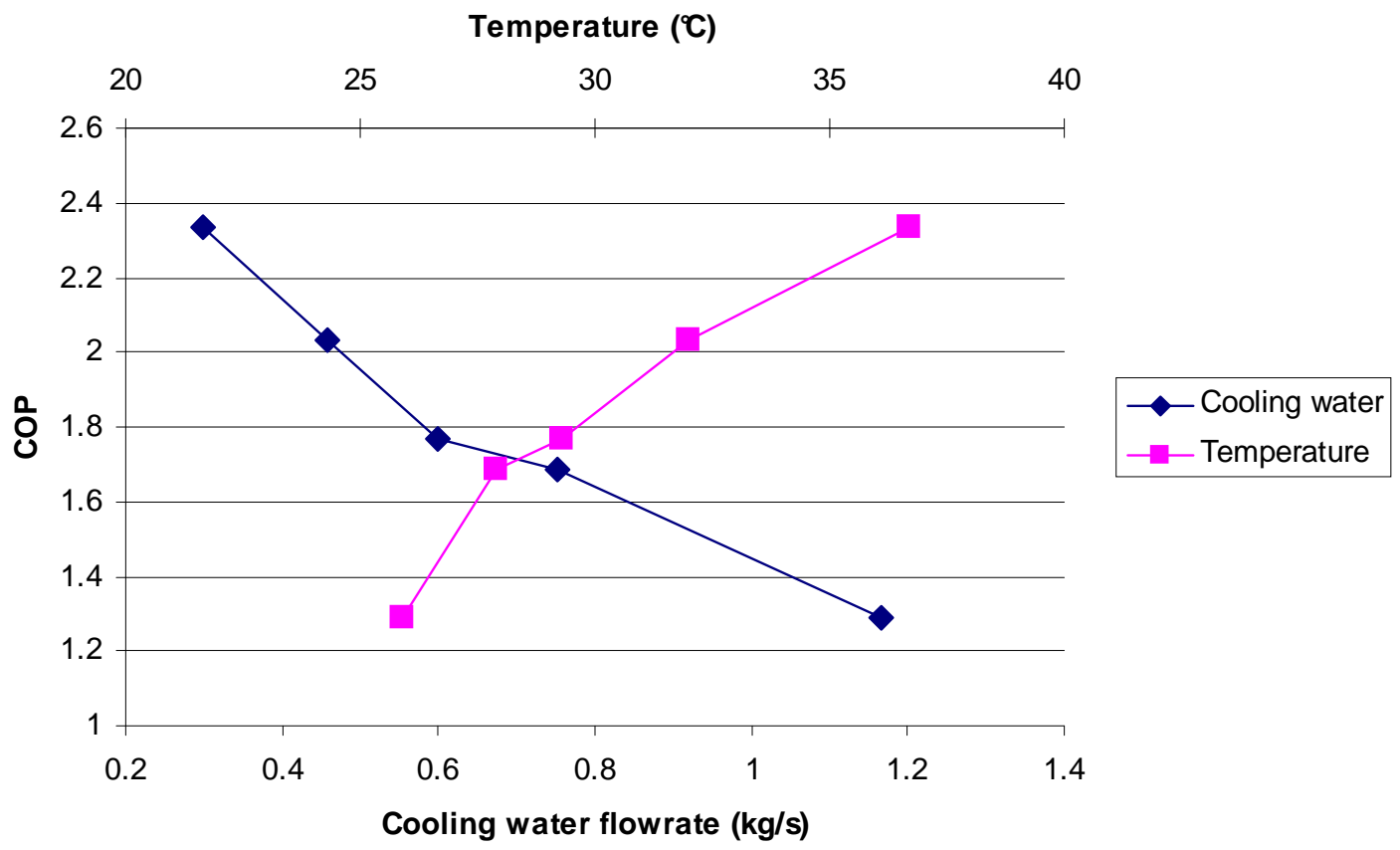

Figure 2.17: The COP of a cooling tower influenced by the mass flowrate and return temperature of the cooling water.

Using the understanding that decreasing the cooling water flowrate (for a fixed duty) increases the COP, Kim \& Smith (2001) developed a systematic method to cater for the above effect, for a given cooling water system. The cooling water system includes the cooling tower and the network of operations that use cooling water supplied by the cooling tower. The method entails a graphical technique based on water pinch. It should be noted that the method developed by Kim \& Smith (2001) is employed after processprocess integration has been applied, therefore, the duty that has to be met by the cooling tower is fixed.

Optimization of the whole cooling water network is accomplished by reducing the cooling water needed for the fixed duties of the hot process streams, by viewing the cooling tower and its HEN as a whole and not as individual components, as seen from Figure 2.18. According to Kim \& Smith (2001) the reason why the cooling tower and the HEN is optimised as one system, is that the performance of the cooling tower influences the performance of the HEN, and vice versa. Therefore, simultaneous management of energy and water takes place (Zhelev (2005)). By reducing the cooling water flow rate, the 
blow down as well as the make-up stream for a cooling tower are also reduced. This has economical and ecological advantages, since less cooling water is used, hence the cooling tower is debottlenecked for further HENs and the blow down is reduced. Pinch analysis in the form of water pinch, was used by Kim \& Smith (2001) to determine the minimum flowrate needed from a cooling tower to its HEN.

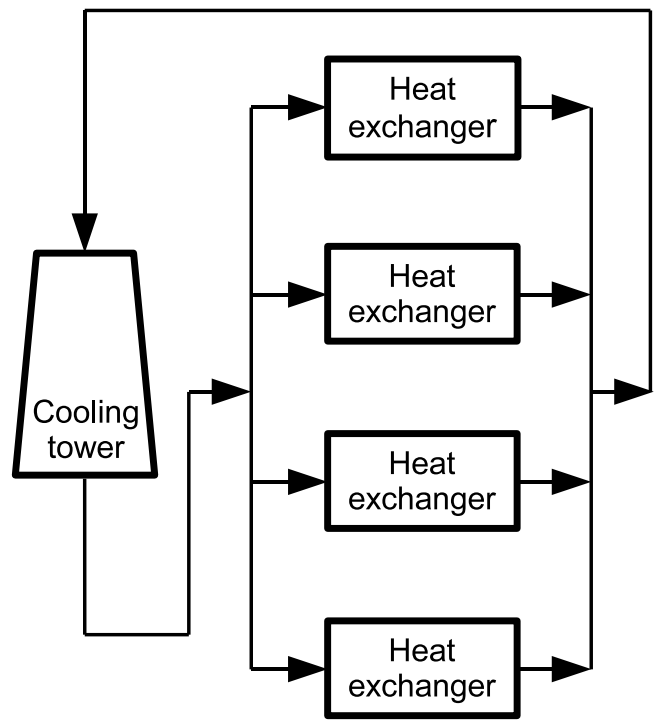

(a)

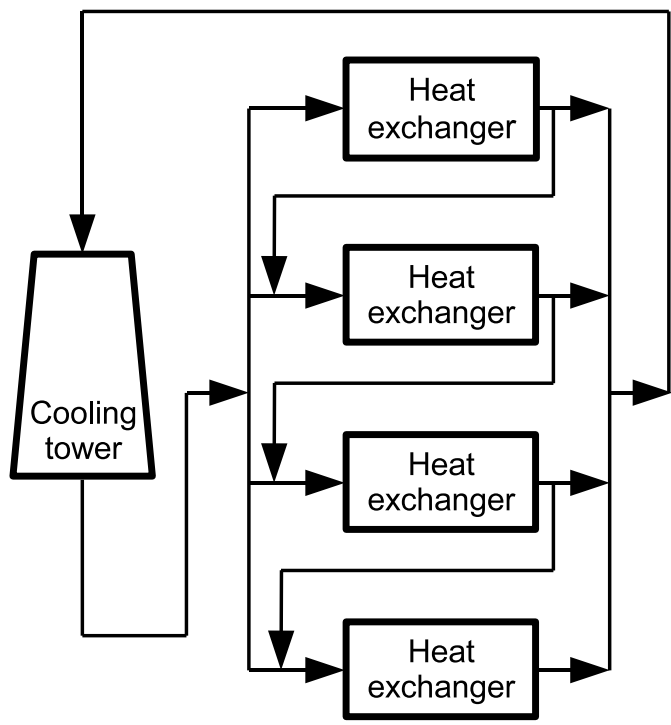

(b)

Figure 2.18: (a) Standard cooling tower and HEN layout, (b) optimization of the cooling tower and HEN as one unit.

\subsubsection{External hot utilities}

External hot utilities are used to heat cold process streams which could not exchange heat using process-process heat transfer. The type of external hot utility to be used for a given cold process stream can vary greatly from hot liquid to heat processes above the ambient temperature, steam for heating to relatively low to medium temperatures, hot oil for heating to relatively high temperatures and cooling water generation. Steam is used as an external hot utility on the majority of chemical plants.

Marechal \& Kalitventzeff (1997) stated the important role steam networks play in the industrial processes, since it is an energy carrier to or inside of processes and even between processes. Furthermore, since steam is used with turbines to produce mechanical work before it is used in processes, the steam network influences the heat and power production of a chemical plant. To obtain the optimal configuration of process and power integration, total site utility system integration can be done (Shang \& Kokossis (2004)). Steam at various temperature and pressure intervals can be generated by the heat sources and 
subsequently used to generate power through steam turbines, before exchanging heat with process streams. A quantity of the steam generated in an interval can also be added to another interval that lies below the initial interval.

Steam is primarily generated by means of a steam boiler. The two main steam boilers which are encountered on chemical plants are fire-tube boilers and water tube boilers. In fire-tube boilers, hot gas (from combustion) is sent through tubes which are surrounded by water inside the shell of the boiler. The water is continuously heated until it changes phase into saturated steam, and if desired, further heated to superheated steam. Since the water is located in the shell side, only low pressure steam can be generated in a fire-tube boiler which implies that the boiler is mainly used to generate steam at relative low temperatures.

In water tube boilers on the other hand, hot gas is sent through the shell of the boiler. The tubes, which are filled with water, are continuously heated up until water changes phase into saturated steam, and if desired, further heated to superheated steam. Since the water is located in the tubes, high pressure steam can be generated in a water-tube boiler which implies that the boiler is mainly used to generate steam at relative high temperatures.

Optimization of steam boilers has primarily been done to reduce pollutants in the flue gas and improving the efficiency of the boiler. The thermal efficiency of a boiler is regarded as the percentage of the combustion energy from the fuel that is converted into useful energy. The combustion energy that is lost through the flue gas and to the environment reduces the efficiency of the boiler.

To reduce heat loss to the environment, the boiler is insulated. The cost of the insulation material has to be taken into account in optimising the efficiency of the boiler, since it increases the capital costs of the boiler. Abdallah \& Ismail (2001) have developed a mathematical model to determine the optimal thickness of insulation material for reduced heat loss for boilers as well as the minimum cost.

The network layout of steam that is used as an external hot utility, has generally been a parallel configuration as seen from Figure 2.19. The main reason for this is that when steam levels and their duties are determined with the GCC, only the latent heat of the steam is used to transfer heat to cold process streams. This is evident when looking at Figure 2.20, where steam as a external hot utility has been applied. The steam lines remain horizontal, therefore, the temperature of the steam does not change at all. Only latent heat is exchanged which implies that phase change from saturated steam to saturated liquid has occurred. 


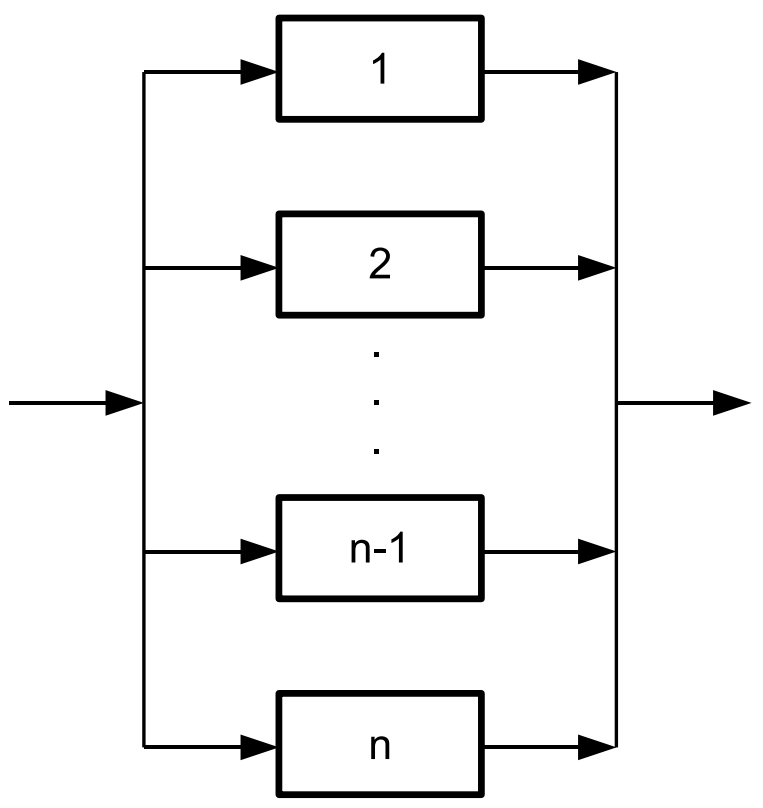

Figure 2.19: Parallel network layout of steam as a utility.

Since the flowrate of the cooling water (external cold utility) can be reduced for a fixed duty, the question arises if the flowrate of steam as an external hot utility can be reduced for a fixed duty, bearing in mind that in the latter case, one has to consider phase change that does not occur in the former case. In this study a graphical targeting technique is developed to obtain the minimum flowrate of saturated steam used as an external hot utility. A linear programming (LP) model is developed to help obtain the network layout after the steam flowrate target has been set using a graphical technique. Furthermore, a mixed integer linear programming model (MILP) is presented in which the target as well as the network layout are obtained simultaneously. The main reason for developing the MILP model is to compare the CPU times between the hybrid graphical technique (which includes the LP model) and the MILP model. Comparing the CPU times between the models illustrates the fact that the hybrid graphical technique required less computing power, which becomes a significant factor when dealing with large scale problems. 


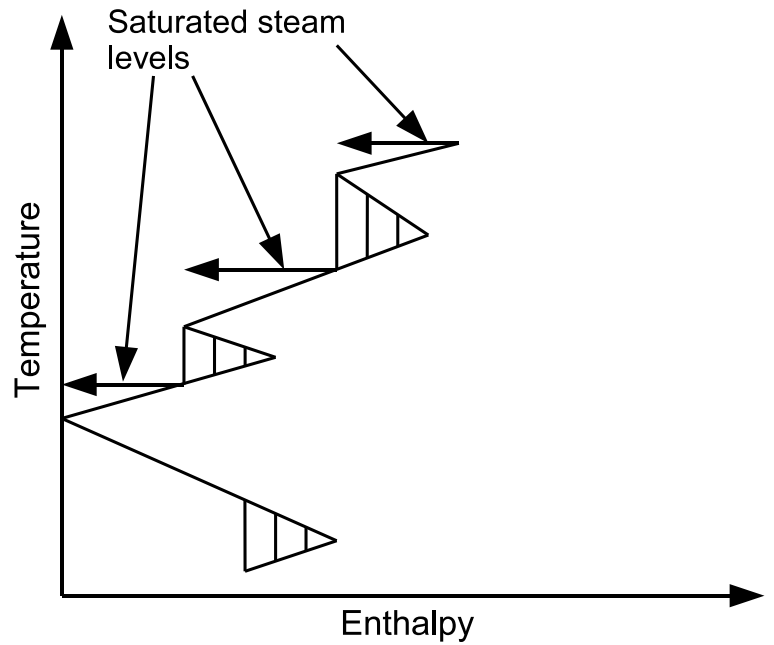

Figure 2.20: Steam levels on a GCC. 


\section{CHAPTER 3}

\section{Methodology}

This chapter describes the methodology that was developed. The methodology presented consists of two steps, i.e, targeting and network design. The first step is to target for the minimum steam flowrate by means of a graphical targeting technique. The second step is to obtain the HEN network that corresponds to the targeted flowrate obtained in step one. A linear programming (LP) model was developed in order to obtain the HEN layout in the sensible heat region, since it becomes difficult for the designer to achieve a feasible network design, given the design options (series and parallel) available in the sensible heat region. Furthermore, a few design aspects are discussed such as stream splitting that can occur.

\subsection{Targeting}

Hot utility streams are used to supply energy to the cold process streams in order to increase the temperature of the cold streams. Therefore, thermodynamically, the utility streams must be at a higher temperature than the cold process streams at all times. This is to ensure that there will always be a driving force of energy from the hot utility streams to the cold process streams. When heat exchangers are designed, a minimum temperature difference $\left(\Delta T_{\text {min }}\right)$ between the utility and process stream is specified, as well as the inlet and outlet temperature limits of the cold process stream. Therefore, the temperature 
range of a utility stream is stipulated by the $\Delta T_{\min }$ value and the temperature limits at the inlet and outlet of the heat exchanger, as seen in Figure 3.1.

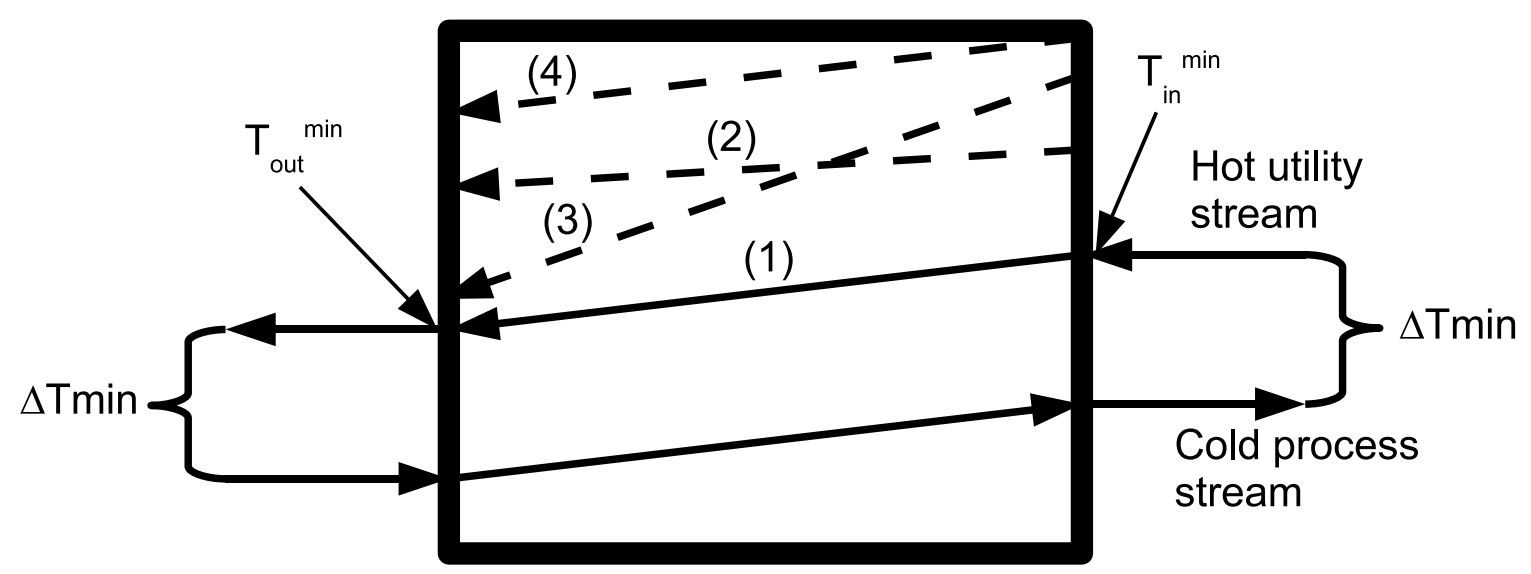

Figure 3.1: Heat exchanger with a hot utility and cold process stream.

Furthermore, from Figure 3.1, it is evident that hot utility line number 1 is the borderline, since the line is at the limiting inlet and outlet temperatures allowed by $\Delta T_{\min }$. The other hot utility lines above the borderline are all valid, therefore, the borderline divides the heat exchanger into a feasible and infeasible regions. The area above the borderline is feasible, whereas the area below the line is infeasible.

When there are several heat exchangers each with its own $\Delta T_{\min }$ value, the maximum $\Delta T_{\min }$ value is selected as the global minimum temperature difference. The global $\Delta T_{\min }$ value, as well as the temperature limits of all the heat exchangers, can be used to construct the hot utility composite curve as seen in Figure 3.2. The hot utility composite shows visually the minimum allowable temperatures one can target for on a Temperature vs. Duty (TH) diagram. Therefore, the hot utility composite curve divides the TH-diagram space into two regions (Figure 3.3), namely region 1 (the feasible region) and region 2 (the infeasible region). Targeting for the minimum steam flowrate may only be done in the feasible region, since the $\Delta T_{\min }$ value and heat exchanger temperature limits are not violated. However, targeting in the infeasible region violates the $\Delta T_{\min }$ value as well as the heat exchanger temperature limits.

Superheated steam at high pressure is generated by steam boilers. In general, the superheated steam is sent to run turbines, the exhaust of which is saturated steam. In this dissertation saturated steam is used as a hot utility. The reason for this is that one wants to take advantage of the latent heat associated with the saturated steam. Equation 3.1 shows the energy supplied by the saturated steam.

$$
Q_{S S}=\dot{m} \lambda
$$




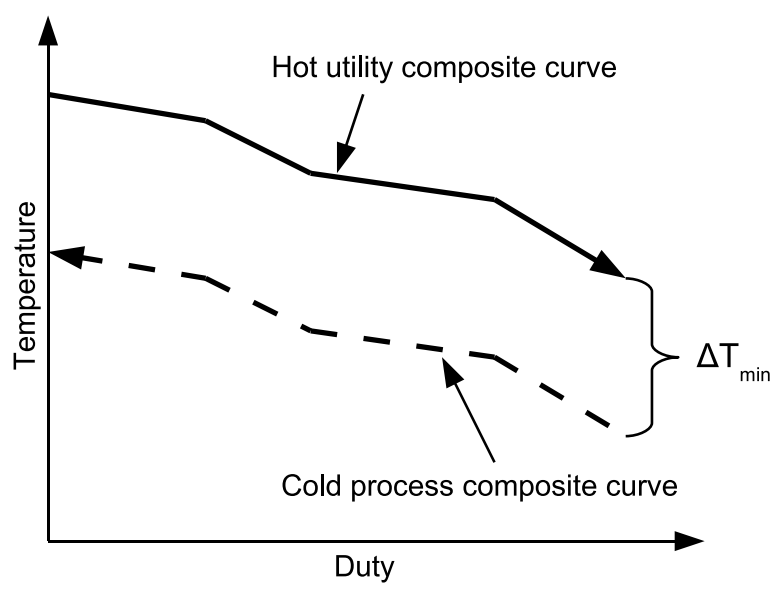

Figure 3.2: The hot utility composite curve.

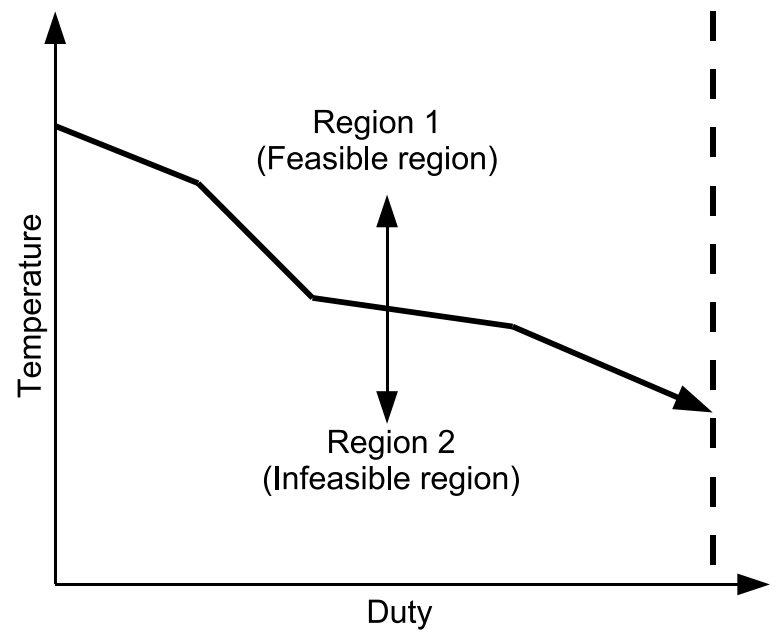

Figure 3.3: The hot utility composite curve divides the graph into two regions.

In Equation 3.1, $Q_{S S}$ is the energy supplied by the saturated steam, $\dot{m}$ is the water flowrate and $\lambda$ is the latent heat of vaporization of the saturated steam.

Since the saturated steam will phase change into saturated liquid, the temperature at which the saturated steam was supplied will remain the same. Therefore, on a THdiagram, the latent heat of vaporisation that the saturated steam transfers is represented as a straight horizontal line, which will be called the saturated steam line. The length of the saturated steam line indicates the quantity of latent heat supplied from the saturated steam. For example, looking at Figure 3.4, the saturated steam in diagram (a) supplies more latent heat than that of the saturated steam in diagram (b), since the length of the saturated steam line in diagram (a) is longer than that of the saturated steam line in diagram (b). The value of $\dot{m}$ determines the length of the saturated steam line for the same temperature. Therefore, the higher the flowrate of water, the more latent heat is supplied from the saturated steam, and vice versa. Consequently, in Figure 3.4, the 
flowrate of steam in diagram (a) is more than that in diagram (b).

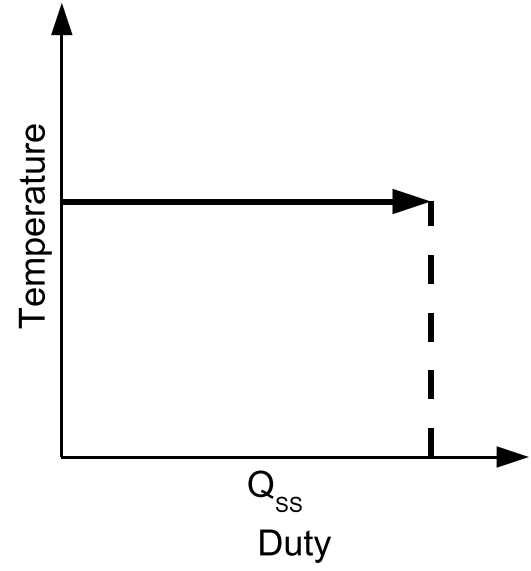

(a)

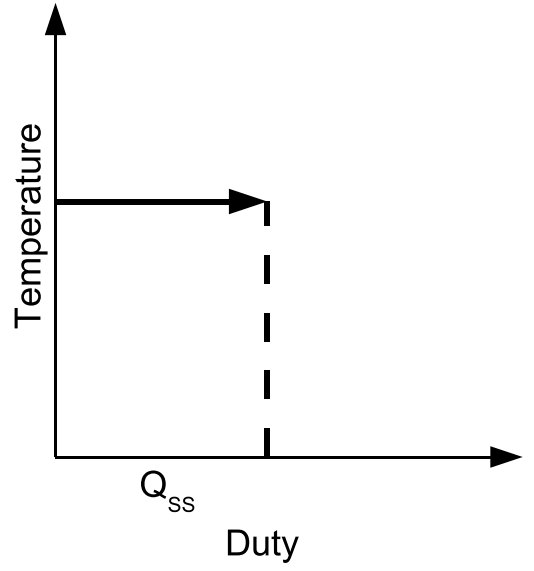

(b)

Figure 3.4: Saturated steam represented as a straight horizontal line.

The saturated liquid resulting from the saturated steam is then used further to supply heat to the remaining cold process streams. The saturated liquid that transfered energy becomes hot liquid below saturation temperature when it exits the heat exchanger. Depending on the energy content the hot liquid is reused to supply energy to other cold process streams. Therefore, the sensible heat that can be supplied by the saturated and hot liquid is given by Equation 3.2.

$$
Q_{L}=\dot{m} c_{p}\left(T_{o}-T_{i}\right)
$$

In Equation 3.2, $Q_{L}$ is the energy supplied by the saturated liquid and reuse liquid, $c_{p}$ is the specific heat capacity of the water, $T_{o}$ is the supply temperature and $T_{i}$ is the target temperature.

Since the temperature does not stay the same when using saturated liquid and reuse liquid, the hot liquid is therefore represented as a diagonal line on a TH-diagram, as shown in Figure 3.5(a), which will be called the hot liquid line. The gradient of the hot liquid line is equal to the inverse of the flowrate. This implies that the gradient of the hot liquid line gives an indication of the quantity of the water flowrate.

Note that, as stated previously, the saturated liquid results from the saturated steam losing its latent heat. Therefore, the flowrate of the hot liquid line is, in essence, the same as the flowrate of the saturated steam line. Since both lines have the same flowrate, by changing the flowrate of one line the other line will adjust to the new flowrate, as shown in Figure 3.5(b). In Figure 3.5(b) the flowrate of graph 1 is less than the flowrates 


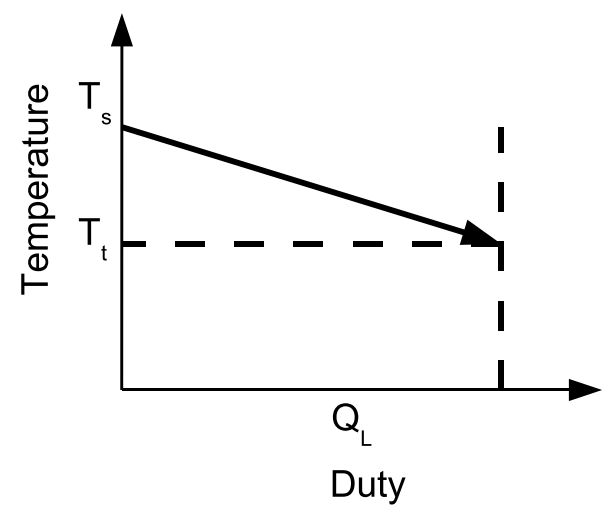

(a)

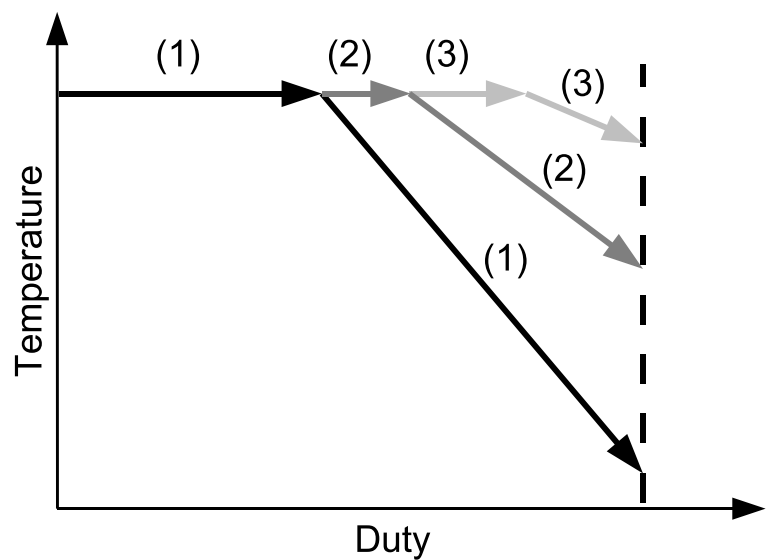

(b)

Figure 3.5: (a) Saturated liquid and reuse liquid represented as a straight line, (b) changing the flowrate of one line influences the other line.

of graphs 2 and 3. Also, the flowrate of graph 2 is less than the flowrate of graph 3. Equation 3.1 and Equation 3.2 are combined to form Equation 3.3, where the total duty of the cold process streams is met by saturated steam as well as hot liquid. Figure 3.6 depicts the final diagram when targeting for the minimum flowrate by using saturated steam as well as hot liquid. $Q_{S S}$ is the duty that is supplied by the saturated steam, whilst $Q_{L}$ is the duty that is supplied by the saturated and hot liquid. The two duties, $Q_{S S}$ and $Q_{L}$, are separated by the borderline which is the line where the saturated steam phase changes into saturated liquid.

$$
\dot{m}=\frac{Q}{\lambda+c_{p}\left(T_{o}-T_{i}\right)}
$$

In Equation 3.3, $Q$ is the energy supplied by the saturated steam and hot liquid. 


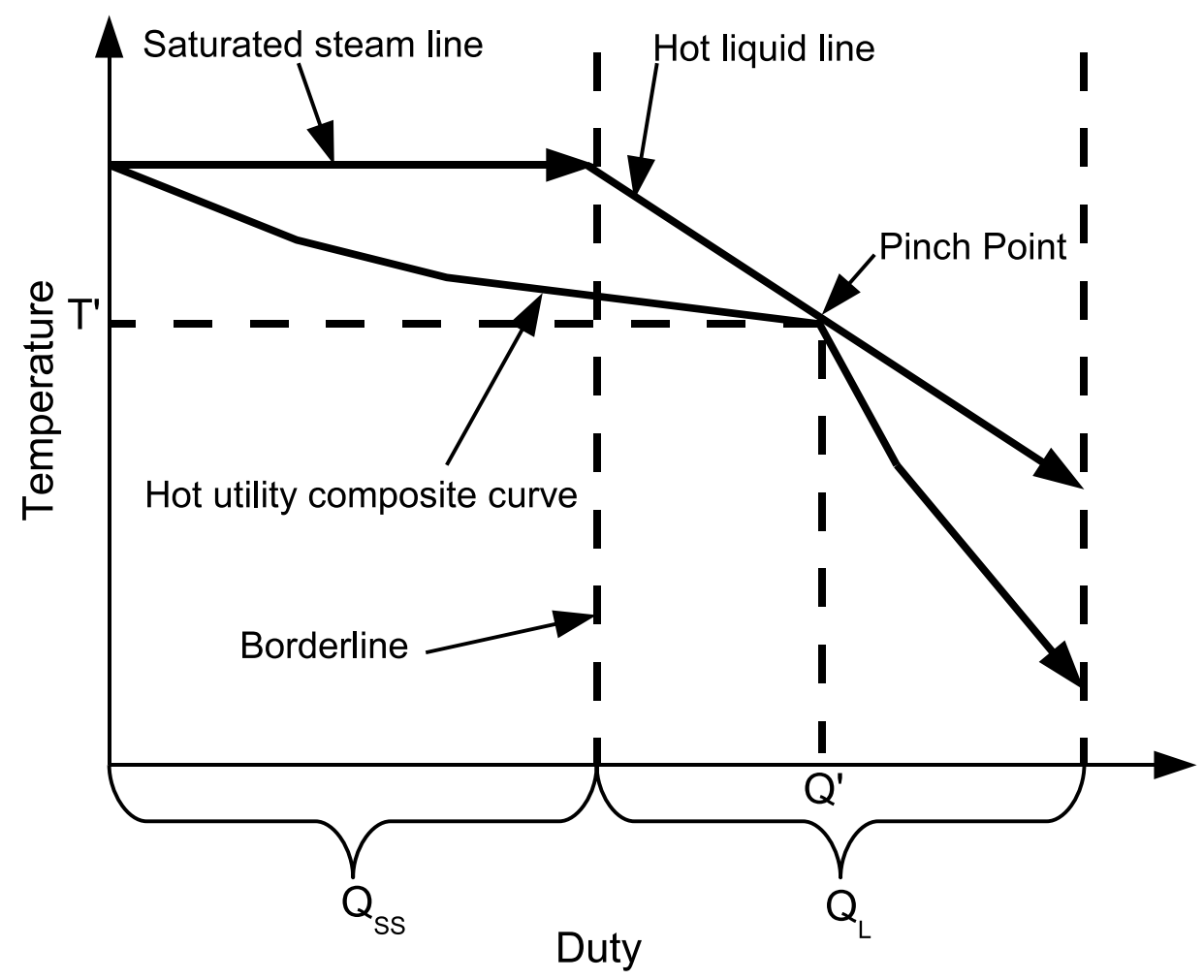

Figure 3.6: Saturated steam and hot liquid are used to target for the minimum flowrate.

\subsubsection{Graphical targeting method}

To obtain the minimum flowrate, one must target for a pinch point on the hot utility composite curve. The shape of the hot utility composite curve determines where the pinch point will occur. In some cases, determining where the pinch point will be on the hot utility composite curve can be difficult, as seen in Figure 3.7. From Figure 3.7, one does not know exactly where the pinch point on the hot utility composite curve will occur. This is further complicated by the fact that saturated steam and hot liquid lines influence each other, as aforementioned. Figure 3.8 shows an algorithm that can be used when targeting for the minimum flowrate.

The algorithm in Figure 3.8 ensures that a minimum flowrate will be obtained, regardless of the shape of the hot utility composite curve. The designer first has to identify all the possible pinch point locations on the hot utility composite curve (see Figure 3.7). Thereafter, the potential pinch point with the highest duty is chosen first i.e., this will be the point where the hot utility composite curve ends. The reason one starts with the point having the highest duty is that the target temperature $\left(T_{o}\right)$ will be at the minimum value. Therefore, the temperature difference will be the highest to ensure a minimum flowrate according to Equation 3.3. 


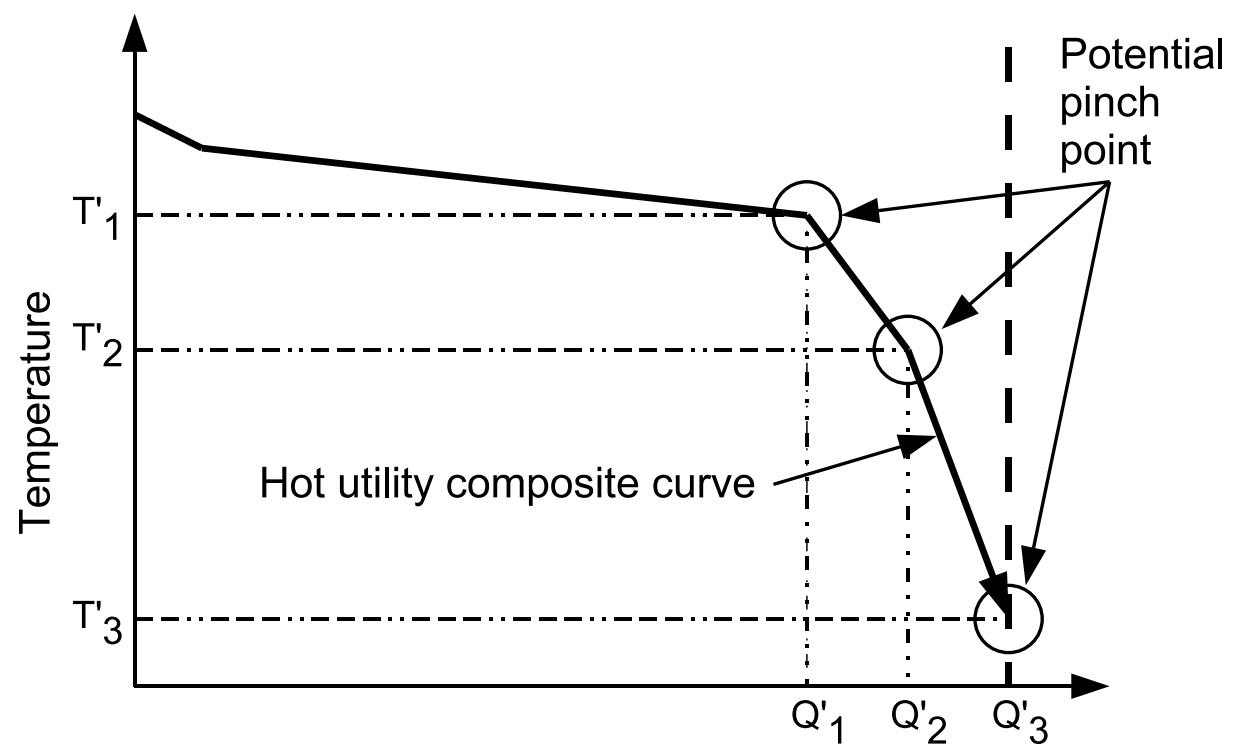

Duty

Figure 3.7: The hot utility composite curve determines where the pinch point will occur.

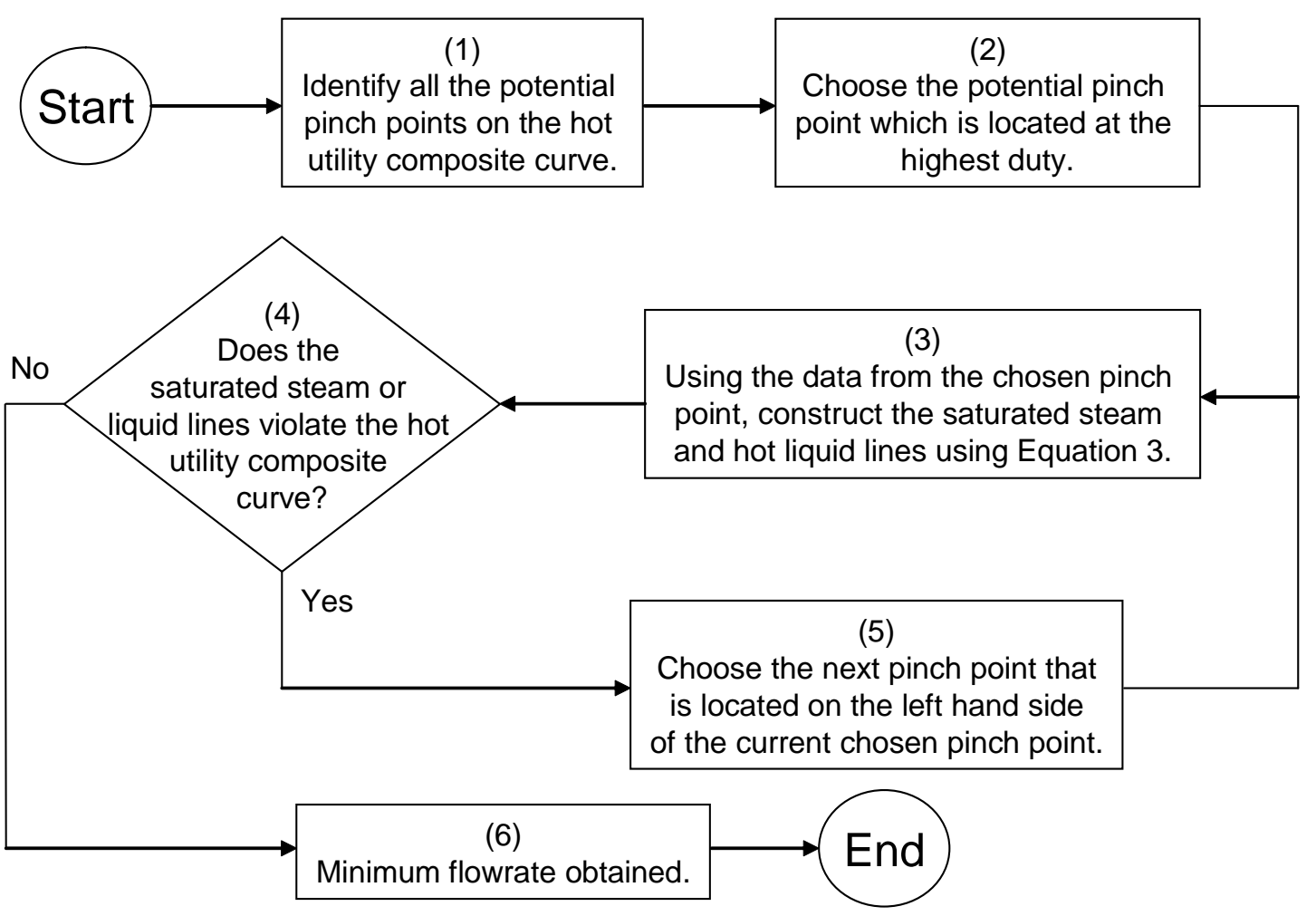

Figure 3.8: The algorithm to use when targetting for the minimum flowrate.

The designer uses the data (duty and temperature) from the chosen pinch point to obtain the hot liquid flowrate $(\dot{m})$ via Equation 3.3. With the obtained flowrate, the saturated steam and hot liquid lines can be constructed on the graph. The designer inspects the 
constructed lines to see whether they violate the hot utility composite curve. Violation in the content of this dissertation implies that the targeting line goes below the hot utility composite curve, i.e., region 2 in Figure 3.3.

If there is no violation, then the minimum flowrate has been obtained. However, if the saturated steam and liquid lines violate the hot utility composite curve, the designer has to choose a new potential pinch point. This is done by choosing the potential pinch point on the left hand side of the current chosen pinch point. The same method as described above is followed with the newly chosen pinch point, until the designer discovers the pinch point that yields the minimum flowrate without any violation.

\subsubsection{Stream splitting}

When targeting for the minimum flowrate, it is most likely that a cold process and hot utility stream will be split between the latent heat and sensible heat regions, as seen in Figure 3.9. This implies that a fraction of the duty of the split cold process stream will have to be met by saturated steam, while the rest is met by hot liquid.

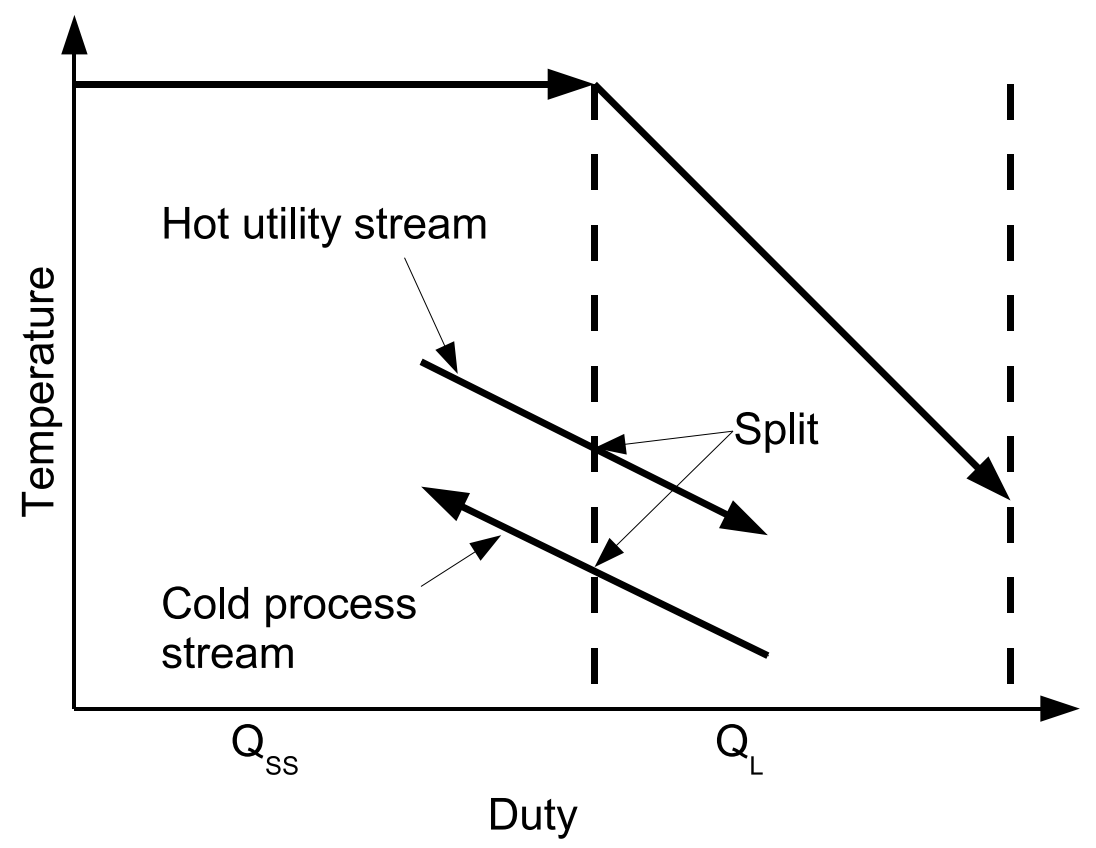

Figure 3.9: Splitting of cold process stream.

A split increases the capital cost, since two heat exchangers with additional piping have to be used instead of one. A split can be eliminated though, by increasing the water flowrate. As the the water flowrate increases, the border between the latent heat and sensible heat region moves to the right on the TH-diagram. Therefore, the flowrate can 
be increased until the total duty of the split stream lies in the latent heat region. One can only increase the water flowrate to eliminate a split, since the minimum flowrate has already been targeted, which implies that the composite curves touches the pinch point. Lowering the water flowrate further will result in violating the $\Delta T_{\min }$ value.

\subsection{Network synthesis}

In order to satisfy the target set using the graphical method described above, one needs to determine the corresponding network layout of the HEN. It is known that saturated steam and saturated liquid are used in the HEN. Furthermore, the available energy of the saturated steam must be used first, before the energy from the saturated liquid and hot liquid below saturation point is used. In this section the method to obtain the network layout, after using the graphical technique to target for the minimum flowrate, is shown.

\section{Network synthesis in the latent heat region}

To help better understand the layout of the HEN, Figure 3.10 shows how the TH-diagram is divided into two additional regions. Recall that the hot utility composite curve divided the diagram into the feasible and infeasible region (Figure 3.3). The border, where saturated steam transforms to saturated liquid, divides the diagram into region 3 (the sensible heat region) and region 4 (the latent heat region). In region 3 , heat transfer takes place through sensible heat, whereas in region 4 heat transfer involves latent heat, i.e., phase change. By exploiting the structure of Figure 3.10, a HEN that meets the target steam flowrate can be designed.

The network layout in region 4 will always be a parallel layout, since latent heat is transfered in this area. This implies that the layout for all the heat exchangers that are situated in this region will be parallel, therefore reducing the complexity of solving for the HEN layout. More accurately, all the heat exchangers in this region are directly connected to the saturated steam boiler. However, the network layout in region 3 can be parallel and/or series since sensible heat is transfered in this area. Determining the network layout in region 3 is certainly not as straightforward as in region 4 . Consequently, a linear programing (LP) model was developed in order to obtain a network layout in the sensible heat region to meet the targeted flowrate.

\section{Network synthesis in the sensible heat region}

Figure 3.11 shows the superstructure for the network design in the sensible heat region. The superstructure shows that every inlet stream to heat exchanger $i$ is comprised of a 


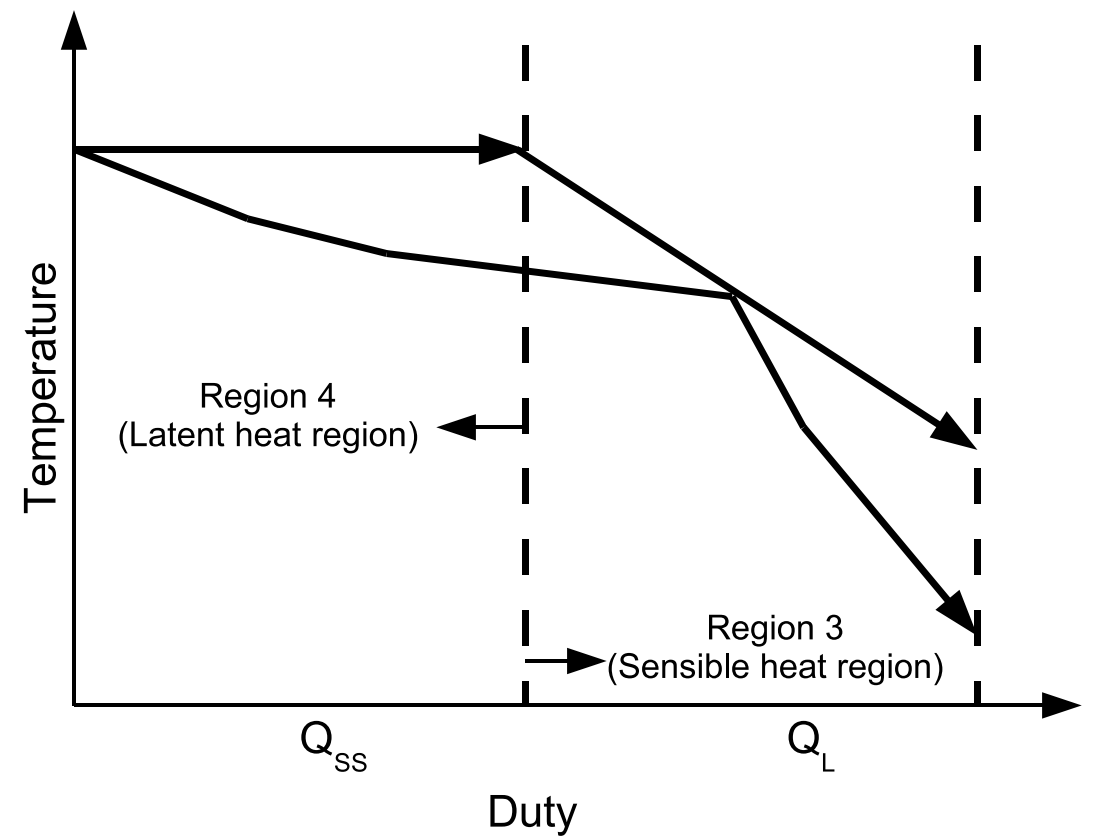

Figure 3.10: The latent heat and sensible heat region.

recycle/reuse stream from other heat exchanger(s) $i^{\prime}$, which is below saturation temperature, and saturated liquid from saturated steam. Similarly, the outlet stream from said heat exchanger $i$ is comprised of recycle/reuse streams to other heat exchangers $i^{\prime}$ and return condensate stream to the boiler.

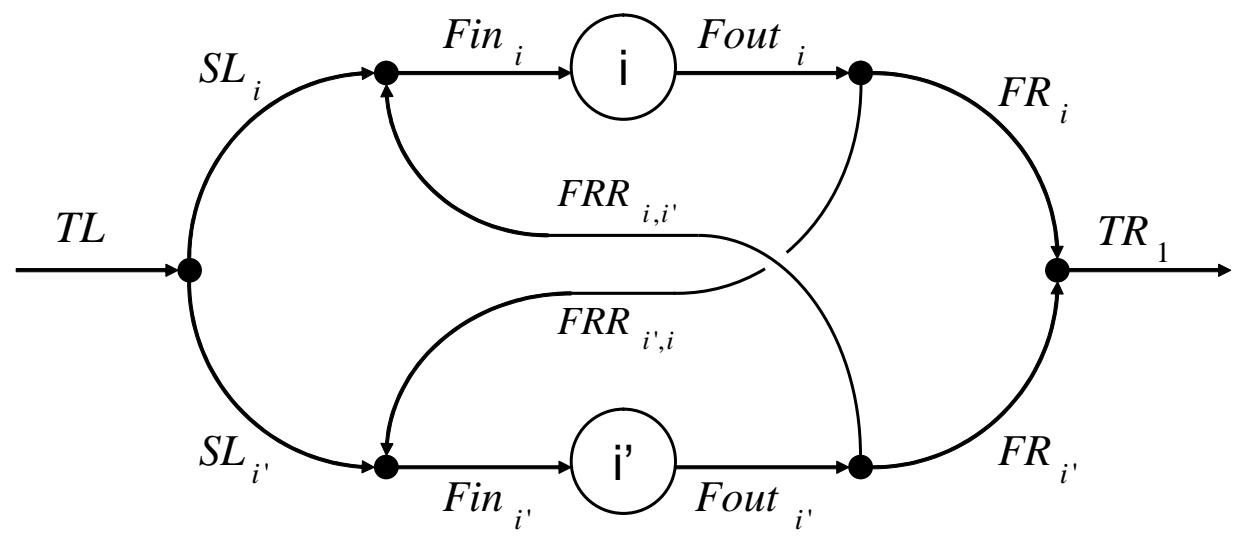

Figure 3.11: The superstructure for the sensible heat region.

\section{Constraints}

Equation 3.4 stipulates that the total flowrate of saturated liquid is equal to the amount used by heat exchangers in the sensible heat region. Equation 3.5 stipulates that the total flowrate of the return condensate stream to the boiler is comprised of the return streams from each heat exchanger. The mass coming into the system must be equal to the mass going out of the system if no accumulation occurs as shown in Equation 3.6. 
The slack variables $S_{j}^{+}$and $S_{j}^{-}$are introduced to account for deviations which could arise from targeting errors. Ideally, these slack variables should be zero, hence the objective function, Equation 3.7.

$$
\begin{aligned}
T L+S_{1}^{+}-S_{1}^{-} & =\sum_{i \in I} S L_{i} \quad \forall i \in I \\
T R_{1}+S_{2}^{+}-S_{2}^{-} & =\sum_{i \in I} F R_{i} \quad \forall i \in I \\
T L & =T R_{1} \\
\operatorname{Min}(O B J) & =\sum_{j=1,2}\left(S_{j}^{+}+S_{j}^{-}\right)
\end{aligned}
$$

As aforementioned, the total inlet flowrate to heat exchanger $i$ is equal to the saturated liquid entering the unit, plus the summation of reused hot liquid from other heat exchangers $i^{\prime}$, as given in Equation 3.8. Furthermore, the total outlet flowrate from heat exchanger $i$ is equal to the returned liquid to the steam boiler, plus the summation of reused hot liquid to other heat exchangers $i^{\prime}$, as given in Equation 3.9. The conservation of mass for heat exchanger $i$ is given by Equation 3.10 .

$$
\begin{aligned}
& F_{i n}=S L_{i}+\sum_{i^{\prime} \in I} F R R_{i^{\prime}, i} \quad \forall i, i^{\prime} \in I \\
& \text { Fout }_{i}=F R_{i}+\sum_{i^{\prime} \in I} F R R_{i, i^{\prime}} \quad \forall i, i^{\prime} \in I \\
& \text { Fin }_{i}=\text { Fout }_{i} \quad \forall i \in I
\end{aligned}
$$

Equation 3.11 ensures that total inlet flowrate to heat exchanger $i$ does not exceed the design flowrate. To obtain the maximum flowrate of hot liquid that can be supplied to a heat exchanger $i$, Equation 3.12 is used.

$$
\begin{gathered}
\text { Fin }_{i} \leq \text { Fin }_{i}^{U} \quad \forall i \in I \\
\operatorname{Fin}_{i}^{U}=\frac{Q_{i}}{c_{p}\left(\operatorname{Tin}_{i}^{L}-\text { Tout }_{i}^{L}\right)} \quad \forall i \in I
\end{gathered}
$$

In a situation where local recycle is forbidden, Equation 3.13 is relevant. 


$$
F R R_{i, i^{\prime}}=0 \quad \forall i, i^{\prime} \in I \quad i^{\prime}=i
$$

Equation 3.14 gives the energy balance across heat exchanger $i$. The inlet temperature into heat exchanger $i$ is given by Equation 3.15.

$$
\begin{aligned}
Q_{i} & =\text { Fin }_{i} c_{p}\left(\text { Tin }_{i}-\text { Tout }_{i}\right) \quad \forall i \in I \\
\operatorname{Tin}_{i} & =\frac{\sum_{i^{\prime} \in I}\left(\text { FRR }_{i^{\prime}, i} \text { Tout }_{i^{\prime}}\right)+S L_{i} T}{\text { Fin }_{i}} \quad \forall i, i^{\prime} \in I
\end{aligned}
$$

Equations 3.4 to 3.15 constitute the overall mathematical model. However, Equations 3.14 and 3.15 contain non-convex bilinear terms which entail computational difficulties. As a result, it is necessary to try and linearise Equations 3.14 and 3.15, as described below.

Both Equations 3.14 and 3.15 have the same bilinear term, namely Fin $_{i}$ Tin $_{i}$. Equation 3.15 also contains the bilinear term $F R R_{i^{\prime}, i}$ Tout $_{i}$. Therefore, by substituting Equation 3.15 in Equation 3.14, the bilinear term Fin $_{i}$ Tin $_{i}$ is eliminated. Furthermore, by setting the outlet temperature of the hot utility streams of the heat exchangers equal to the minimum outlet temperature, the problem is reduced to a LP problem. Savelski \& Bagajewicz (2000b) proved this to be necessary condition for minimising flowrate, albeit in wastewater minimization. Therefore, by using the same analogy, at an optimal solution in the reduction of the hot utility flowrate, the outlet temperature of the hot utility streams will be at the minimum value. Therefore, Equations 3.14 and 3.15 are replaced with Equation 3.16 in the model. Consequently, the overall model without Equations 3.14 and 3.15 is an LP model.

$$
Q_{i}=c_{p} \sum_{i^{\prime} \in I}\left(F_{R R} R_{i^{\prime}, i} \text { Tout }_{i^{\prime}}^{L}\right)+c_{p} S L_{i} T-\text { Fin }_{i} c_{p} \text { Tout }_{i}^{L} \quad \forall i, i^{\prime} \in I
$$

The objective function is still Equation 3.7. 


\section{CHAPTER 4}

\section{Simultaneous targeting and synthesis}

In this chapter it is demonstrated that targeting and design can be achieved simultaneously using a mathematical approach. The mathematical model developed shares much of the same principles of the LP model developed in the previous chapter, however, since phase change of water has to be taken into account the model uses binary terms. Therefore, the model is classified as a mixed integer linear programming (MILP) model.

The disadvantage of using a pure mathematical model for targeting and design however, is that the solution becomes a black box approach for the user, i.e, the user enters the required data and the program yields a solution. Therefore, the user does not have an indepth understanding of the problem and design. Furthermore, huge problems can require a lot of CPU time to solve, since the size and complexity of the problem increases sharply with the number of heat exchangers. Complexity mainly arises from the inherent binary dimensions in the problem.

One of the benefits of using a mathematical model to target and design the network simultaneously, is that a solution for large problems can be obtained in very short times. Using the graphical approach for targeting takes time and can contain errors from reading off the graph. Furthermore, introducing additional constraints to the targeting and design is easier to implement with a mathematical model than with the graphical approach. 
Figure 4.1 shows the superstructure for the network design in the latent and sensible heat region. It is worth noting that although this superstructure has the same structure as that shown in Figure 3.11, the variables involved are rather different.

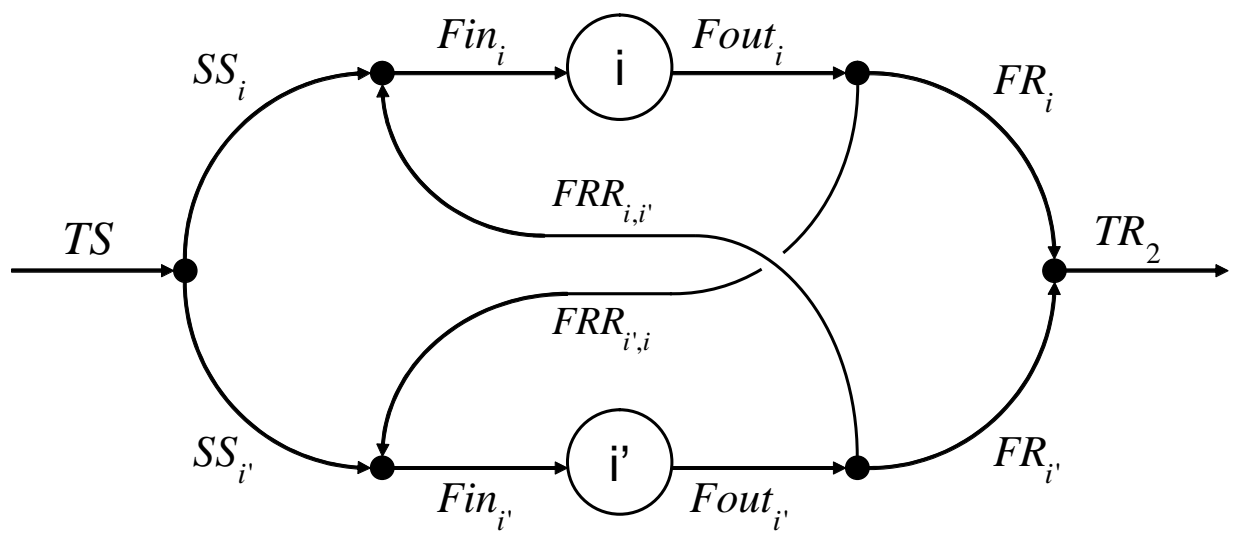

Figure 4.1: The superstructure for the latent and sensible heat region.

\section{Constraints}

To obtain the maximum flowrate of saturated steam or recycle/reuse hot liquid that can be supplied to a heat exchanger $i$, Equations 4.1 and 4.2 are used respectively.

$$
\begin{aligned}
S S_{i}^{U} & =\frac{Q}{\lambda} \quad \forall i \in I \\
F R R_{i}^{U} & =\frac{Q_{i}}{c_{p}\left(\operatorname{Tin}_{i}^{L}-\text { Tout }_{i}^{L}\right)} \quad \forall i \in I
\end{aligned}
$$

Equation 4.3 stipulates that the total flowrate of saturated steam from the steam boiler, is equal to the overall amount of saturated steam used by each heat exchanger $i$, while Equation 4.4 stipulates that the total amount of hot liquid leaving all heat exchangers $i$, to return to the steam boiler, is equal to the total steam input into the HEN. Equation 4.5, therefore, gives the mass conservation for the whole superstructure.

$$
\begin{aligned}
T S & =\sum_{i \in I} S S_{i} \quad \forall i \in I \\
T R_{2} & =\sum_{i \in I} F R_{i} \\
T S & =T R_{2}
\end{aligned}
$$


The total inlet flowrate to heat exchanger $i$ is equal to either saturated steam entering the unit, or the total reused hot liquid from other heat exchangers $i^{\prime}$, as given in Equation 4.6. Furthermore, the total outlet flowrate from heat exchanger $i$ is equal to the returned liquid to the steam boiler, plus the summation of reused hot liquid to other heat exchangers $i^{\prime}$, as given in Equation 3.9. The conservation of mass for heat exchanger $i$ is given by Equation 3.10.

$$
F_{i n}=S S_{i}+\sum_{i^{\prime} \in I} F R R_{i^{\prime}, i} \quad \forall i, i^{\prime} \in I
$$

The hot liquid that is reused in heat exchanger $i^{\prime}$ from heat exchanger $i$, is either saturated liquid (if heat exchanger $i$ was supplied by saturated steam) or below saturation point (if heat exchanger $i$ was supplied by hot liquid), as given by Equation 4.7.

$$
F R R_{i, i^{\prime}}=S L_{i, i^{\prime}}+L_{i, i^{\prime}} \quad \forall i, i^{\prime} \in I
$$

The saturated liquid that is reused from heat exchanger $i$ to $i^{\prime}$ cannot exceed the flowrate of saturated steam that entered heat exchanger $i$, as seen in Equation 4.8. Likewise, Equation 4.9 states that the liquid that is reused from heat exchanger $i$ to $i^{\prime}$ cannot exceed the flowrate of hot liquid that entered heat exchanger $i$.

$$
\begin{aligned}
\sum_{i^{\prime} \in I} S L_{i, i^{\prime}} & \leq S S_{i} \quad \forall i \in I \\
\sum_{i^{\prime} \in I} L_{i, i^{\prime}} & \leq \sum_{i^{\prime} \in I} F R R_{i^{\prime}, i} \quad \forall i, i^{\prime} \in I
\end{aligned}
$$

Equation 4.10 ensures that total saturated steam flowrate to heat exchanger $i$, does not exceed the maximum flowrate obtained in Equation 4.1. Furthermore, Equation 4.11 ensures that the total flowrate of hot liquid to heat exchanger $i$, does not exceed the maximum flowrate obtained in Equation 4.2.

$$
\begin{aligned}
S S_{i} & \leq S S_{i}^{U} y_{i} \quad \forall i \in I \\
\sum_{i^{\prime} \in I} F R R_{i^{\prime}, i} & \leq F R R_{i}^{U} x_{i} \quad \forall i, i^{\prime} \in I
\end{aligned}
$$


To ensure that heat exchanger $i$ does not recycle hot liquid back to itself, Equation 4.12 is implemented.

$$
L_{i, i^{\prime}}=0 \quad \forall i, i^{\prime} \in I \quad i^{\prime}=i
$$

Equation 4.13 gives the energy balance across heat exchanger $i$, which is supplied by either saturated steam $\left(Q_{i}^{S S}\right)$ or hot liquid $\left(Q_{i}^{H L}\right)$. The duty that is supplied by the saturated steam is given by Equation 4.14, whilst the duty supplied by the hot liquid is given by Equation 4.15 .

The duty in Equation 4.15 is obtained by the difference of the energy that comes into the heat exchanger $i$, from the energy leaving the heat exchanger. The energy coming into heat exchanger $i$ comprises of saturated liquid and hot liquid reused from other heat exchangers and their respective outlet temperatures. The duty that is exchanged in the heat exchanger is the difference between the energy content of the exit stream and inlet streams into the heat exchanger.

$$
\begin{aligned}
Q_{i}= & Q_{i}^{S S}+Q_{i}^{H L} \quad \forall i \in I \\
Q_{i}^{S S}= & S S_{i} \lambda \quad \forall i, i^{\prime} \in I \\
Q_{i}^{H L}= & \sum_{i^{\prime} \in I}\left(c_{p} S L_{i^{\prime}, i} T\right)+\sum_{i^{\prime} \in I}\left(c_{p} L_{i^{\prime}, i} \text { Tout }_{i^{\prime}}\right) \quad \forall i, i^{\prime} \in I \\
& -\left(c_{p} \text { Fout }_{i} \text { Tout }_{i}\right)
\end{aligned}
$$

In order to ensure that the duty of heat exchanger $i$ is not split between the sensible and latent heat regions, Equation 4.16 is implemented. Equation 4.16 ensures that heat exchanger $i$ is supplied by either saturated steam or hot liquid, but not both.

$$
y_{i}+x_{i} \leq 1
$$

If one wants to allow a maximum of one split to occur, Equations 4.17 and 4.18 are introduced into the formulation. Equations 4.17 and 4.18 ensure that a maximum of one heat exchanger split can occur. Therefore, the duty of only one heat exchanger $i$, can be supplied by saturated steam as well as hot liquid, while the remaining heat exchangers duties may only be supplied by either saturated steam or hot liquid. This implies that the heat exchanger, in which the split occurs, will lie in the latent heat as well as in the 
sensible heat region. In physical terms, this implies heat exchanger $i$ will be split into two heat exchangers, $i_{1}$ and $i_{2}$, supplied by saturated steam and hot liquid, respectively.

$$
\begin{aligned}
& \sum_{i \in I} y_{i}+\sum_{i \in I} x_{i} \geq|i| \\
& \sum_{i \in I} y_{i}+\sum_{i \in I} x_{i} \leq|i|+1
\end{aligned}
$$

Equation 4.15 is the only nonlinear equation. To transform Equation 4.15 to a linear equation, the outlet temperatures of the heat exchangers are set to their minimum values in accordance with the observation made in section 3.2 of this study. Therefore, Equation 4.15 becomes linear as seen in Equation 4.19, which implies that one obtains an overall mixed integer linear programming (MILP) model.

$$
\begin{aligned}
Q_{i}^{H L}= & \sum_{i^{\prime} \in I}\left(c_{p} S L_{i^{\prime}, i} T\right)+\sum_{i^{\prime} \in I}\left(c_{p} L_{i^{\prime}, i} \text { Tout }_{i^{\prime}}^{L}\right) \\
& -\left(c_{p} \text { Fout }_{i} \text { Tout }_{i}^{L}\right)
\end{aligned} \forall i, i^{\prime} \in I
$$

The objective function is the minimization of the total flowrate of saturated steam $(T S)$ supplied to the heat exchangers, without violating any of the operational constraints within the network as given in Equation 4.20.

$$
\operatorname{Min} Z=\sum_{i \in I} T S_{i}
$$




\section{CHAPTER 5}

\section{Case study}

The case study as well as the results are discussed in this chapter. The graphical targeting technique and LP model, as well as the MILP model were used to solve the case study.

In order to demonstrate the applicability of the developed hybrid graphical targeting and LP design method, as well as the MILP model, a case study from a South African petrochemical company is presented. The process produces high value phenols, cresols and xylenols and includes liquid-liquid extraction. The reboilers of the columns used for stripping throughout the process require saturated steam as an external hot utility.

The cold process stream data that will be used for the case study is given in Table 5.1. Saturated steam is provided at $225^{\circ} \mathrm{C}$ (25.5 bar) with a latent heat capacity of 1834.3 $\mathrm{kJ} / \mathrm{kg}$. The specific heat capacity of the resulting saturated liquid is $4.30 \mathrm{~kJ} / \mathrm{kg}{ }^{\circ} \mathrm{C}$. The global $\Delta T_{\min }$ value is $10^{\circ} \mathrm{C}$, therefore, the limiting hot utility data is obtained as seen in Table 5.2.

Using the graphical technique, the hot utility data in Table 5.2 is used to construct a hot utility composite curve on a TH-diagram, as shown in Figure 5.1. Thereafter, the pinch point must be obtained by using the developed algorithm in Figure 3.8. The first step of the algorithm states that all the potential pinch points on the hot utility composite curve must be identified, as shown in Figure 5.2. 
Table 5.1: Cold process stream data for the example.

\begin{tabular}{cccc}
\hline Cold process stream & $T_{\text {target }}\left({ }^{\circ} \mathrm{C}\right)$ & $T_{\text {supply }}\left({ }^{\circ} \mathrm{C}\right)$ & Duty $(\mathrm{kW})$ \\
\hline 1 & 45 & 25 & 135 \\
2 & 45 & 25 & 320 \\
3 & 215 & 209 & 3620 \\
4 & 185 & 79 & 12980 \\
5 & 207 & 207 & 1980 \\
6 & 70 & 44 & 635 \\
7 & 70 & 44 & 330 \\
\hline Total & & & 20000 \\
\hline
\end{tabular}

Table 5.2: Hot utility data for the example.

\begin{tabular}{cccc}
\hline Hot utility stream & $T_{\text {target }}\left({ }^{\circ} \mathrm{C}\right)$ & $T_{\text {supply }}\left({ }^{\circ} \mathrm{C}\right)$ & Duty $(\mathrm{kW})$ \\
\hline 1 & 35 & 55 & 135 \\
2 & 35 & 55 & 320 \\
3 & 219 & 225 & 3620 \\
4 & 89 & 195 & 12980 \\
5 & 217 & 217 & 1980 \\
6 & 54 & 80 & 635 \\
7 & 54 & 80 & 330 \\
\hline Total & & & 20000 \\
\hline
\end{tabular}

Temperature vs. Duty

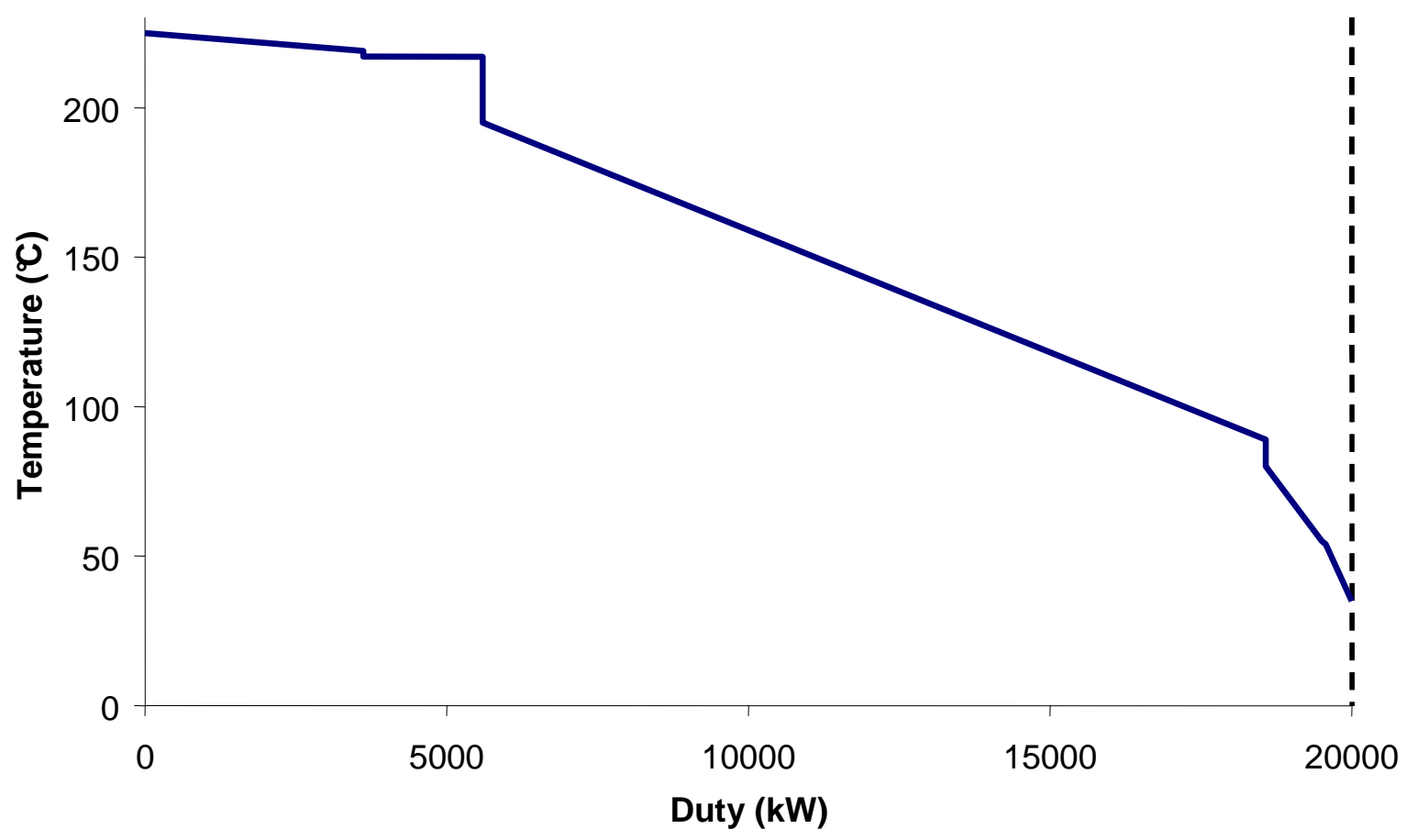

Figure 5.1: The hot utility composite curve.

The first potential pinch point that will be targeted, is the one that has the highest duty 
Temperature vs. Duty

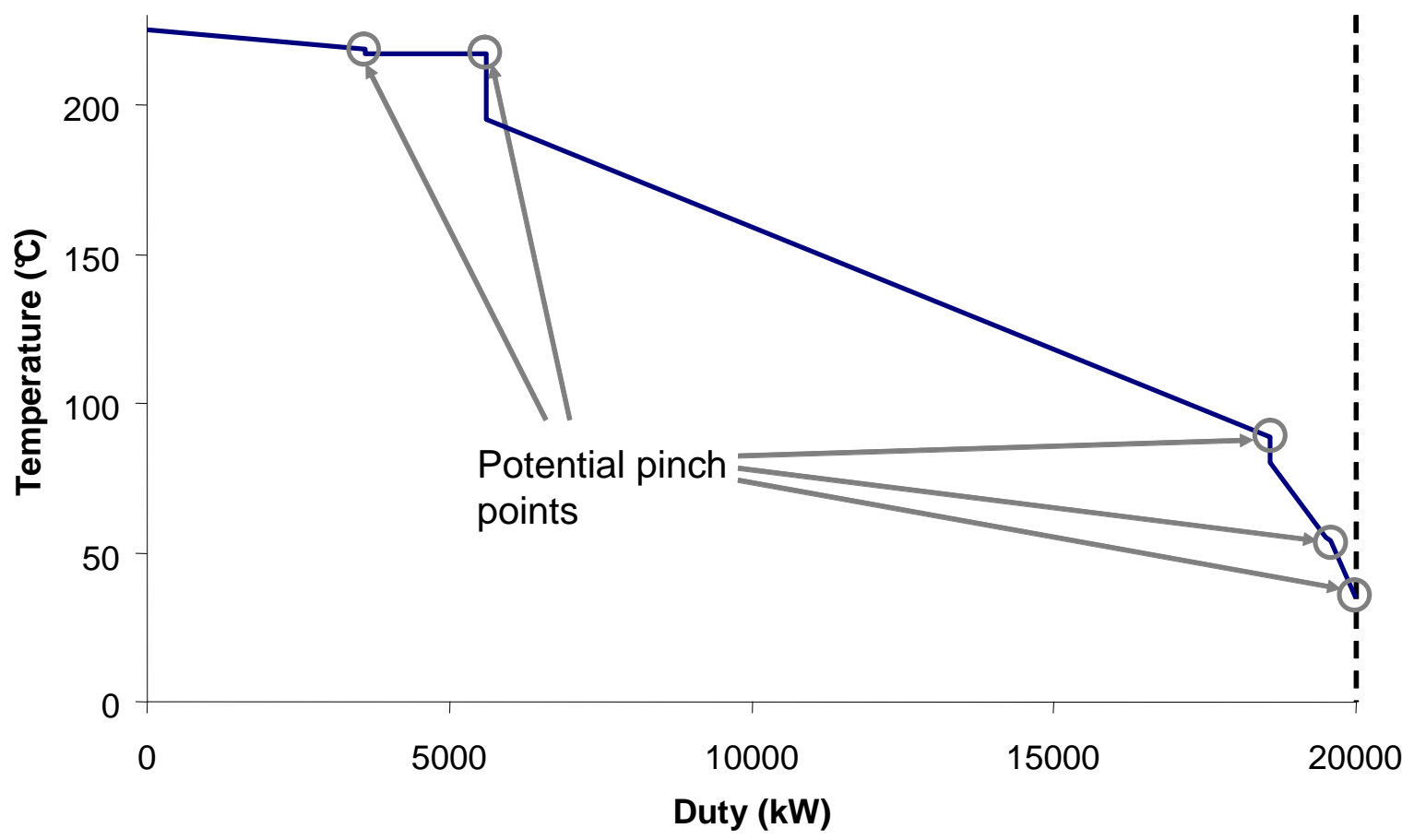

Figure 5.2: The potential pinch points on the hot composite curve.

i.e., pinch point $(20000,35)$. Using data from the point and Equation 3.3, the flowrate is obtained as follows.

$$
\begin{aligned}
\dot{m} & =\frac{Q}{\lambda+c_{p}\left(T_{o}-T_{i}\right)} \\
\Rightarrow \dot{m} & =\frac{20000}{1834.3+4.30(225-35)} \\
\Rightarrow \dot{m} & =7.54 \mathrm{~kg} / \mathrm{s}
\end{aligned}
$$

With the flowrate known, the duty of the latent heat region can be obtained by using Equation 3.1. The duty of the sensible heat region is obtained by subtracting the latent heat region duty from the total duty.

$$
\begin{aligned}
Q_{S S} & =\dot{m} \lambda \\
\Rightarrow Q_{S S} & =(7.54)(1834.3) \\
\Rightarrow Q_{S S} & =13831 \mathrm{~kW}
\end{aligned}
$$




$$
\begin{aligned}
Q_{L} & =20000-Q_{S S} \\
\Rightarrow Q_{L} & =20000-13831 \\
\Rightarrow Q_{L} & =6169 \mathrm{~kW}
\end{aligned}
$$

From the above data, the saturated steam and hot liquid lines can be constructed. Figure 5.3 illustrates the saturated steam and hot liquid lines for the first potential pinch point. As can be seen from Figure 5.3, the hot liquid line violates the hot utility composite curve. Therefore, the point $(20000,35)$ is an invalid pinch point, and a new potential pinch point must be chosen.

Temperature vs. Duty

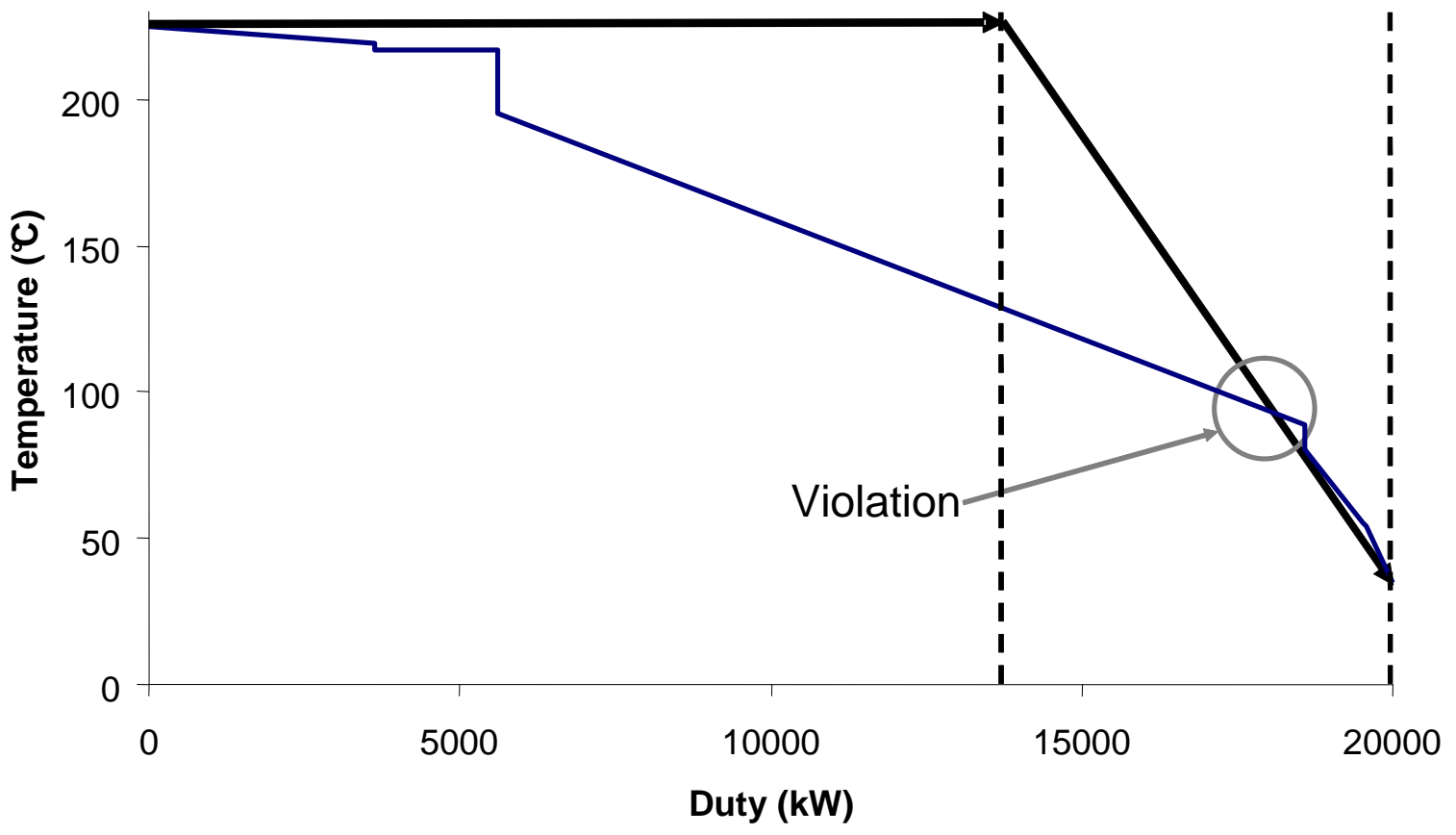

Figure 5.3: Targeting result for the first pinch point.

The new pinch point that will be used, is the pinch point located on the left hand side of the failed pinch point $(20000,35)$ i.e., point $(19567.7,54)$. Using the data of the point and Equation 3.3, the flowrate is obtained as follows. 


$$
\begin{aligned}
\dot{m} & =\frac{Q}{\lambda+c_{p}\left(T_{o}-T_{i}\right)} \\
\Rightarrow \dot{m} & =\frac{19567.7}{1834.3+4.30(225-54)} \\
\Rightarrow \dot{m} & =7.62 \mathrm{~kg} / \mathrm{s}
\end{aligned}
$$

Using Equation 3.1 and the newly obtained flowrate, the duty of the latent heat region is obtained. Subtracting the latent heat region duty from the total duty results in obtaining the duty of the sensible heat region.

$$
\begin{aligned}
Q_{S S} & =\dot{m} \lambda \\
\Rightarrow Q_{S S} & =(7.62)(1834.3) \\
\Rightarrow Q_{S S} & =13977 \mathrm{~kW}
\end{aligned}
$$

$$
\begin{aligned}
Q_{L} & =20000-Q_{S S} \\
\Rightarrow Q_{L} & =20000-13997 \\
\Rightarrow Q_{L} & =6023 \mathrm{~kW}
\end{aligned}
$$

Using the above data, the saturated steam and hot liquid lines for the second potential pinch point are constructed, as shown in Figure 5.4. As can be seen from Figure 5.4, the hot liquid line violates the hot utility composite curve. Therefore, the point $(19567.7,54)$ is an invalid pinch point, and a new potential pinch point must be chosen.

The new pinch point that will be used, is the pinch point located on the left hand side of the failed pinch point $(19567.7,54)$ i.e., point $(18580,89)$. Using the data of the point and Equation 3.3, the flowrate is obtained as follows: 
Temperature vs. Duty

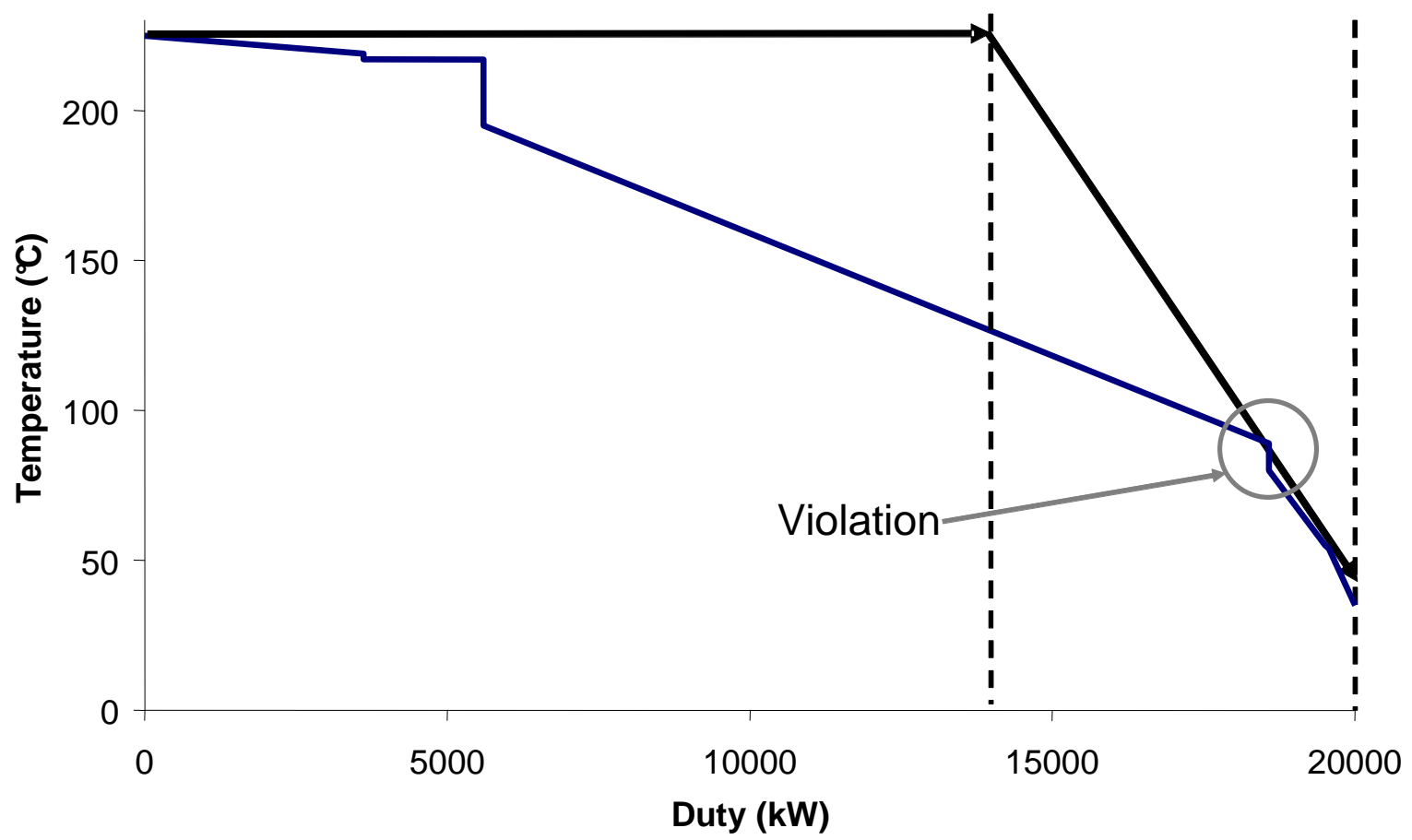

Figure 5.4: Targeting result for the second pinch point.

$$
\begin{aligned}
\dot{m} & =\frac{Q}{\lambda+c_{p}\left(T_{o}-T_{i}\right)} \\
\Rightarrow \dot{m} & =\frac{18580}{1834.3+4.30(225-89)} \\
\Rightarrow \dot{m} & =7.68 \mathrm{~kg} / \mathrm{s}
\end{aligned}
$$

With the flowrate known, the duty of the latent heat region can be obtained by using Equation 3.1. The duty of the sensible heat region is obtained by subtracting the latent heat region duty from the total duty.

$$
\begin{aligned}
Q_{S S} & =\dot{m} \lambda \\
\Rightarrow Q_{S S} & =(7.68)(1834.3) \\
\Rightarrow Q_{S S} & =14087 \mathrm{~kW}
\end{aligned}
$$




$$
\begin{aligned}
Q_{L} & =20000-Q_{S S} \\
\Rightarrow Q_{L} & =20000-14087 \\
\Rightarrow Q_{L} & =5913 \mathrm{~kW}
\end{aligned}
$$

From the above data, the saturated steam and hot liquid lines can be constructed. Figure 5.5 illustrates the saturated steam and hot liquid lines for the third chosen pinch point. From Figure 5.5 it is evident that the hot liquid line does not violate the hot utility composite curve, but that it only touches the hot utility composite curve. Thus, the correct pinch point has been obtained and the minimum flowrate is therefore $27.7 \mathrm{t} / \mathrm{h}$. The duty that has to be supplied by saturated steam is $14 \mathrm{MW}$, while the saturated liquid and re-use liquid has to supply 5.9 MW of energy. It is also evident from Figure 5.5 that hot utility stream 4 is supplied by latent as well as sensible heat, therefore, the stream is split.

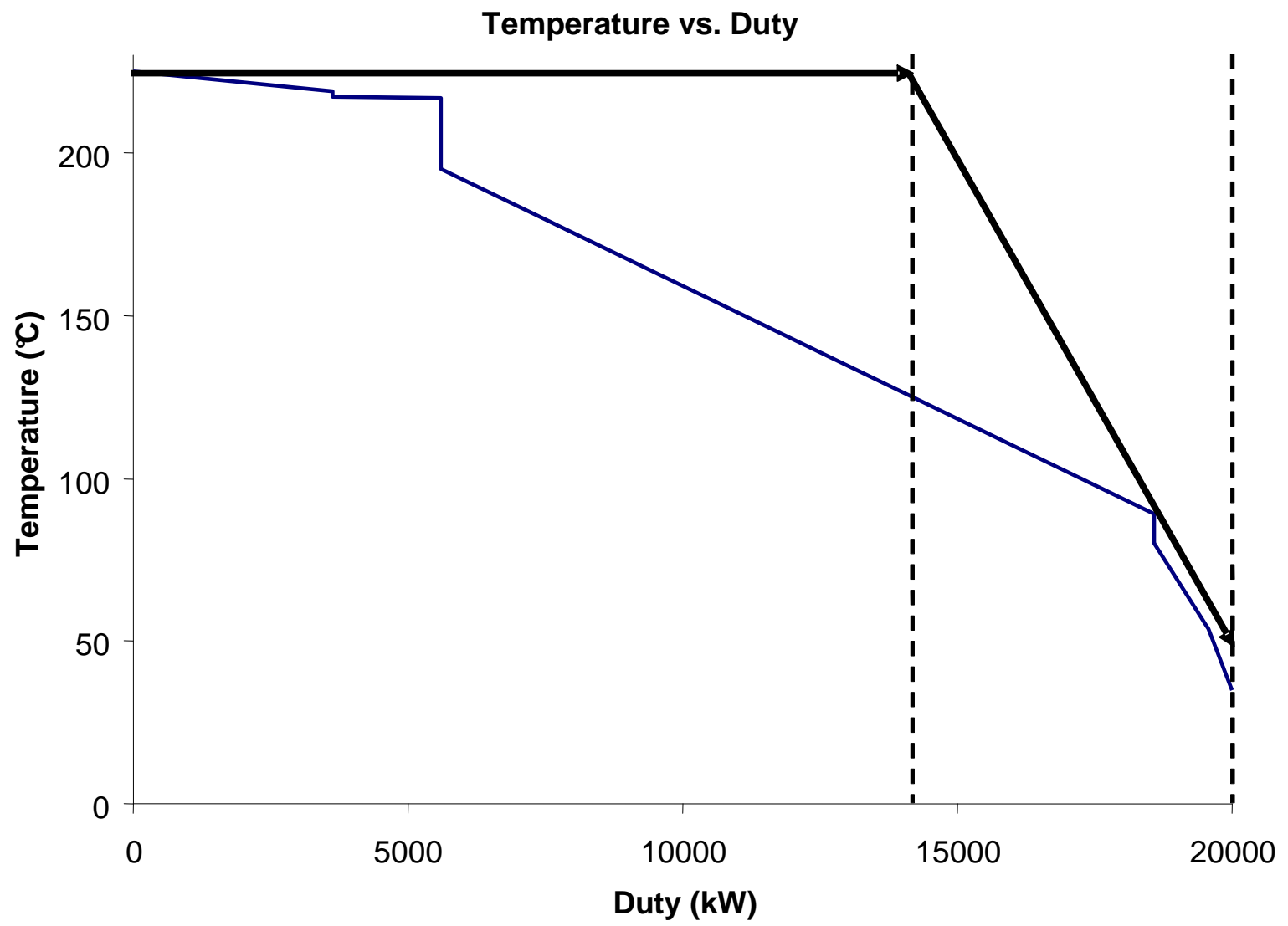

Figure 5.5: Graphical targeting for the minimum water flowrate.

If only saturated steam was used as a hot utility i.e., assuming a parallel design, the flowrate would be $39.2 \mathrm{t} / \mathrm{h}$. However, by using the methodology described above, the 
flowrate needed is only $27.7 \mathrm{t} / \mathrm{h}$, reducing the original flowrate by $29.6 \%$. After targeting for the minimum flowrate, the network layout has to be constructed.

The hot utility streams that lie in the latent heat region will always be a parallel layout, as mentioned before. Knowing the temperature at which hot utility stream 4 is split, allows one to determine which utillity streams from Table 5.2 lie in the latent heat region. From Figure 5.5, the temperature where the split occurs on the hot utility composite curve is located at $125^{\circ} \mathrm{C}$.

From this temperature, all the hot utility streams in the latent heat region can be obtained. From Table 5.2, the hot utility streams that lie completely in the latent heat region are streams 3 and 5, whilst stream 4 lies partially in the latent heat region as mentioned above. The remaining duty of stream 4 , as well as the duty of streams 1, 2, 6 and 7 , lie in the sensible heat region. To obtain the network layout for this region, the LP model will be used.

However, before the LP model can be used, accurate data is required for the model. Knowing which streams lie completely in the latent heat region, the exact temperature where the split occurs in stream 4 can be obtained. The combined duty of stream 3 and 5 is $5600 \mathrm{~kW}$. Therefore, the duty of stream 4 that lies in the latent heat region is $14087-5600=8487 \mathrm{~kW}$. Hence, the duty of stream 4 that lies in the sensible heat region is $12980-8487=4493 \mathrm{~kW}$. To calculate the exact temperature where the split in stream 4 occurs, the linear equation describing stream 4 must be obtained first, as shown below. The end points of stream 4 are used to obtain the linear equation parameters i.e., points $(195,0)$ and $(89,12980)$.

$$
y=m x+c
$$

Substituting the data point $(195,0)$ :

$$
\begin{aligned}
& 195=m(0)+c \\
& \Rightarrow c=195 \\
& \Rightarrow y=m x+195
\end{aligned}
$$

Substituting the data point $(89,12980)$ : 


$$
\begin{aligned}
89 & =m(12980)+195 \\
\Rightarrow m & =\frac{89-195}{12980} \\
\Rightarrow m & =-0.00817
\end{aligned}
$$

Therefore, the linear equation describing stream 4 is given Equation 5.11:

$$
y=(-0.00817) x+195
$$

To obtain the accurate temperature where the split occurs in stream 4 , the duty of stream 4 that lies in the latent heat region is substituted into Equation 5.11.

$$
\begin{aligned}
y & =(-0.00817) x+195 \\
\Rightarrow y & =(-0.00817)(8487)+195 \\
\Rightarrow y & =126^{\circ} \mathrm{C}
\end{aligned}
$$

Providing the flowrate obtained through targeting and the data of all the hot utility streams in the sensible heat region to the LP model, the network layout in the sensible heat region is developed. The objective function of the LP model is 0.005937. Ideally, this value should be zero, however, since targeting errors and rounding occurs during the calculations, obtaining an objective function of zero is not practical. However, it is noted that in this case the objective function is very small, therefore, the error is negligible. The CPU time for the LP model is 0.001 seconds. The computer used to solve the model was a Pentuim $43.4 \mathrm{GHz}$ with $1 \mathrm{~GB}$ of RAM and the solver used was GAMS CPLEX 9. Figure 5.6 shows the network layout that incorporates the latent and sensible heat region.

The MILP model was also used to target for the minimum flowrate, as well as obtaining a network layout, as seen in Figure 5.7. The same flowrate of $27.7 \mathrm{t} / \mathrm{h}$ was achieved with the MILP model, however, the network layout obtained from the MILP model differs slightly from that obtained by using the graphical and LP model. This indicates that for the optimal flowrate several different network layouts can be obtained, each one making the minimum flowrate possible without violating any of the constraints. The CPU time of 


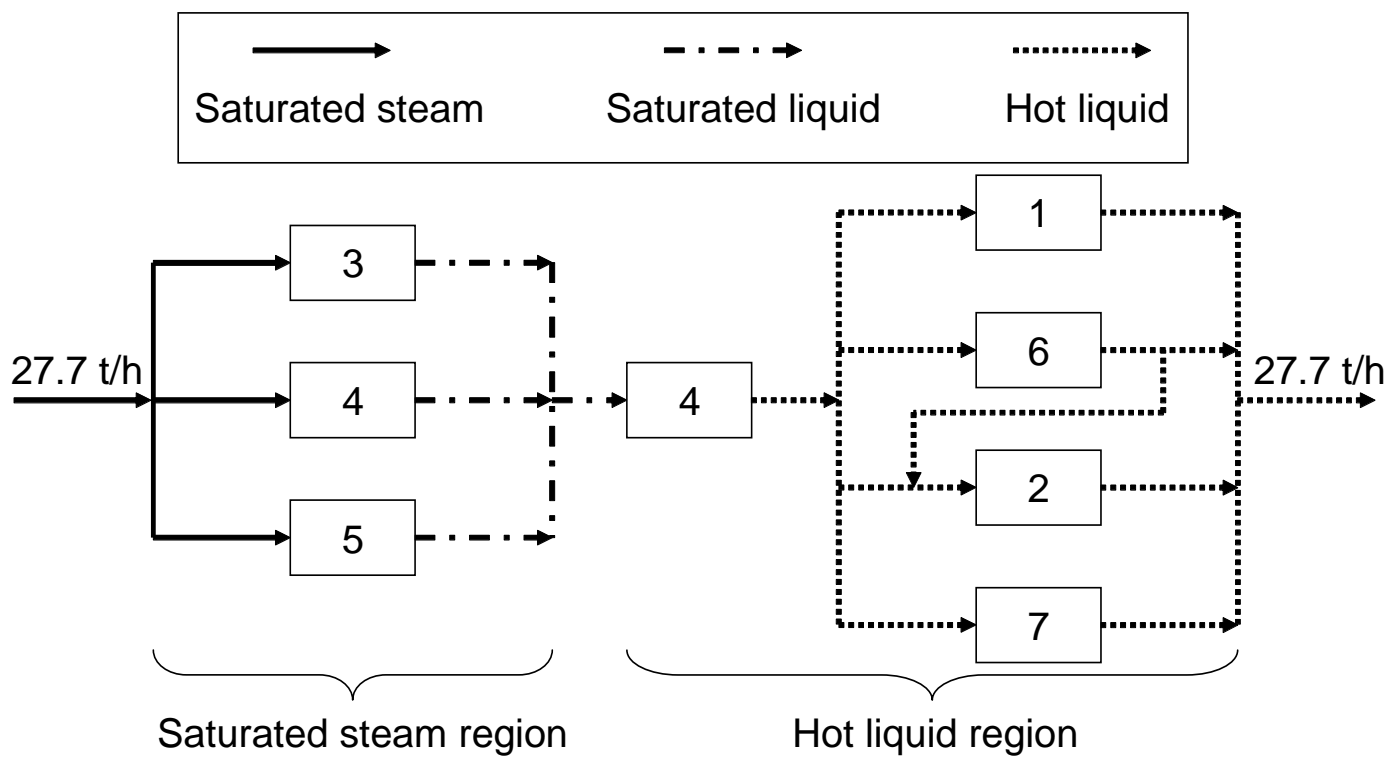

Figure 5.6: Heat exchanger network layout using the graphical method and LP model.

the MILP model is 0.062 seconds. The computer used to solve the model was a Pentuim $43.4 \mathrm{GHz}$ with $1 \mathrm{~GB}$ of RAM and the solver used was GAMS CPLEX 9.

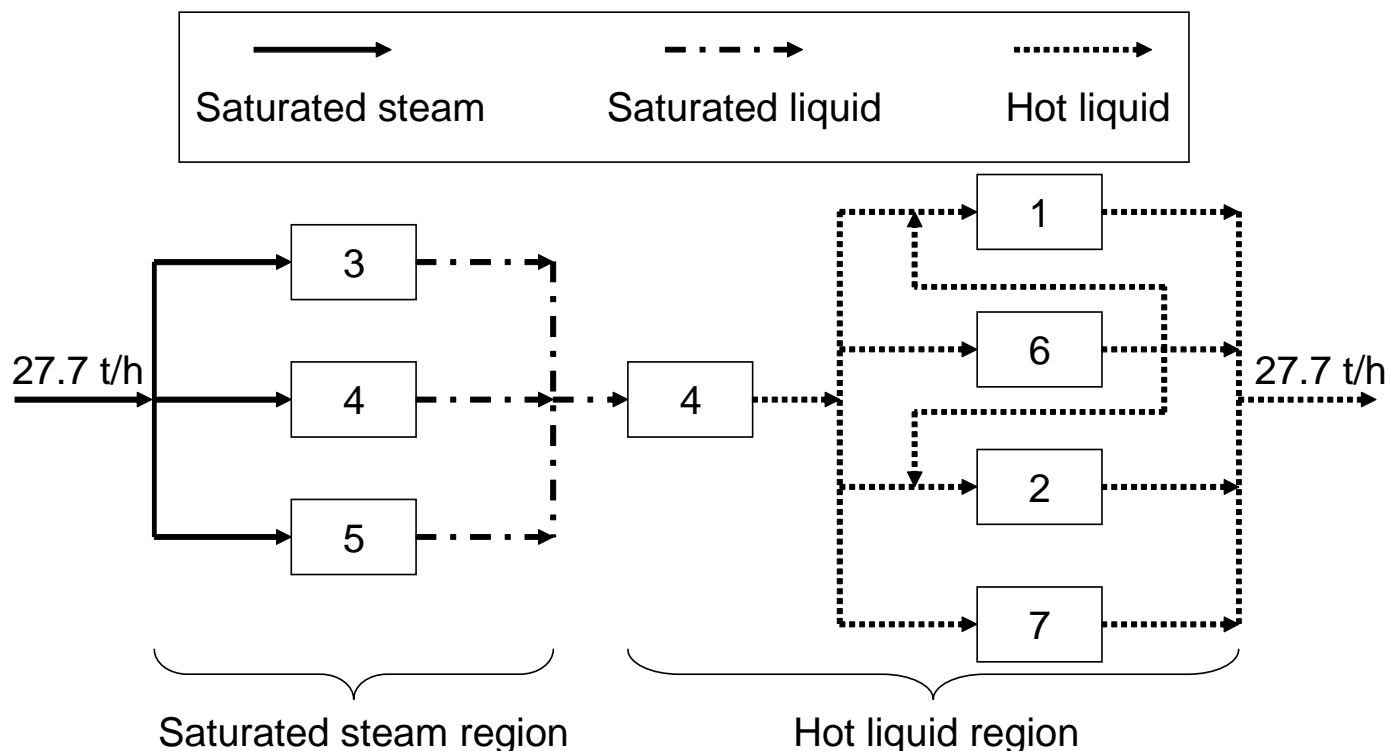

Figure 5.7: Heat exchanger network layout using the MILP model.

It is evident when comparing the CPU times of the LP and MILP model, that the LP model solves faster than the MILP model. This is due to numerous reasons, one being that the MILP model contains binary variables which increases the complexity of the problem. Furthermore, the MILP model has to obtain the minimum steam flowrate, whereas the minimum steam flowrate is already specified in the LP model through the graphical targeting technique. Also, the MILP model has to cater for the latent as well 
as the sensible heat regions, hence an increase in the size of the problem. On the other hand the LP model only has to cater for the sensible heat region. As the data for a problem increases (more process streams), the CPU time of the MILP model tends to increase significantly, due to binary variables. Therefore, the hybrid graphical targeting and LP model is very viable for huge problems, since targeting and the network layout in the latent heat region is first obtained before the LP model is used to obtain the network layout in the sensible heat region. 


\section{CHAPTER 6}

\section{Conclusions and recommendations}

The findings that have been made in this study are given in this chapter, as well as recommendations for further research and investigation.

\subsection{Conclusions}

A novel hybrid graphical and LP design targeting technique using pinch analysis has been developed in this dissertation, where the minimum saturated steam (external hot utility) flowrate is obtained by exploiting phase change of saturated steam. Since the designer has to cater for two phases on the TH-diagram, an algorithm was developed to assist the designer in obtaining the pinch point without violating the hot utility composite curve.

With regards to the design of the network after targeting for the minimum flowrate, it was found that the network layout in the latent heat region will always be parallel. However, obtaining the network layout in the sensible heat region can be quite complex. The reason for this is that in the sensible heat region the network layout can be parallel, series or a mixture of parallel and series connections. Therefore, to assist the designer, an LP model was developed to obtain the network layout in the sensible heat region after the minimum steam flowrate target has been obtained.

An MILP model was developed were targeting and network design were achieved simultaneously. However, the network layout obtained by the MILP model differs slightly from 
that obtained by the LP model, suggesting multiple network layouts are possible for the same flowrate target. However, it must be noted that the MILP model does not give much insight into the problem for a designer, compared to the graphical targeting technique. Furthermore, the CPU time of the MILP model is far greater than that of the LP model. Therefore, for large problems the MILP model will require more computational resources than the graphical technique and LP model.

An case study using real life data illustrated the applicability of the developed methodology. The original steam flowrate was reduced by $29.6 \%$, showing that saturated steam as an external hot utility can be reduced for a given fixed duty.

\subsection{Recommendations}

The following recommendations were identified during and after the study:

(i) In this study, only one steam boiler is supplying the network with steam. On many chemical plants there are multiple steam boilers available. Therefore, further research must be done to cater for situations where there are more than one steam boilers present, when using the hybrid graphical technique and models developed in this study.

(ii) Pressure drop was omitted in the study. However, since the water has to flow through pipes and heat exchanger units, pressure drop will occur. Therefore, the effects of pressure drop on the targeting and network layout should be investigated.

(iii) Temperature loss must also be investigated. This study has not taken any temperature losses to the environment into account. It was assumed in the study that the pipes and heat exchangers were adequately insulated such that heat losses could be ignored. However, not all scenarios can guarantee zero heat loss, therefore, the effect of heat loss must be investigated.

(iv) It is recommended to develop a cost model. Instead of targeting for the minimum steam flowrate, the cost model will target for the minimum overall cost. 


\section{APPENDIX A}

\section{GAMS mathematical models}

The following two mathematical models, i.e. the LP and MILP model described in Chapters 3 and 4 respectively, have been programmed using GAMS Build 22.0 143.

\section{A.1 LP model}

Sets

i heat exchangers /i1, i2, i4, i6, i7/;

\section{Parameters}

Q(i) duty of the utility streams

/i1 $\quad 135$

i2 320

i4 4493

i6 $\quad 635$

i7 $\quad 330 /$

ToutL(i) outlet temperature of the utility streams 


$\begin{array}{ll}/ \mathrm{i} 1 & 35 \\ \mathrm{i} 2 & 35 \\ \mathrm{i} 4 & 89 \\ \mathrm{i} 6 & 54 \\ \mathrm{i} 7 & 54 /\end{array}$

TinL(i) minimum inlet temperature of the utility streams

$\begin{array}{ll}/ \mathrm{i} 1 & 55 \\ \mathrm{i} 2 & 55 \\ \mathrm{i} 4 & 126 \\ \mathrm{i} 6 & 80 \\ \text { i7 } & 80 /\end{array}$

FinL(i) minimum flowrate to a heat exchangers;

\section{Scalar}

TS total saturated liquid

TR return temperature to the steam boiler

Cp heat capacity of water

$\mathrm{T}$ supply temperature of the steam boiler

$\operatorname{Alias}(\mathrm{i}, \mathrm{ii})$;

$\operatorname{FinL}(\mathrm{i})=\mathrm{Q}(\mathrm{i}) /\left(\mathrm{Cp}^{*}(\operatorname{TinL}(\mathrm{i})-\operatorname{ToutL}(\mathrm{i}))\right)$;

$\mathrm{TR}=\mathrm{TS}$;

\section{Variables}

SL(i) saturated liquid supplied to heat exchanger i

FR(i) liquid returning to the steam boiler from heat exchanger $i$

$\operatorname{FRR}(\mathrm{i}, \mathrm{ii}) \quad$ re-used hot liquid from heat exchanger i, to heat exchanger ii

Fin(i) total flowrate to heat exchanger i

Fout(i) total flowrate from heat exchanger i

Splus slack variable for undershooting TR

Sminus slack variable for overshooting TR

SSplus slack variable for undershooting TS

SSminus slack variable for overshooting TS

OB objective function;

\section{Positive variables}


SL(i) saturated liquid supplied to heat exchanger i

FR(i) return liquid from heat exchanger $i$ to the steam boiler

FRR(i,ii) re-used hot liquid from heat exchanger i, to heat exchanger ii

Fin(i) total flowrate to heat exchanger i

Fout(i) total flowrate from heat exchanger i

Splus slack variable for undershooting TR

Sminus slack variable for overshooting TR

SSplus slack variable for undershooting TS

SSminus slack variable for overshooting TS;

\section{Equations}

Eq1, Eq2, Eq3, Eq4, Eq5, Eq6, Eq7, Eq8, Eq9;

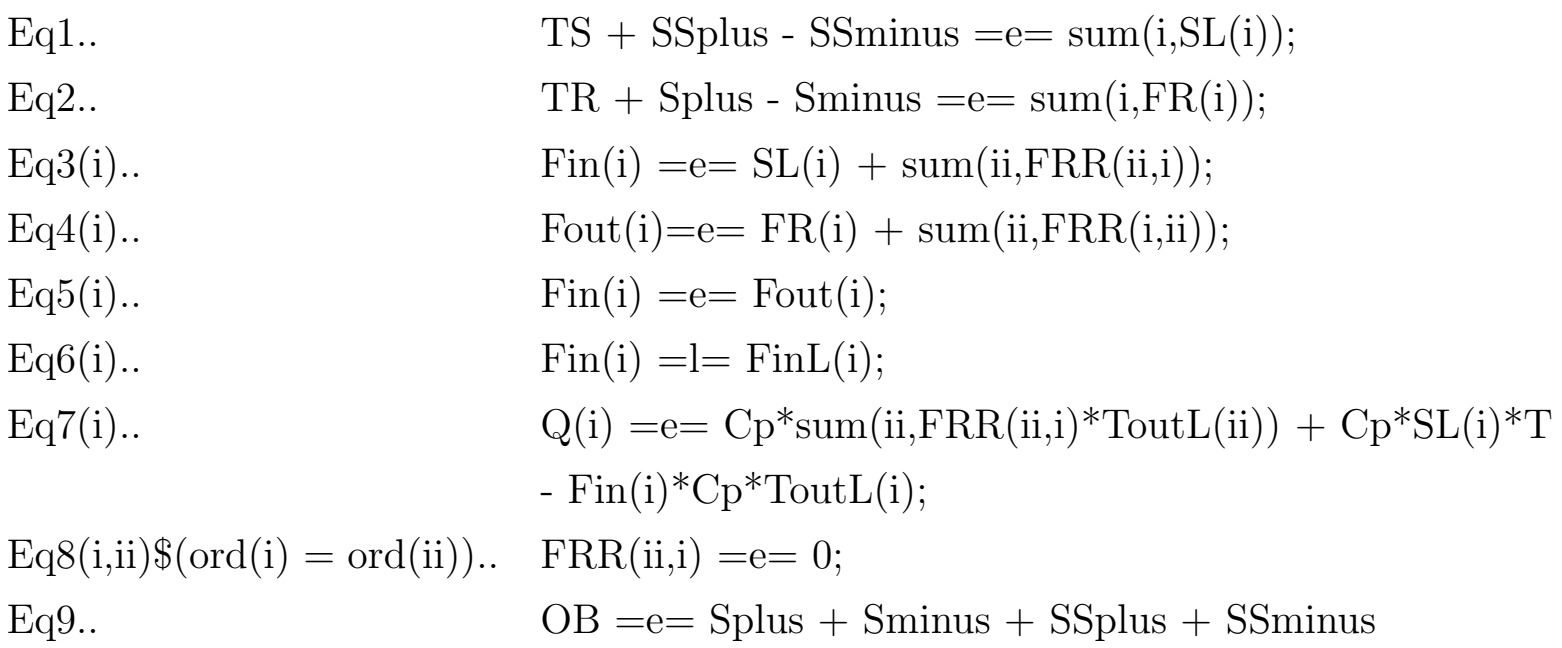

Model steamdesign /all/ ;

Solve steamdesign using LP minimizing OB;

Display OB.l;

\section{A.2 MILP model}

\section{Sets}

i utility streams /i1, i2, i3, i4, i5, i6, i7/;

\section{Parameters}

Q(i) duty of the utility streams 


$\begin{array}{ll}/ \text { i1 } & 135 \\ \text { i2 } & 320 \\ \text { i3 } & 3620 \\ \text { i4 } & 12980 \\ \text { i5 } & 1980 \\ \text { i6 } & 635 \\ \text { i7 } & 330 /\end{array}$

ToutL(i) outlet temperature of the utility streams

$/$ i1 35

i2 35

i3 219

i4 89

i5 217

i6 $\quad 54$

i7 54/

TinL(i) minimum inlet temperature of the utility streams

$\begin{array}{ll}/ \text { i1 } & 55 \\ \text { i2 } & 55 \\ \text { i3 } & 225 \\ \text { i4 } & 195 \\ \text { i5 } & 217.1 \\ \text { i6 } & 80 \\ \text { i7 } & 80 /\end{array}$

FinSS(i) maximum flowrate of saturated steam to heat exchanger i

FinFRR(i) maximum flowrate of re-used liquid to heat exchanger i;

\section{Scalars}

Cp heat capacity of water

$\mathrm{T} \quad$ supply temperature of steam boiler /225/

lan latent heat of saturated steam /1834.3/;

$\operatorname{Alias}(\mathrm{i}, \mathrm{ii})$;

$\operatorname{FinFRR}(\mathrm{i})=\mathrm{Q}(\mathrm{i}) /\left(\mathrm{cp}^{*}(\operatorname{TinL}(\mathrm{i})-\operatorname{ToutL}(\mathrm{i}))\right) ; \operatorname{FinSS}(\mathrm{i})=\mathrm{Q}(\mathrm{i}) / \operatorname{lan}$;

\section{Binary variables}

$\mathrm{y}(\mathrm{i}) \quad 1$ if heat exchanger is supplied by saturated steam, otherwise 0

$\mathrm{x}(\mathrm{i}) \quad 1$ if heat exchanger is supplied by re-used liquid, otherwise 0 ; 


\section{Variables}

TS total steam supply from steam boiler

TR total return liquid to steam boiler

SS(i) saturated steam to heat exchanger i

Fin(i) total flowrate to heat exchanger i

Fout(i) total flowrate out of heat exchanger i

FRR(i,ii) re-used liquid from unit i to unit ii

FR(i) liquid returning to the steam boiler from heat exchanger i

L(i,ii) hot liquid re-used from heat exchanger i, to heat exchanger ii

SL(i,ii) saturated liquid re-used from heat exchanger $i$, to heat exchanger ii

Q_SS(i) duty that is supplied by saturated steam to heat exchanger i

Q_SL(i) duty that is supplied by saturated liquid to heat exchanger i;

\section{Positive variables}

TR total return liquid to steam boiler

SS(i) saturated steam to heat exchanger i

Fin(i) total flowrate to heat exchanger i

Fout(i) total flowrate out of heat exchanger i

FRR(i,ii) re-used liquid from unit i to unit ii

FR(i) liquid returning to steam boiler from heat exchanger i

L(i,ii) hot liquid re-used from heat exchanger $i$, to heat exchanger ii

SL(i,ii) saturated liquid re-used from heat exchanger $i$, to heat exchanger ii

Q_SS(i) duty that is supplied by saturated steam to heat exchanger i

Q_SL(i) duty that is supplied by saturated liquid to heat exchanger i;

\section{Equations}

Eq1, Eq2, Eq3, Eq4, Eq5, Eq6, Eq7, Eq8, Eq9, Eq10,

Eq11, Eq12, Eq13, Eq14, Eq15, Eq16, Eq17; 
Eq1..

$\mathrm{Eq} 2$..

Eq3..

$\operatorname{Eq} 4(i) .$.

Eq5(i)..

Eq6(i)..

$\operatorname{Eq7}(i, i i)$.

$\operatorname{Eq} 8(i)$.

Eq9(i)..

Eq10(i,ii) $\$(\operatorname{ord}(\mathrm{i})=\operatorname{ord}(\mathrm{ii}))$..

$\operatorname{Eq11(i)..~}$

Eq12(i)..

Eq13..

Eq14..

Eq15(i)..

Eq16(i)..

$\mathrm{Eq17(i)..}$
$\mathrm{TS}=\mathrm{e}=\operatorname{sum}(\mathrm{i}, \mathrm{SS}(\mathrm{i}))$;

$\mathrm{TR}=\mathrm{e}=\operatorname{sum}(\mathrm{i}, \mathrm{FR}(\mathrm{i}))$;

$\mathrm{TS}=\mathrm{e}=\mathrm{TR}$;

$\operatorname{Fin}(\mathrm{i})=\mathrm{e}=\mathrm{SS}(\mathrm{i})+\operatorname{sum}(\mathrm{ii}, \mathrm{FRR}(\mathrm{ii}, \mathrm{i}))$;

$\operatorname{Fin}(\mathrm{i})=\mathrm{e}=\operatorname{Fout}(\mathrm{i})$;

Fout(i) $=\mathrm{e}=\operatorname{FR}(\mathrm{i})+\operatorname{sum}(\mathrm{ii}, \operatorname{FRR}(\mathrm{i}, \mathrm{ii}))$;

$(\operatorname{FRR}(i i, i))=\mathrm{e}=(\operatorname{SL}(i i, \mathrm{i}))+(\mathrm{L}(\mathrm{ii}, \mathrm{i}))$;

$\operatorname{sum}(\mathrm{ii}, \mathrm{SL}(\mathrm{i}, \mathrm{ii}))=\mathrm{l}=\mathrm{SS}(\mathrm{i})$;

$\operatorname{sum}(\mathrm{ii}, \mathrm{L}(\mathrm{i}, \mathrm{ii}))=\mathrm{l}=\operatorname{sum}(\mathrm{ii}, \operatorname{FRR}(\mathrm{ii}, \mathrm{i}))$;

$\mathrm{L}(\mathrm{ii}, \mathrm{i})=\mathrm{e}=0$;

$\mathrm{SS}(\mathrm{i})=\mathrm{l}=\operatorname{FinSS}(\mathrm{i}) * \mathrm{y}(\mathrm{i})$;

$\operatorname{sum}(i i, F R R(i i, i))=l=\operatorname{FinFRR}(i) * x(i)$;

$\operatorname{sum}(\mathrm{i}, \mathrm{x}(\mathrm{i}))+\operatorname{sum}(\mathrm{i}, \mathrm{y}(\mathrm{i}))=\mathrm{g}=\operatorname{card}(\mathrm{i})$;

$\operatorname{sum}(\mathrm{i}, \mathrm{x}(\mathrm{i}))+\operatorname{sum}(\mathrm{i}, \mathrm{y}(\mathrm{i}))=\mathrm{l}=\operatorname{card}(\mathrm{i})+1 ;$

$\mathrm{Q}(\mathrm{i})=\mathrm{e}=$ Q_SS$(\mathrm{i})+$ Q_SL $(\mathrm{i})$;

Q_SS $(\mathrm{i})=\mathrm{e}=\mathrm{SS}(\mathrm{i}) * \operatorname{lan}$;

Q_SL(i) $=\mathrm{e}=\operatorname{sum}\left(\mathrm{ii},\left(\mathrm{SL}(\mathrm{ii}, \mathrm{i})^{*} \mathrm{cp} * \mathrm{~T}\right)\right)$

$+\operatorname{sum}\left(\mathrm{ii},\left(\mathrm{L}(\mathrm{ii}, \mathrm{i}){ }^{*} \mathrm{cp}^{*} \operatorname{ToutL}(\mathrm{ii})\right)\right)$

- $(\operatorname{sum}(\mathrm{ii}, \operatorname{FRR}(\mathrm{ii}, \mathrm{i})))^{*} \mathrm{cp}^{*} \operatorname{ToutL}(\mathrm{i})$;

Model steamdesign /all/;

Solve steamdesign using MIP minimizing TS;

Display TS.l; 


\section{BIBLIOGRAPHY}

Abdallah, A. M. and Ismail, A. L. (2001) "Saving energy loss from steam boilers", Chem Eng Sci, 23, 537-550.

Adonyi, R.; Romero, J.; Puigjaner, L. and F., F. (2003) "Incorporating heat integration in batch process scheduling", Applied Thermal Engineering, 23, 1743-1762.

Almató, M.; Sanmartí, E.; Espuña, A. and Puigjaner, L. (2004) "Rationalizing water use in the batch process industry", Computers and Chemical Engineering, 21, 971-976.

Bauer, M. H. and Stichlmair, J. (1996) "Superstructures for the mixed integer optimization of nonideal and azeotropic distillation processes.", Computers chem. Engng, 20, S25-S30.

Bernier, M. A. (1994) "Cooling tower performance: theory and experiments.", ASHRAE Transactions: Research, 100, 114-121.

De Oliveira Filho, L. O.; Queiroz, M. E. and Costa, L. H. (2007) "A matrix approach for steady-state simulation of heat exchanger networks.", Applied Thermal Engineering, 27, 2385-2393.

El-Halwagi, M. M. (1997) Pollution prevention through process integration: systematic design tools, San Diego: Academic Press, .

El-Halwagi, M. M. and Manousiouthakis, V. (1990) "Automatic synthesis of massexchange networks with single-component targets.", Chemical Engineering Science, 45, 2813-2831. 
Grau, R.; Graells, M.; Corominas, J.; Espuña, A. and Puigjaner, L. (1996) "Global strategy for energy and waste analysis in scheduling and planning of multiproduct batch chemical products", Process Safety and Environmental Protection, 20, 853-868.

Kaggerud, K. H.; Bolland, O. and Gundersen, T. (2006) "Chemical and process integration: Synergies in co-production of power and chemicals from natural gas with $\mathrm{CO} 2$ capture", Applied Thermal Engineering, 26, 1345-1352.

Khan, J.; Yaqub, M. and Zubair, M. (2003) "Performance characteristics of counter flow wet cooling towers", Energy Conversion and Management, 44, 2073-2091.

Kim, J. K. and Smith, R. (2001) "Cooling water system design", Chemical Engineering Science, 56, 3641-3658.

Kim, J. K. and Smith, R. (2004) "Automated design of discontinuous water systems", Process Safety and Environmental Protection, 82, 238-248.

Lee, B. and Reklaitis, V. (1995) "Optimum scheduling of cyclic batch processes for heat integration - I. Basic formulation.", Chemical Engineering Science, 19, 883-905.

Linnhoff, B. and Ahmad, S. (1990) "Cost optimum heat exchanger networks - I. Minimum energy and capital using simple models for capital costs.", Chemical Engineering Science, 14, 729-750.

Linnhoff, B. and Flower, J. R. (1978) "Synthesis of Heat Exchanger Networks", AIChE Journal, 24, 633.

Linnhoff, B. and Hindmarsh, E. (1983) "The pinch design method for heat exchanger networks", Chem Eng Sci, 38, 745-763.

Linnhoff, B.; Mason, D. R. and Wardle, I. (1979) "Understanding heat exchange networks", Computers \& Chemical Engineering, 3, 295-302.

Lund, H. (2006) "The Kyoto mechanisms and technological innovation", Energy, 31, $2325-2332$.

Majozi, T. (2005) "Wastewater minimization using central reusable storage in batch plants", Computers and Chemical Engineering, 29, 1631-1646.

Majozi, T. (2006) "Heat integration of multipurpose batch plants using a continuous-time framework.", Applied Thermal Engineering, 26, 1369-1377. 
Majozi, T.; Brouckaert, C. J. and Buckley, C. A. (2006) "A graphical technique for wastewater minimization in batch processes", Journal of Environmental Engineerin, 78, 317-329.

Majozi, T. and Moodley, A. (2007) "Simultaneous targeting and design for cooling water systems with multiple cooling water supplies.", Computers and Chemical Engineering, doi:10.1016/j.compchemeng.2007.03.016.

Marechal, F. and Kalitventzeff, B. (1997) "Identification of the optimal pressure levels in steam networks using integrated combined heat and power method", Chem Eng Sci, 52, 2977-2989.

Marechal, F. and Kalitventzeff, B. (1998) "Process Integration: Selection of the optimal utility system.", Chem Eng Sci, 22, 149-156.

Mavromatis, S. P. and Kokossis, A. C. (1998) "Conceptual optimization of utility networks for operational variations - II. Network development and optimization", Chem Eng Sci, 53, 1609-1630.

Milosavljevic, N. and Heikkillä, P. (2003) "Performance characteristics of counter flow wet cooling towers", Energy Conversion and Management, 44, 2073-2091.

Naphon, P. (2005) "Study on the heat transfer characteristics of an evaporative cooling tower", International Communications in Heat and Mass, 32, 1066-1074.

Papageorgiou, L. G.; Shah, N. and Pantelides, C. C. (1994) "Optimal scheduling of heat-integrated multipurpose plants.", Chemical Engineering Science, 33, 3168-3186.

Papalexandri, K. P.; Pistikopoulos, E. N.; Kalitventzeff, B.; Dumont, M. N.; Urmann, K. and Gorschluter, J. (1996) "Operation of a steam production network with variable demands modeling and optimization under uncertainty", Chem Eng Sci, 20, 763-768.

Papoulias, S. A. and Grossman, I. E. (1983)a "A structural optimization approach in process synthesis - I: utility systems", Computers and Chemical Engineering Science, 7, 695-706.

Papoulias, S. A. and Grossman, I. E. (1983)b "A structural optimization approach in process synthesis - II: heat recovery networks", Computers and Chemical Engineering Science, r, 707-721.

Papoulias, S. A. and Grossman, I. E. (1983)c "A structural optimization approach in process synthesis - III: total processing systems", Computers and Chemical Engineering Science, 7, 723-734. 
Peters, M. S. and Timmerhaus, K. D. (1991) Plant design and economics for chemical engineers, McGraw-Hill Book Co., .

Savelski, M. J. and Bagajewicz, M. J. (2000)a "Design of water utilization systems in process plants with a single contaminant.", Waste Management, 58, 5349-5362.

Savelski, M. J. and Bagajewicz, M. J. (2000)b "On the optimality conditions of water utilization systems in process plants with single contaminants.", Chemical Engineering Science, 55, 5035-5048.

Savelski, M. J. and Bagajewicz, M. J. (2002) "On the optimality conditions of water utilization systems in process plants with multiple contaminants.", Chemical Engineering Science, 58, 5349-5362.

Savulescu, L.; Kim, J. and Smith, R. (2005)a "Studies on simultaneous energy and wastewater minimisation - Part I: Systems with no water re-use", Chemical Engineering Science, 60, 3279-3290.

Savulescu, L.; Kim, J. and Smith, R. (2005)b "Studies on simultaneous energy and wastewater minimisation - Part II: Systems with maximum re-use of water", Chemical Engineering Science, 60, 3291-3308.

Shang, Z. and Kokossis, A. (2004) "A transshipment model for the optimization of steam levels of total site utility system or multiperiod operation", Chem Eng Sci, 28, $1673-1688$.

Söylemz, M. S. (2004) "On the optimum performance of forced draft counter flow cooling towers", Energy Conversion and Management, 45, 2335-2341.

Soytas, U. and Sari, R. (2006) "Can China contribute more to the fight against global warming?", Journal of Policy Modeling, 28, 837-846.

Umeda, T.; Harada, T. and Shiroko, K. (1979) "A thermodynamic approach to the synthesis of heat integration systems in chemical processes", Computers 8 Chemical Engineering, 3, 273-282.

Vaselenak, J. A.; Grossmann, I. E. and Westerberg, A. W. (1986) "Heat integration in batch processing.", Chemical Engineering Science, 25, 357-366.

Wang, D. C. Y.; Manan, Z. A. and Tan, Y. L. (2005) "Synthesis of maximum water recovery network for batch process systems", Journal of Cleaner Production, 13, 1381-1394. 
Wang, Y. P. and Smith, R. (1994) "Wastewater minimization", Chemical Engineering Science, 49, 981-1006.

Wang, Y. P. and Smith, R. (1995) "Time pinch analysis", Trans IChemE, 73, 905-914.

Zhelev, T. (2007) "The conceptual design approach - A process integration approach on the move.", Resource, Conservation and Recycling, 50, 143-157.

Zhelev, T. K. (2005) "Water conservation through energy management", Journal of Cleaner Production, 13, 1395-1404. 